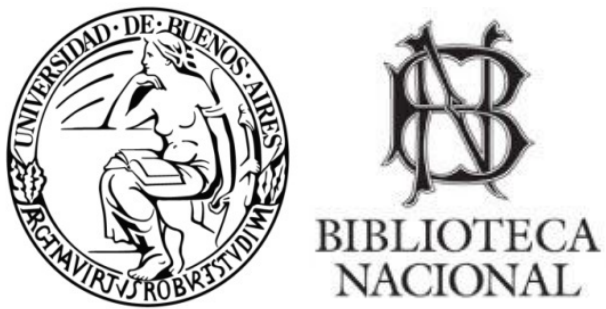

UNIVERSIDAD DE BUENOS AIRES /

BIBLIOTECA NACIONAL ARGENTINA

MAESTRÍA EN BIBLIOTECOLOGÍA Y CIENCIA DE LA INFORMACIÓN

\title{
NECESIDADES DE INFORMACIÓN EN LA COMUNIDAD GLTTIBQ (gay, lésbica, transexual, travesti, intersexual, bisexual, queer)
}

POR

Prof. JULIO DÍAZ JATUF

TESIS DE MAESTRÍA

Directora: Dra. MARTHA SABELLI

Co-Directora: Dra. SANDRA MIGUEL 
Es peligroso escribir sobre sexualidad, lo hace a uno "moralmente sospechoso"

Plummer, Ken. (1975). Sexual stigma: an interactionist account. London: Routledge and Kegal Paul

En lo que se escribe, cada uno defiende su sexualidad Barthes, Roland (1978)Roland Barthes por Roland Barthes.Barcelona: Kairós. 
Resumen

\section{NECESIDADES DE INFORMACIÓN EN LA COMUNIDAD GLTTIBQ (GAY, LÉSBICA, TRANSEXUAL, TRAVESTI, INTERSEXUAL, BISEXUAL, QUEER)}

\section{Por Julio Díaz Jatuf}

En toda biblioteca las necesidades de información de sus usuarios tienen que estar representadas garantizando, así, equidad e inclusión en la información con la finalidad de conformar ciudadanía. Esta tesis versa sobre dichas necesidades en la comunidad GLTTIBQ.

\section{ABORDAJE}

Toda carencia informativa sobre experiencias de estudios de usuarios en la comunidad GLTTIBQ hace imposible abordar las formas de brindar servicios accesibles e inclusivos a través de una colección pertinente que permita a sus individuos sentirse identificados con su orientación. El objetivo de este trabajo es tratar de colaborar para paliar esa situación en la lengua española.

\section{DATOS Y METODOLOGÍA}

Se realizó un abordaje de tipo documental de índole cuali-cuantitativo a partir de la literatura relevada en la base de datos especializada Library Literature Science Abstracts (LISA) durante 2015-2016 con el objeto de establecer un estudio comparativo de los documentos recuperados.

\section{CONCLUSIONES}

El principal resultado que establece esta investigación es la escasa literatura sobre el tema y la inexistente presencia de producciones científicas en lengua española sobre la temática abordada de la base de datos analizada. 
Resumo

NECESSIDADES DE INFORMAÇÃO NA COMUNIDADE GLTTIBQ (GAY, LÉSBICA, TRANSEXUAL, TRAVESTI, INTERSEXUAL, BISEXUAL, QUEER)

Por Julio Díaz Jatuf

As necessidades de informação dos usuários em toda biblioteca tem que estar representadas, de jeito de garantir a equidade e a inclusão em informação com a finalidade de conformar as expectivas de toda a cidadania. Esta tesis versa sobre essas necesidades na comunidade GLTTIBQ.

\section{ABORDAGEM}

Toda carência informativa sobre experiências de estudos de usuários na comunidade GLTTIBQ faz impossível abordar as diferentes formas de brindar serviços accessíveis e inclusivos com uma coleção pertinente, que favoreça aos indivíduos sentirse identificados com a sua orientação de gênero. O objetivo deste trabalho é tentar ajudar a paliar essa situação, já que não existem outras pesquisas em espanhol.

\section{DADOS E METODOLOGÍA}

A abordagem é de tipo documental e a sua índole cuali-cuantitativo, tudo foi feito sobre a literatura recopilada na base especializada Library Literature Science Abstracts (LISA), durante os anos 2015-2016, com o objetivo de estabelecer um estudo comparativo dos documentos recuperados.

\section{RESULTADOS}

O principal resultado que estabelece a pesquisa é que existe muito pouca literatura sobre o tema e não existem produções cientificas em espanhol sobre a temática, na base de dados que foi analisada. 


\author{
Abstract \\ INFORMATION NEEDS IN THE LGBT COMMUNITY (GAY, LESBIAN, \\ TRANSGENDER, TRANSVESTITE, INTERSEXUAL, BISEXUAL QUEER) \\ Por Julio Díaz Jatuf
}

In every library, users' information needs should be represented, thus guaranteeing equity and inclusion in terms of information, aiming to build citizenship. This thesis deals with such needs in the GLTTIBQ community.

\title{
APPROACH
}

There exists an evident lack of information in terms of users' studies in the GLT'TIBQ community, which uncovers the need to approach ways of rendering accessible and inclusive services by means of a pertinent collection to enable their members to feel identified with their sexual choice. The aim of this work is to try to find a remedy to this situation, in Spanish.

\section{DATA AND METHODOLOGY}

A quali-quantitative documentary approach was carried out by reviewing the literature in the Library Literature Science Abstracts (LISA) database over 2015 2016, to perform a comparative study of the recovered documents.

\section{CONCLUSIONS}

The main result arising from this research is the shortage of literature on the subject and the lack of scientific production in Spanish in the analyzed database. 


\author{
Résumé \\ BESOINS D'INFORMATION DANS LA COMMUNAUTÉ GLTTIBQ (GAY, LESBIAN, \\ TRANSGENRE, TRAVESTI, INTERSEXE, BISEXUAL, QUEER) \\ Par Julio Diaz Jatuf
}

Dans toute bibliothèque, les besoins d'information de ses usagers doivent être représentées, assurant ainsi l'équité et l'inclusion d'information afin de former citoyenneté. Cette thèse aborde les besoins de la communauté GLTTIBQ.

\title{
APPROCHE
}

La manque d'information sur l'expérience des études d'usager dans la communauté GLTTIBQ rend impossible traiter les moyens de fournir des services accessibles et inclusives à travers une collection pertinente, qui permet à ses membres de se sentir identifiés avec leur orientation. Le but de ce travail est d'essayer d'aider à atténuer cette situation en espagnol.

\section{DONNÉES ET MÉTHODOLOGIE}

On a effectué un analyse documentaire de type qualitative et quantitative de la littérature recensée dans la base de données spécialisée Library Literature Science Abstract (LISA) au cours de 2015-2016, afin d'établir un étude comparatif des documents récupérés.

\section{CONCLUSIONS}

Le principal résultat qu'établit cette recherche est la manque de littérature sur le sujet et la présence inexistante de la production scientifique en langue espagnole sur les sujets abordés dans la base de données analysée. 


\section{Riassunto}

\section{NECESSITÀ DI INFORMAZIONE NELLA COMUNITÀ GLTTTIBQ (GAY, LESBICA, TRANSESSUALE, TRAVESTITI, INTERSESSUALI, BISESSUALI, QUEER) \\ Par Julio Diaz Jatuf}

In tutte le biblioteche, le necessità di informazione degli utenti devono essere rappresentate, garantendo così una equità e inclusione di informazione con il fine di conformare la cittadinanza. Questa tesi verte su tali necessità nella comunità GLTTIBQ.

\section{APPROCCIO}

Tutta la carenza informativa su esperienze di studi di utenti nella comunità GLT'TIBQ rende impossibile approcciare i modi con cui dare servizi accessibili e inclusivi attraverso una raccolta pertinente che permetta ai sui individui di sentirsi identificati con $i$ loro orientamenti. L'obiettivo di questo lavoro è quello di trattare di aiutare ad alleviare questa situazione, in lingua castigliana.

\section{DATI E METODOLOGIA}

Si è effettuato un approccio di tipo documentale qualitativo-quantitativo a partire da una letteratura rilevata sulla base di dati specialistici Library Literature Science Abstract (LISA) durante il 2015-2016 con l'obiettivo di stabilire uno studio comparativo dei documenti recuperati.

\section{CONCLUSIONI}

Il principale risultato che stabilisce questa ricerca è la scarsa letteratura su questo tema e la inesistente presenza di produzione scientifica in lingua spagnola sulla tematica trattata, sulla base dei dati analizzati. 
- A mis padres, que además del amor, me regalaron la educación

- A mi familia

- A mis Ángeles Guardianes: Darío Fabio y Lucas Gabriel

- A Profa. Viviana Appella,

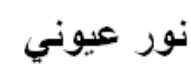

\section{AGRADECIMIENTOS}

- A mi directora de tesis Dra. Martha Sabelli, por siempre apoyar mis proyectos

- A mi co-directora, Dra. Sandra Miguel, por aceptar el desafío

- A mujeres argentinas que marcaron mi camino académico y docente

Dra. Susana Soto y Prof. Susana Romanos de Tiratel

- A Mg. Carmen Silva, Mg. Patricia Prada, Lic. Mónica Magrané y Bibl. Graciela

Piantanida

- A mis alumnos: maravillosos sustentos de mis continuos conocimientos

- A la generosidad de Dr. Saúl Soto-Fuentes y Arq. Fernando Britos Di Clementi

- A la beca MacroUniversidades que me permitió concluir la tesis

- A Montevideo y a su linda gente

- A todas aquellas personas que me ayudaron a hacer este sueño, realidad

A toda la comunidad GLTTIBQ argentina por el orgullo, el valor y el coraje de la constante lucha por los Derechos Humanos. 
Lista de siglas 11

Lista de tablas 12

Lista de gráficos.

Lista de figuras. 14

Capítulos

1. INTRODUCCIÓN

1.1. Justificación y relevancia 15

1.2. Definición de términos 16

1.3. Limitaciones. 19

1.4. Organización de la tesis. 20

2. MARCO TEÓRICO 22

2.1. Introducción 22

2.2. Derechos Humanos y Diversidad Sexual ........................................................ 22

2.3. Bibliotecología y Responsabilidad Social........................................................ 28

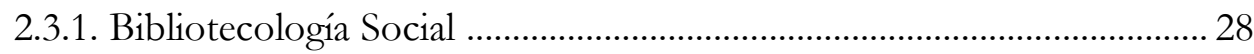

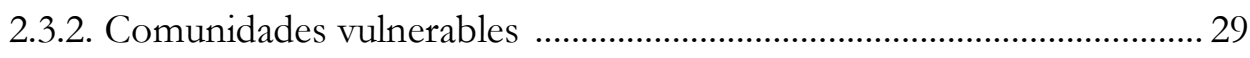

2.3.3. Servicios bibliotecarios y perspectivas sociales ……….......................... 30

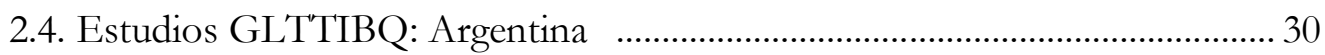

2.5. Bibliotecas y comunidad GLTTIBQ ................................................................. 39

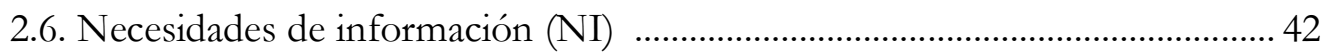

2.6.1. Información y Conocimiento .................................................................. 47

2.6.2. Necesidades, Búsqueda y Uso de información ......................................... 47 
2.7. Antecedentes de estudios de NI en Argentina ..................................................... 53

2.8. Necesidades de información en la comunidad GLTTIBQ ................................ 62

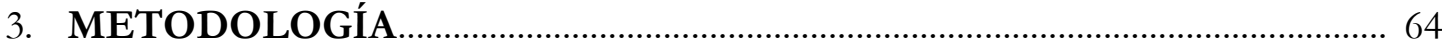

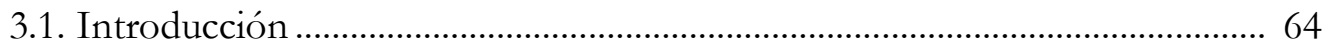

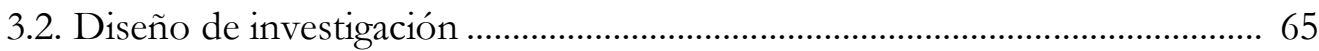

3.3. Técnicas e instrumentos de recolección de la información ............................... 66

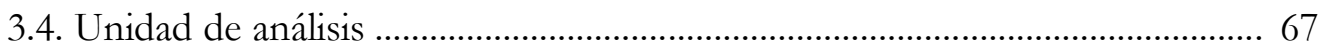

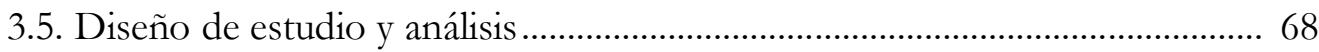

3.6. Análisis e interpretación de resultados................................................................. 70

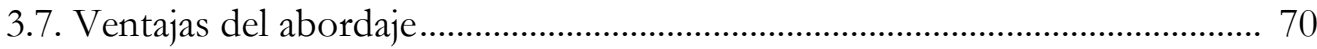

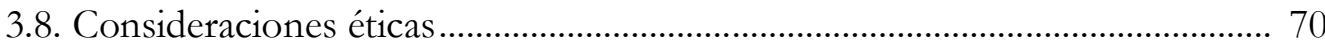

4. ANALISIS DE DATOS, RESULTADOS E INTERPRETACIÓN .................. 71

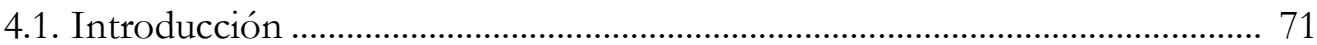

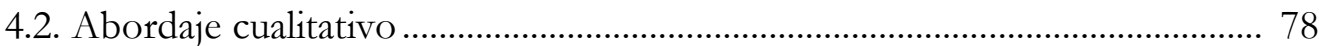

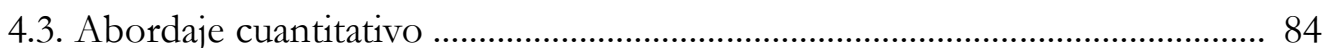

5. COROLARIO, CONCLUSIONES Y RECOMENDACIONES ...................... 104

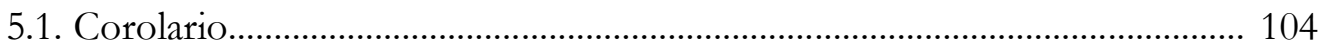

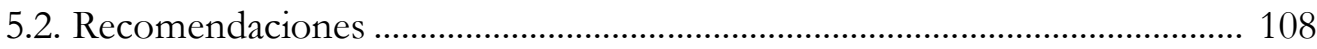

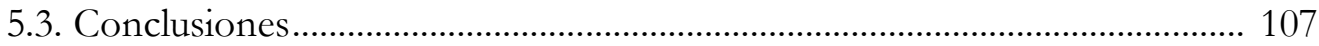

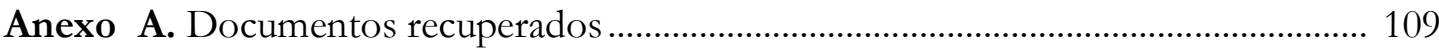

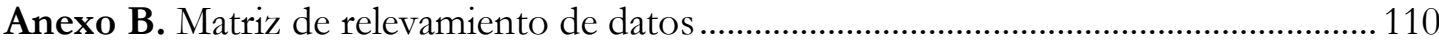

Anexo C. Estimación de Necesidades de Información......................................................... 111

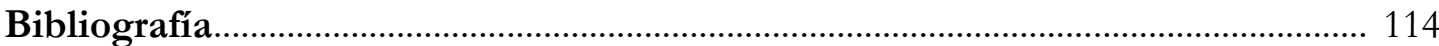




\section{LISTADO DE SIGLAS}

ABGRA: Asociación de Bibliotecarios Graduados de la República Argentina

ALA: American Library Association

APA: American Psychological Association

B/CI: Bibliotecología y Ciencia de la Información

CaLiBiSo: Cátedra Libre Bibliotecología Social

CIB: Centro de Investigaciones Bibliotecológicas

EEUU: Estados Unidos de Norteamérica

GLTB: Gay, lésbica, transexual, bisexual

GLTTIBQ: Gay, lésbica, transexual, travesti, intersexual, bisexual, queer

LGBTQ: Lésbica, gay, bisexual, transexual, queer

LISA: Library Information Science Abstracts

NI: Necesidades de información

ONU: Organización de las Naciones Unidas

SPSS: Statistical Product and Service Solutions

UBA: Universidad de Buenos Aires

UNC: Universidad Nacional de Córdoba

UNLP: Universidad Nacional de La Plata 


\section{LISTA DE TABLAS}

Tabla

Página

1. Principales legislaciones internacionales sobre Diversidad Sexual .......................... 24

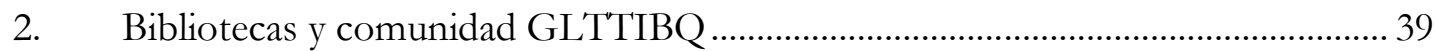

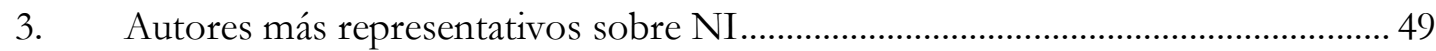

4. Principales antecedentes de NI en Argentina........................................................ 54

5. Documentos recuperados por año …………….................................................... 72

6. Documentos analizados cualitativamente............................................................. 78

7. Referencias bibliográficas de la literatura citada......................................................... 84

8. Cantidad de referencias bibliográficas por año …………………………….............. 102 


\section{LISTA DE GRÁFICOS}

Gráfico

Página

1. Cantidad de referencias bibliográficas por documentos relevados ........................ 101

2. Cantidad de referencias bibliográficas por año de los documentos........................101 


\section{LISTA DE FIGURAS}

Figura Página

1. Representación de pueblos originarios. 33

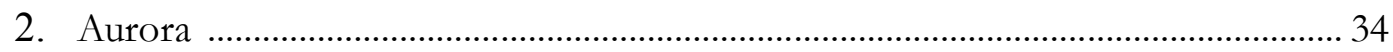

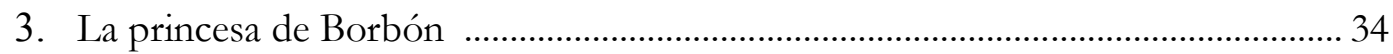

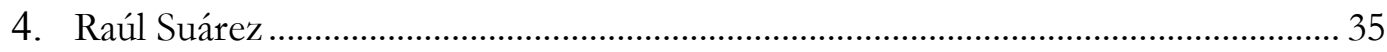

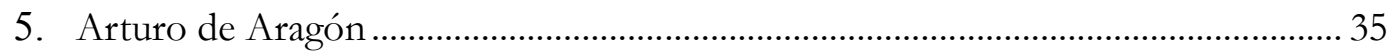

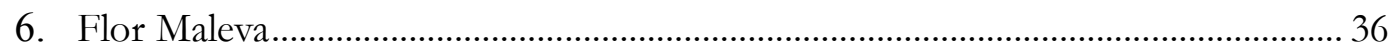

7. Modelo de comportamiento informativo de Wilson .............................................. 43

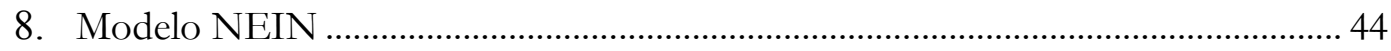

9. Modelo de comportamiento de búsqueda de Krikelas ................................................4 44

10. Modelo del proceso de búsqueda de Kuhlthau.......................................................... 45

11. Cuadro comparativo de los modelos ......................................................................... 46

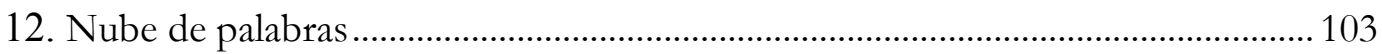




\section{INTRODUCCIÓN}

\subsection{Justificación y relevancia}

La presente tesis de maestría propone presentar un estado de la cuestión, en lengua española, de los estudios de las Necesidades de Información (en adelante, NI) de la comunidad GLTTIBQ a partir de la bibliografía científica existente/disponible en Argentina. A tal efecto, es su cometido revisar los distintos abordajes que se han ido introduciendo en el campo de investigación constituido por los estudios de usuarios en relación con la comunidad enunciada. No pretende ser exhaustiva sino selectiva, dado que tratará de sintetizar e integrar aquellos textos/autores que se han recuperado y que han dejado plasmada su experiencia. La elección de esta temática obedece a la imperiosa necesidad e interés de explorar un tema escasamente tratado en la Bibliotecología/Ciencia de la Información (en adelante, B/CI) e invisibilizado en la literatura española. De esta manera, trata de cumplir con la propuesta establecida en el Reglamento de Maestría (Universidad de Buenos Aires, 2014), en la que se establece:

...consistirá en el análisis crítico y actualizado de una problemática de un área temática de la especialidad, sustentada en un trabajo de investigación, que incluya un estado de la cuestión, el tratamiento de la información recopilada y la presentación de las conclusiones a las que se haya arribado. (p. 3).

La elección de la comunidad elegida se encuentra como categoría principal y orientadora del análisis con la intención de elaborar una investigación de carácter documental que contenga los elementos necesarios y precisos para fundamentar cualquier aplicación a futuro dentro de los servicios bibliotecológicos y con un andamiaje ajustado a las necesidades de dicho colectivo. Al organizar el contenido de los diversos capítulos, se advierten diversos ejes que enriquecen su temática y proponen trayectorias alternativas al enfoque de las NI y los estudios GLTTIBQ. Por ende, no se trata solo de una investigación documental de los estudios existentes y registrados de las NI en/para una comunidad definida, sino también intenta establecer relaciones y representaciones vinculadas a realidades socio-sexuales específicas con relación a la información.

La metodología empleada se apoya en un dispositivo documental que se nutre, 
asimismo, de un enfoque teórico/práctico, una perspectiva historiográfica y un análisis documental relacionado a su objeto de estudio; a fin de esclarecer los entornos de las NI, en cada momento o comunidad. La interrelación de estos diferentes enfoques aporta una pluralidad de miradas que resulta pertinente para enfocar el tema. La forma heterogénea de ver este tema ayudará a comprender cómo han operado los contextos sociales, las luchas por los derechos igualitarios, la colección y los servicios en las bibliotecas, a través de los sujetos que practican/representan una sexualidad no normativa.

Si bien existe una revisión somera sobre este tema en lengua inglesa (Keilty, 2009), desde la literatura monográfica, no se ha detectado un estado de la cuestión en lengua española, que integre la literatura generada y figure en las principales bases de datos referenciales para B/CI. Se espera que este trabajo sea una contribución para hacer visibles las NI de la comunidad GLTTIBQ.

Las preguntas guías para abordar este análisis documental son las siguientes:

¿Cuál fue el primer estudio realizado en y sobre NI en la comunidad GLTTIBQ y por qué es relevante?

Los estudios realizados sobre NI en comunidad GLTTIBQ ¿a qué población específica apuntan principalmente dentro de esa comunidad?

A partir de la literatura existente ¿cuál es el estado de la situación de las NI en la comunidad GLT'TIBQ?

\subsection{Definición de términos}

La cuestión terminológica ocupa un lugar relevante en el marco de esta tesis. Para ello, se torna necesario definir algunos términos básicos, productos de momentos históricos, para abordarlos desde la lengua española, siguiendo en primera instancia a Rodríguez González (2008), luego el Glosario de conceptos sobre Diversidad Sexual (COGAM, 20??)y a otros/as autores/as u organismos:

Asexualidad: Falta de atracción sexual por ambos sexos(Bogaert, 2004: 279). 
Bisexual:Referido a la persona que siente atracción erótica por los dos sexos. (p. 44).

Cisgénero: en el campo de los estudios de género, es un término que se utiliza para describir a personas cuyas identidades de género y género asignados al nacer son concordantes con los comportamientos que les fueron socialmente asignados. Es decir, se emplea para describir a personas que no se identifican como transgénero. El prefijo "cis-" en latín significa "de este lado", antónimo del prefijo "trans-", que significa "del otro lado".

Gay:Homosexual. (p. 161).

Género: De acuerdo a la obra de personalidades en los estudios de género, tales como Simone de Beauvoir (2012) y Judith Butler (2001, 2002, 2006), el género es un sistema de clasificaciones socialmente construido que adscribe cualidades de masculinidad y feminidad a las personas. Las características del género pueden cambiar a través del tiempo y diferir entre culturas. El género también es identificado como un sistema complejo de roles, expresiones, identidades, comportamientos, etcétera, a los cuales se los identifica con un sexo asignado a las personas de acuerdo a la apariencia física al nacer.

GLTTIBQ: Acrónimo de uso común para la comunidad: gay, lésbica, travesti, transexual, intersexual, bisexual y queer. Se utiliza para referirse a las identidades no heterosexuales y no-cisgénero. No siempre refleja la percepción individual de los miembros de la respectiva comunidad.

Heteronormatividad: es un régimen social, político y económico que impone las prácticas sexuales heterosexuales mediante diversos mecanismos médicos, artísticos, educativos, religiosos, jurídicos, etcétera y aquellas instituciones que establecen la heterosexualidad como necesaria para el funcionamiento de la sociedad y como el único modelo válido de relación sexoafectiva y de parentesco.

Heterosexual: Persona que siente atracción afectiva y/o sexual hacia personas del sexo opuesto. (COGAM, 20??)

Homofobia: Miedo irracional, odio o intolerancia hacia personas que se identifican o son percibidas como no heterosexuales. Incluye el temor de ser percibido como miembro de la comunidad gay. El comportamiento homofóbico se manifiesta de diversas formas: chistes, burla, violencia verbal y hasta actos de agresión física.

Homosexual: Referido a la persona (bombre o mijer) atraída por el mismo sexo. (p. 210). Término para referirse a una persona que se siente principalmente atraída en términos emocionales, físicos y/o sexuales hacia miembros del mismo sexo. Muchas personas consideran este término inapropiado por su reduccionismo al limitarse a la orientación sexual de las personas. 
Identidad de género: Comprende la experiencia individual de género profundamente sentida por cada persona, que puede o no corresponder al sexo asignado al nacer, incluyendo el sentido personal del cuerpo (que podría conllevar, si se elige libremente, la modificación de la apariencia física o de funciones a través de medios médicos, quirúrgicos $u$ otros) y otras expresiones de género, incluyendo vestimenta, forma de bablar y maneras. (Principios de Yogyakarta, 2007)

Intersexual: término referido a la condición del individuo que tiene rasgos de los dos sexos, masculino y femenino, mezclados (p. 223)

Lesbiana: término referido a la homosexual femenina (p. 242).

Minorías sexuales: Comprendenel grupo formado por homosexuales, lesbianas $y$ transexuales, es decir, colectivos que son objeto de discriminación y abusos en razón de su orientación e identidad sexual. (p. 312)

Orientación sexual: la capacidad de cada persona de experimentar una profunda atracción emocional, afectiva y sexual hacia, y para intimar y tener relaciones sexuales con, individuos de un género diferente o del mismo género o de más de un género. (Principios de Yogyakarta, 2007).

Pansexualidad (u Omnisexualidad): orientación sexual humana caracterizada por la atracción estética, romántica y/o sexual por cualquier otra persona, independientemente de su sexo y género. (COGAM, 20??)

Queer:Homosexual (p. 385).

Salir del armario (placard o clóset):modismo aplicado a personas: aludea la declaración voluntaria y pública de su homosexualidad.

Teoría Queer: Comprende la elaboración teórica de la disidencia sexual y laconstrucción de identidades estigmatizadas, que a través de la resignificación del insulto consigue reafirmar a la opción sexual distinta como un derecho humano.

Trans: Abreviación utilizada para referirse a una persona (transgénero/género queer) disconforme con el género. Este uso permite declarar una identidad de género sin tener que revelar una condición o apariencia hormonal o quirúrgica. Este término se emplea en ocasiones para referirse a toda la comunidad disconforme con el género.

Transexual: Usualmente se utiliza para designar a las personas que han concluido su transición hacia el género deseado; que han tenido una cirugía de reasignación genital o quienes consideran dicha cirugía como fundamental para su identidad de género.

Transgénero: referido a la persona que 'cambia de género', es decir que se presenta con un género diferente del que corresponde a su sexo biológico o legal, ya que no se siente cómo con él (p.451).

Travesti: Refiere a la persona que se viste con la ropa y usa los accesorios asignados al género opuesto.

Esta variedad de combinaciones terminológicas manifiesta la amplitud y diversidad 
de criterios con que los investigadores de los estudios GLTTIBQ han tomado a través de sus investigaciones los diferentes enfoques. Se abordaron los principales significados y significaciones a modo de poder introducir en el tema principal de esta tesis; por lo tanto la misma:

1. No cubre aspectos históricos de dichos términos desde lo lingüístico.

2. No se definen aquellos conceptos que nuclean características especiales o subgrupos de cada comunidad descripta (Osos, Bear, Bucht, Drag Queen, Drag King, etcétera).

3. Tampoco aquellos términos que son traducción, jerga o slang como maricón, puchero, puto, tortillera, traba, trava, etcétera.

La cuestión de los términos y de su traducción constituye un aspecto relevante y complejo de debate con respecto a la conveniencia o inconveniencia, oportunidad o interés, de importar y de adaptar a los países iberoamericanos/latinoamericanos la estructura teórica concebida en otras latitudes. Por lo antes mencionado el autor de esta tesis, se apropió del acrónimo GLTTIBQ para identificar a individuos gays, lesbianas, transexuales, travestis, intersexuales, bisexuales y queer.

\subsection{Limitaciones}

Este estudio se enfrenta a tres limitaciones fundamentales:

1 A la dificultad de no poder reunir todo el material de estudio deseado por falta de accesibilidad a bases de datos GLTTIBQ especializadas (e inexistentes) en bibliotecas argentinas y que hubieran sido de un gran continente para el abordaje de la temática (Ej: LGTB Thought and Culture).

2 La imposibilidad de localizar material de soporte fundamental y básico sobre la temática, especialmente a nivel monográfico, por su carencia en colecciones de bibliotecas públicas argentinas como por el contrario ocurre en:

Accardi, María. (2013). Feminist pedagogy for library instruction. Los Angeles, CA: LitwinBooks, LLC.

Bly, Lyz y Kelly Wooten (edit). (2012). Make your own history: documenting feminist and queer activism in the 21st Century. Los Angeles, CA: Litwin Books, LLC. 
Dean, Rebecca y Patrick Keilty.(2013). Feminist and queer information studies reader. Los Angeles, CA: Litwin Books, LLC.

Gough, Cal y Greenblatt, Ellen, (Eds). (1990). Gay and lesbian library service. Jefferson: McFarland.

Jacobson, T.E. y Williams, Helene C., (Eds). (2000). Teaching the new library to today's user: reacbing international minority, senior citizens, gay/lesbian, first generation college, at-risk, graduate and returning students, and distance learners. New York: Neal-Schuman.

Kester, Norman G. (Ed.).(1997). Liberating minds: the stories and professional lives of gay, lesbian, and bisexual librarians and their advocates. Jefferson: McFarland.

Kumbier, Alana. (2014). Ephemeral material: queering the archive. Sacramento, CA: Litwin Books.

Nectoux, Tracy. (2011). Out behind the desk: workplace issues for LGBTQ librarians. Los Angeles, CA: Litwin Books, LLC.

Vincent, J. (1999). Lesbian, bisexual, gay men and transgendered people. London: Library Association.

Wexelbaum, Rachel (ed.). (2013). Queers online: LGBT digital practices in libraries, archives, and museums. Los Angeles, CA: Litwin Books, LLC.

3 Finalmente, al realizar este estudio se observó en lo social y a través de la literatura científica, otras comunidades que comenzaron a empoderarse (asexuales y pansexuales) y se incorporaron al acrónimo GLTTIBQAP. Al momento de producción de esta tesis, las poblaciones no estaban sustancialmente representadas y menos dentro de la B/CI, por lo cual no fueron incorporadas a la investigación.

Por todo lo anteriormente descripto, este estudio incluye un proceso de elaboración a partir de lo existente con el objeto de crear una muestra intencional que pueda llegar a ser lo más representativa posible sobre el tema en lengua española para futuros usos en B/CI.

1.4. Organización de la tesis

La tesis está estructurada en cinco partes, cada una de las cuales se compone de las siguientes características: 
La primera parte, de carácter introductorio, apuntala a la justificación y relevancia del tema, a una necesaria definición terminológica para poder abordar el tema y las decisiones de su elección. También contiene las limitaciones más representativas que posee el trabajo y la organización de la tesis.

El marco teórico corresponde a la segunda parte. Aquí se procura establecer un abordaje somero sobre 'Derechos Humanos y Diversidad Sexual', condición fundamental para abordar el tema desde el enfoque social; 'Bibliotecología y responsabilidad social', donde se tratará el tema de Bibliotecología Social, Comunidades vulnerables y Servicios bibliotecarios y perspectivas sociales; Estudios GLTTIBQ, dando un enfoque, principalmente desde América Latina y Argentina; Bibliotecas y comunidad GLTTTIBQ y Necesidades de información: sobre este punto se presenta solo un panorama general sobre el tema, haciendo una descripción de la producción científica realizada desde Argentina.

La tercera parte, se ocupa de la parte metodológica a partir del: diseño de investigación, las técnicas e instrumentos de recolección de datos, la unidad de análisis, el diseño de estudio, análisis e interpretación de resultados, ventajas del abordaje y por último, las consideraciones éticas que merece el estudio.

La cuarta parte analiza los datos estudiados, estableciéndolas resultados y su respectiva interpretación a partir de un abordaje culi-cuantitativo.

Finalmente, la quita parte contiene el Corolario, Recomendaciones y Conclusiones.

Completa la obra una lista de tablas, figuras, anexos y referencias bibliográficas, de la bibliografía usada y citada, confeccionada a través del Manual de APA. 6th ed. 


\section{MARCO TEÓRICO}

\subsection{Introducción}

La revisión de la literatura, en la visión de Hernández-Sampieri y otros (2010), implica: Detectar, consultar y obtener la bibliografía (referencias) y otros materiales que sean útiles para los propósitos del estudio, de donde se tiene que extraer y recopilar la información relevante y necesaria para enmarcar nuestro problema de investigación. (p.53). En este proceso, la dimensión del relevamiento bibliográfico es tarea fundamental para el encuadre de la investigación Por lo antes expuesto, la misma se ha realizado bajo los siguientes ejes principales: Derechos Humanos y Diversidad Sexual, Bibliotecología y responsabilidad social, Estudios GLLTIBQ, Bibliotecas y comunidad GLTTIBQ y Necesidades de Información; este último constituye el punto focal y principal, para abordar a la comunidad estudiada.

\subsection{Derechos Humanos y Diversidad Sexual}

Durante las últimas décadas, las consecuencias derivadas de los procesos de globalización se asientan en forma abrupta. Los movimientos migratorios, la velocidad vertiginosa de los cambios sociales y la revolución en las actualizaciones tecnológicas producen transformaciones significativas no solo en la fisonomía de los lugares y ciudades o en la variabilidad étnica y cultural de su gente sino también en las mentalidades, creencias y valores dominantes e imperantes. La economía del siglo XXI está caracterizada por una gran complejidad y dinamismo que produce una amplia forma de mercado mundial donde se han liberalizado al máximo los flujos financieros, los movimientos de mercancías y los desplazamientos de trabajadores/as (Sampedro, 2002). Junto con estas transformaciones, la segregación y discriminación ideológica, política y/o por orientación sexual, en los diferentes espacios sociales - públicos y privados - es un fenómeno presente en la mayoría de países, independientemente de las condiciones socioeconómicas y de la existencia de leyes antidiscriminatorias que velan por la plena ciudadanía de todos los sujetos.

Thomas Hobbes (1588-1679) marcó los inicios del pensamiento político moderno, al considerar que el fin del Estado no es ni más ni menos que proteger la vida y la seguridad de las personas (muy lejos de la realidad en muchos países de la comunidad GLTTIBQ). Expuso el derecho de naturaleza correspondiente a la libertad que cada hombre tiene de usar su 
propio poder como quiera, para la conservación de su propia naturaleza, es decir, de su propia vida" (2005: 106). Con Jean Jacques Rousseau (1712-1778), se llegó al pensamiento igualitario, afirmando que "fácil es ver que entre las diferencias que distinguen a los hombres, muchas que pasan por naturales son únicamente obra del bábito y de los diversos géneros de vida que adoptan en la sociedad"(2004: 55), convirtiéndose en un gran crítico de las desigualdades sociales de su época.

Una nueva etapa se abre con Jeremy Bentham (1748-1832), filósofo inglés, que fue uno de los primeros en cuestionar y escribir sobre la criminalización y la prohibición legal de las relaciones sexuales entre personas del mismo sexo. El prisma desde el cual Bentham argumentaba era el utilitarismo, corriente de la cual él fue iniciador y que planteaba, polemizando con la moral tradicionalista que todavía imperaba en Europa, que las instituciones sociales debían ser constantemente reformadas a fin de aumentar el bienestar social, y más específicamente la utilidad de cada uno de los integrantes de la sociedad, estableciendo: ... es evidente que no produce daño ninguno en nadie. Por el contrario, produce placer... Los participantes consienten ambos. Si alguno de los dos no consintiera, el acto no sería el que tenemos en mente aqui; sería un delito totalmente diferente en su naturaleza o efectos, un daño personal, una especie de violación" (2002).

Esta situación, llevadas al plano de la comunidad abordada, establece una división ideológica entre quienes se autoidentifican como gays y aquellos que lo hacen como queer, en las prácticas de militancia, en cuanto reconocen o no al Estado como interlocutor válido para lograr cambios normativos o políticas específicas (Lind y Argüello Pazmiño, 2009).

Las exigencias de legislaciones igualitarias ejercidas por parte de la población se dan en Occidente y en pleno Siglo XX, con la revuelta del bar gay 'Stonewall Inn' en Manhattan, Estados Unidos, el 27 de junio de 1969. Se produce en contra de una brutal operación policial, dando inicio así, a un momento fundamental en la liberación homosexual. A partir de este acontecimiento se van a consolidar distintas agrupaciones, con el objeto de promocionar la visibilidad de la homosexualidad, combatir la homofobia e ir consolidando éxitos legales parciales y casi nunca exentos de polémica.

A través de la historia, los principales organismos internacionales han establecido principios respecto a la diversidad sexual, vinculantes para sus estados miembros. Las 
acciones llevadas a cabo, y promovidas a través de ONU, se encargan de promover la lucha contra la discriminación, la igualdad entre los géneros, la salud sexual y reproductiva para las mujeres y hombres. A continuación se detallan las principales legislaciones internacionales sobre el tema:

\section{Tabla 1}

Principales legislaciones internacionales sobre Diversidad Sexual

\begin{tabular}{|c|c|c|}
\hline año & Declaratoria & Principal contenido \\
\hline 1948 & $\begin{array}{l}\text { Declaración Universal de los } \\
\text { Derechos Humanos }\end{array}$ & $\begin{array}{l}\text { Toda persona tiene los derechos y libertades } \\
\text { proclamados en esta Declaración, sin distinción } \\
\text { alguna de raza, color, sexo, idioma, religión, } \\
\text { opinión política o de cualquier otra índole, origen } \\
\text { nacional o social, posición económica, nacimiento } \\
\text { o cualquier otra condición. }\end{array}$ \\
\hline 1974 & $\begin{array}{l}\text { Conferencia de Población de } \\
\text { Bucarest }\end{array}$ & $\begin{array}{l}\text { Reconoce el papel del Estado como garante de los } \\
\text { derechos reproductivos, incluyendo la información } \\
\text { y acceso a los métodos del control natal. }\end{array}$ \\
\hline 1975 & $\begin{array}{l}\text { Conferencia del Año } \\
\text { Internacional de la Mujer }\end{array}$ & $\begin{array}{l}\text { Reconoce en su declaración el derecho a la } \\
\text { integridad física y a decidir sobre el propio cuerpo. } \\
\text { El cuerpo humano, sea de hombre o de mujer, es } \\
\text { inviolable, y el respeto por él es un elemento } \\
\text { fundamental de la dignidad y libertad humanas. }\end{array}$ \\
\hline 1979 & $\begin{array}{l}\text { Convención } \\
\text { Eliminación de Todas las } \\
\text { Formas de Discriminación } \\
\text { contra las Mujeres }\end{array}$ & $\begin{array}{l}\text { Constituye el primer tratado internacional que } \\
\text { asegura la igualdad de acceso a los servicios de } \\
\text { planificación familiar. }\end{array}$ \\
\hline 1994 & $\begin{array}{l}\text { Conferencia Mundial } \text { de } \\
\text { Población y Desarrollo de El } \\
\text { Cairo }\end{array}$ & $\begin{array}{l}\text { Incorpora los contenidos del manejo del rol } \\
\text { procreativo, así como el acceso a la información } \\
\text { confiable y a los servicios de salud reproductiva de } \\
\text { calidad, los cuales incluyen a la planificación } \\
\text { familiar. De esta forma se amplía el alcance de este } \\
\text { derecho en tanto que había sido constreñido al } \\
\text { control de la natalidad. }\end{array}$ \\
\hline
\end{tabular}




\begin{tabular}{|c|c|c|}
\hline 1995 & $\begin{array}{l}\text { Conferencia Mundial sobre la } \\
\text { Mujer Beijing }\end{array}$ & $\begin{array}{l}\text { Se ratifica que los derechos reproductivos son } \\
\text { derechos humanos, reconocidos en las leyes } \\
\text { nacionales, en los documentos internacionales } \\
\text { sobre derechos humanos y en los documentos } \\
\text { pertinentes de las Naciones Unidas aprobados por } \\
\text { consenso. }\end{array}$ \\
\hline 1997 & $\begin{array}{l}\text { Declaración Universal de los } \\
\text { Derechos Sexuales }\end{array}$ & $\begin{array}{l}\text { "Los derechos sexuales son derechos humanos universales } \\
\text { basados en la libertad, dignidad e igualdad inherentes a } \\
\text { todos los seres humanos. Dado que la salud es un derecho } \\
\text { bumano fundamental, la salud sexual debe ser un derecho } \\
\text { bumano básico. Para asegurar el desarrollo de una } \\
\text { sexualidad saludable en los seres humanos y las sociedades, } \\
\text { los derechos sexuales siguientes deben ser reconocidos, } \\
\text { promovidos, respetados y defendidos por todas las sociedades } \\
\text { con todos sus medios." }\end{array}$ \\
\hline 2000 & $\begin{array}{l}\text { Carta de } \quad \text { Derechos } \\
\text { Fundamentales de la Unión } \\
\text { Europea. «Derecho de no } \\
\text { discriminación» Art.21.1 }\end{array}$ & $\begin{array}{l}\text { Se prohíbe toda discriminación, y en particular la } \\
\text { ejercida por razón de sexo, raza, color, orígenes } \\
\text { étnicos o sociales, características genéticas, lengua, } \\
\text { religión o convicciones, opiniones políticas o de } \\
\text { cualquier otro tipo, pertenencia a una minoría } \\
\text { nacional, patrimonio, nacimiento, discapacidad, } \\
\text { edad u orientación sexual. }\end{array}$ \\
\hline 2003 & $\begin{array}{l}\text { Resolución de Brasil sobre } \\
\text { "Derechos Humanos y Orientación } \\
\text { Sexual" (E/CN.4/2003/L.92) }\end{array}$ & $\begin{array}{l}\text { La diversidad sexual constituye una parte } \\
\text { integrante de los Derechos Humanos Universales, } \\
\text { tal como recoge la Declaración Universal de los } \\
\text { Derechos Humanos. }\end{array}$ \\
\hline 2007 & Principios de Yogyakarta & $\begin{array}{l}\text { Es un documento que recoge una serie de } \\
\text { principios relativos a la orientación sexual e } \\
\text { identidad de género, con la finalidad de orientar la } \\
\text { interpretación y aplicación de las normas del } \\
\text { Derecho internacional de los derechos humanos, } \\
\text { estableciendo unos estándares básicos, para evitar } \\
\text { los abusos y dar protección a los derechos } \\
\text { humanos de las personas lesbianas, gays, } \\
\text { bisexuales y transexuales (LGBT). }\end{array}$ \\
\hline
\end{tabular}




\begin{tabular}{|ll}
2008 Declaración de la ONU sobre & 96 países de las Naciones Unidas firmaron una \\
orientación sexual e identidad & declaración en defensa de los derechos sexuales, \\
de género & incluyendo la mayoría de América y Europa, más \\
& Sudáfrica, Israel, Japón, Corea del Sur, Australia y \\
& Nueva Zelanda. 57 países de las Naciones Unidas, \\
& en su mayoría islámicos, firmaron una declaración \\
& en contra de los derechos sexuales.
\end{tabular}

En todo ello, el sexo no ha sido ajeno de descripción política y tal cual como lo detalla Foucault (1998) al considerar al biopoder como un elemento indispensable para el desarrollo del capitalismo, que asegura la inserción controlada de los cuerpos en el aparato productivo y así ajusta los fenómenos de la población a los procesos económicos, demuestra que resulta imposible dejar a la sexualidad fuera del debate sobre la población y el desarrollo que se sostiene en el seno de la ONU (Girard, 2008).

Considerar hoy a la sexualidad como un derecho supone distinguir a los diferentes actores sociales que han incidido en su construcción: feministas, comunidad GLTTIBQ, organizaciones defensoras de los derechos humanos y de la sociedad civil, académicos y legisladores.Todos han creado espacios de interpelación, proposición e interlocución con los actores estatales, políticos y sociales al punto de haber impulsado la concreción y desarrollo de los: derechos sexuales y reproductivos, de la política de la salud sexual y reproductiva y la creación/promoción de leyes que defienden el derecho a la autodeterminación, la no discriminación y la lucha en contra de la violencia. El punto de encuentro entre los mencionados actores se ubica en la reflexión-acción que han identificado en el cuerpo-sexualidad, binomio considerado como territorio de derechos, como lo establece Lamas (2001):

El cuerpo como uno de los sitios privilegiados donde se encarna la libertad y se forjan los significados de la pluralidad y la democracia. Precisamente tomar el cuerpo como espacio de ejercicio ciudadano ha llevado a un grupo de feministas a plantear que bajo la idea de que todos los ciudadanos tenemos los mismos derechos se encuentra una realidad distinta. (p. VII).

En Argentina, entre los artículos más emblemáticos de la primera parte de la Constitución Argentina referidos a las garantías y derechos de los ciudadanos, redactado en 
1853 (y no alterado en las sucesivas modificaciones que sufrió la Carta Magna a lo largo del tiempo) se encuentra el artículo 16 que dice textualmente:

La Nación Argentina no admite prerrogativas de sangre, ni de nacimientos: no hay en ella fueros personales ni titulos de nobleza. Todos sus habitantes son iguales ante la ley, y admisibles en los empleos sin otra condición que la idoneidad. La igualdad es la base del impuesto y de las cargas públicas.

Pero a pesar de ello y por muchos años, la comunidad GLTTIBQ no fue reconocida.

Buenos Aires fue la primera ciudad en América Latina en legalizar las uniones civiles para personas del mismo sexo en el año 2003. Asimismo, se aprobaron leyes similares en las siguientes ciudades argentinas: 2005 la provincia de Río Negro, en 2007 Villa Carlos Paz, Córdoba y en 2009 Río Cuarto, Córdoba. La Ley de Matrimonio Igualitario, comienza el 5 de mayo de 2010, la Cámara de Diputados aprobó un proyecto de ley modificatorio del Código Civil que permitía el matrimonio entre personas del mismo sexo y que fue realizado gracias a la modificación en la ley de los términos marido y mujer por "Contrayentes". El 15 de julio de 2010 el Senado aprobó el dictamen de modificación de la Ley Civil de Matrimonio, permitiendo el matrimonio entre personas del mismo sexo, tal cual había sido sancionado en Diputados. Así Argentina, se convirtió en el primer país de Latinoamérica y el décimo en el mundo, en tener una legislación sobre matrimonio entre personas del mismo sexo en condiciones de igualdad, incluso en la adopción, en todo su territorio nacional.

La Ley de Identidad de Género ( $n^{\circ}$ 26.743), en Argentina, fue sancionada el 9 de mayo de 2012 y permite que las personas trans (travestis, transexuales y transgéneros) sean inscriptas en sus documentos personales con el nombre y el sexo de elección; además ordena que todos los tratamientos médicos de adecuación a la expresión de género sean incluidos en el Programa Médico Obligatorio, lo que garantiza una cobertura de las prácticas en todo el sistema de salud, tanto público como privado. Es la única ley de identidad de género del mundo que, conforme las tendencias en la materia, no categoriza como patológica la condición trans. 
En contraste con estas diferenciaciones hegemónicas, la cultura de los derechos humanos promueve la aceptación horizontal e inclusiva de las identidades.

\subsection{Bibliotecología y responsabilidad social}

En este apartado se pone a consideración términos relevantes que ayudan a constituir el continente necesario disciplinar, para abordar la temática establecida.

\subsubsection{Bibliotecología Social}

Las corrientes actuales de la disciplina consideran a las actividades que se llevan a cabo en relación con los fondos bibliográficos y servicios de las unidades de información como un sistema integrado, que involucra toda una serie de elementos que se ponen en acción y se interrelacionan en un proceso cuyo objetivo es formar la mejor colección, en cualquier soporte de una forma pertinente y adecuada, que satisfaga las demandas concretas de usuarios específicos, sin discriminación de ningún tipo. En esta compleja tarea intervienen factores de todo tipo: de organización, políticos, administrativos, sociales, contables, bibliográficos, intelectuales y técnicos, incorporándose además el nuevo ambiente digital, que muta cada vez más rápido y propone nuevos desafíos para los servicios que se le deben brindar al usuario para su correcta inclusión con la comunidad.

En palabras de Fois y Gimeno-Perelló (2008) son dos los aspectos en que la Bibliotecología Social centra su interés: asumir su compromiso social de los profesionales de la información/bibliotecas con la comunidad a la que sirve y realizar una revisión crítica de los métodos y los contenidos doctrinarios de la disciplina misma.

En Argentina, a partir de la implementación de la Cátedra Libre Bibliotecología Social (CaLiBiSo) FFyL/UBA, se han realizado experiencias innovadoras desde diferentes ángulos: de capacitación general sobre la temática (Díaz Jatuf, 2012, 2016) y extensibles para abordar servicios sociales bibliotecarios para la comunidad GLTTIBQ (Díaz Jatuf, 2015). 
La B/CI deberá siempre, desde lo social, ayudar al desarrollo de cualquier proceso humano a través de la accesibilidad de la información y el conocimiento para que los sujetos puedan satisfacer sus necesidades de información, tomar decisiones y resolver diferentes tipos de problemáticas, ayudando al empoderamiento de los usuarios a través de competencias informativas inclusivas, para el fortalecimiento de la ciudadanía.

\subsubsection{Comunidades Vulnerables}

Plantear la función social de la B/CI es la tarea fundamental, a partir de aquí detallar el concepto de comunidades vulnerables es relevante, debido a que con muchas las razones que la información y el conocimiento no son accesibles para toda tipo de usuarios. Una definición para este tema puede ser la de Meneses-Tello(2008) que establece:

...los «grupos vulnerables» son los que por sus condiciones sociales, económicas y culturales, por un lado, físicas, sensoriales, intelectuales o psicológicas, por el otro, pueden sufrir vejaciones contra sus derechos humanos, es decir, son aquellos grupos sociales en condiciones de desventaja y riesgo. En esta tesitura, son grupos de personas que presentan características sociales especiales que les impiden incorporarse al desarrollo y acceder a mejores realidades de bienestar social, en consecuencia, proyectan necesidades especiales en relación con la situación de la vulnerabilidad que padecen, ya sea por desventajas físicas, sensoriales o mentales; o por privaciones económicas, sociales, politicas y culturales. En esta perspectiva, los grupos vulnerables se definen como aquellos que se enfrentan a contingencias de deterioro, pérdida o imposibilidad de obtener condiciones de oportunidades alimentarias, habitacionales, sanitarias, laborales, participativas, educativas y de acceso diferencial a la información, recurso que pueden y deben ofrecer de manera organizada las instituciones bibliotecarias de diverso género. (р. 51).

El acceso a la información es un derecho humano básico, que contribuye a la inclusión. En este sentido, la biblioteca es el único lugar en muchas comunidades vulnerables pueden acceder a información que les ayudará a mejorar su formación, 
desarrollar nuevas habilidades, encontrar trabajos, poner en marcha empresas, tomar decisiones informadas en materia de agricultura y salud, entender qué está ocurriendo en cuestiones medioambientales o en sus procesos de orientación sexual. Identificar estas comunidades es muy importante para el desarrollo de las naciones.

\subsubsection{Servicios bibliotecarios con perspectivas sociales}

En el marco de la función social de la B/CI es necesario identificar las NI de las comunidades vulnerables para proporcionarles servicios y recursos que, con el compromiso principal del profesional de la información, garanticen la inclusión de estas poblaciones. Asimismo, los servicios bibliotecarios deben incluir la colaboración para la producción y gestión de políticas que permitan la preservación de la memoria, imprescindible para el funcionamiento de una comunidad.

Estos tipos de servicios se deberán evitar todo tipo de marginación de carácter social por diferentes motivos: étnicos, lingüísticos, físicos, culturales, de orientación sexual tratando de favorecer el acceso equitativo a los mismos en base de la igualdad de oportunidades de las comunidades vulnerables en relación con el resto de la población, para ayudar a construir una sociedad más justa y así evitar desigualdades.

Los usuarios con mayores oportunidades de acceder a la información y al conocimiento estarán mejor preparados para la sociedad. Al ser parte holística social, la construcción de ciudadanía compete, de manera esencial, a las bibliotecas.

\subsection{Estudios GLTTIBQ: Argentina}

Las escrituras sobre el tema de sexualidades, comenzaron a finales de la década del 20 dónde el antropólogo Alexander Goldenweiser (1880 - 1940), con su Sex and primitive society, completó una de las pocas revisiones que se publicaron acerca del tema. Durante la primera mitad del siglo pasado, las alusiones al comportamiento homosexual estaban ambiguamente disimuladas. Desde allí, hasta la década del 60, hubo escasa producción de publicaciones específicas sobre el tema. 
En materiales como la Historia de La Sexualidad, La Voluntad de saber, La ética del cuidado de sí como práctica de liberación y No al Sexo Rey, convierte en necesario y relevantes las obras del autor Michel Foucault (1926-1984), por darle el mérito de ser el primer texto sobre Historia de la Sexualidad que imprimió al mundo homosexual, tras establecer los Estudios Sexuales dentro de las Ciencias Sociales y en la Filosofía, a lo que deriva en Estudios de Género, a los Estudios Gays-Lésbico y a los Estudios Queer

A partir de la década de los 90 comenzaron a surgir los análisis etnográficos del comportamiento e identidad homosexual, de la flexibilidad de géneros, de las comunidades lesbianas y gays, del tema transgénero, de las prácticas sexuales transgresoras y de la homosexualidad. Queer refleja la naturaleza subversiva y transgresora de una mujer que se desprende de la costumbre de la femineidad subordinada; de una mujer masculina; de un hombre afeminado o con una sensibilidad contraria a la tipología dominante; de una persona vestida con ropa del género opuesto, etcétera. Las prácticas queer reflejan la transgresión a la heterosexualidad institucionalizada que constriñe los deseos que intentan escapar de su norma (Mérida, 2002). El vocablo queer no tiene traducción al español y la Teoría Queer se ha intentado traducir como teoría torcida, teoría marica, teoría rosa, teoría "entendida", teoría transgresora. Sin embargo, casi siempre se pierde el sentido preciso de la palabra inglesa, por lo que se recomienda que es preferible utilizarla en el idioma original (Llamas, 1998; Guasch, 1998, 2000; Mérida, 2002).

La aparición de los estudios queer tiene su origen en un complejo contexto social en Estados Unidos. En primer término, surgen a partir de nuevas teorías sobre la sexualidad (Weeks, 1998); de los descubrimientos sobre la tolerancia a la homosexualidad desde la Antigüedad y hasta la Alta Edad Media de Boswell (1980); de la aparición del artículo de Adrienne Rich (1996) sobre la heterosexualidad obligatoria y la existencia lesbiana; y de las evidencias arqueológicas de comportamientos homosexuales en la Grecia antigua de Dover (1980). Posteriormente, habría que destacar el cambio social y significativo que surgió a partir de los movimientos en favor de los derechos de las mujeres, de los homosexuales, la lucha contra el SIDA y la incorporación a las ciencias de otros investigadores. Asimismo, el creciente interés de las instituciones universitarias por estudiar las sexualidades también provocó un aliciente para los estudios queer. La primera universidad estadounidense que contribuyó al desarrollo de la teoría mencionada fue Columbia (1989); posteriormente las 
de Duke, Nueva York, y el Centro de Estudios de Lesbianas y Gays de la Universidad de la Ciudad de Nueva York. En Estados Unidos se editan las principales revistas periódicas de estudios sobre la diversidad sexual, tales como The Journal of Sex Research, Journal of Homosexuality, Journal of the History of Sexuality, A Journal of Lesbian and Gay Studies.En Europa la pionera fue la Universidad de Utrecht, ubicada en el centro de los Países Bajos, con su Departamento de Estudios Interdisciplinarios Gays y Lesbianos, que edita el Forum Homosexualität und Literatur Además, la Universidad de Amsterdam tiene el Centro de Documentación especializada Homodok.

Es variada la cantidad de publicaciones académicas especializadas en el tema, principalmente, del mundo anglosajón como lo detallan Phillips y Price (2012):

Canadian Online Journal of Queer Studies in Education, Columbia Journal of Gender \& Law, Duke Journal of Gender Law \& Policy, Gay and Lesbian Issues and Psychology Review, Gay \& Lesbian Review Worldwide, GLQ: A Journal of Gay \& Lesbian Studies, International Journal of Gay, Lesbian \& Transgender Studies, International Journal of Sexuality and Gender Studies, International Journal of Transgenderism, Journal of Bisexuality, Journal of Gay \& Lesbian Mental Health, Journal of Gay \& Lesbian Social Services, Journal of GLBT Family Studies, Journal of LGBT Issues in Counseling, Journal of LGBT Youth, Journal of Homosexuality, Journal of the History of Sexuality, Journal of Lesbian Studies, Lambda Nordica, LBGT Health, LBGTQ Policy Journal [Harvard University], Psychology of Sexual Identity and Gender Diversity, QED: A Journal in GLBTQ Worldmaking, Sextures, Sexualities, SGP: Sexuality, Gender, and Policy Journal Policy Studies Organization), SQS: Journal of Queer Studies in Finland, Tulane Journal of Law \& Sexuality: A Review of Sexual Orientation and Gender Identity in the Law, Transgender Studies Quarterly, Orientaciones y en Argentina Uni(+di)versidad.

En España se han realizado tesis doctorales sobre trabajo sexual, homosexualidad y lesbianismo, de las cuales algunas se han publicado a través de editoriales independientes. La Universidad de Gran Canaria ofrece desde 2002 una asignatura de libre configuración en la carrera de Derecho sobre orientaciones sexuales, y se han dictado cursos sobre transexualidad en las universidades de Sevilla en 2001 y Menéndez Pelayo en 2000.

En América Latina, desde la represión practicada por los colonizadores (Fig. 1) hasta el presente, se han realizado varias investigaciones sobre homosexualidad y trabajo 
sexual. La Universidad de Bahía en Brasil ha documentado las muertes por homofobia en aquel país y ha estudiado profundamente fenómenos como la transexualidad, la bisexualidad, el lesbianismo y la homosexualidad. Existen trabajos como el de Miano (2003) que publicado un estudio sobre las concepciones de género en el istmo de Tehuantepec, con una importante población indígena zapoteca, donde conviven hombres, mujeres y muxes (transgéneros con alto valor social en Oaxaca). La Universidad Nacional Autónoma de México tiene el Programa Universitario de Estudios de Género, que ofrece el Seminario de Investigación en Diversidad Sexual desde 1999 y la UNAM publica nuevas investigaciones y traduce textos al español de otras lenguas sobre género y diversidad sexual.

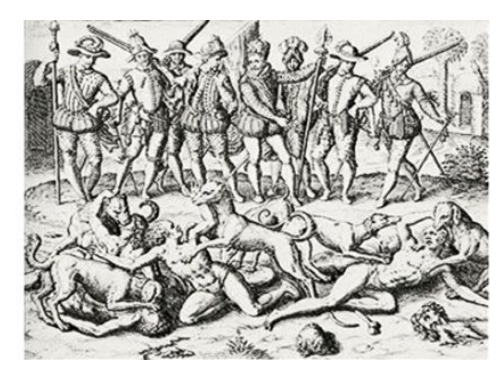

Figura 1. Vasco Nuñez de Balboa envia a sus perros sobre 50 indígenas centroamericanos, practicantes del amor masculino (1994). Grabado: Théodore de Bry

Desde la producción intelectual: En Argentina, existe una tradición de producciones representativas: desde el libro de Carlos Da Gris, pasando por el Fuskova y Berkins/Fernándezy llegando hasta el de Osvaldo Bazán; con ediciones de revistas institucionales y comerciales y legislación pertinente al tema, como la de Identidad de Género (Ley $n^{\circ}$ 26.743/12) y Matrimonio Igualitario (Ley $n^{o}$ 26.618 (10). Dicha situación lleva a pensar como ha marcado la necesaria, pero escasa producción sobre la temática, por esta zona geográfica. (Díaz Jatuf, 2014). Y testimonios de vida que ha reflejado la vida GLTTIBQ (Fig. 2, 3, 4 y 5) que lleva la cotidianidad hasta crónicas recientes del tango gay/queer en Buenos Aires (Fig. 6). Dicha situación lleva a pensar como ha marcado la necesaria, pero escasa producción sobre la temática por esta zona geográfica. 

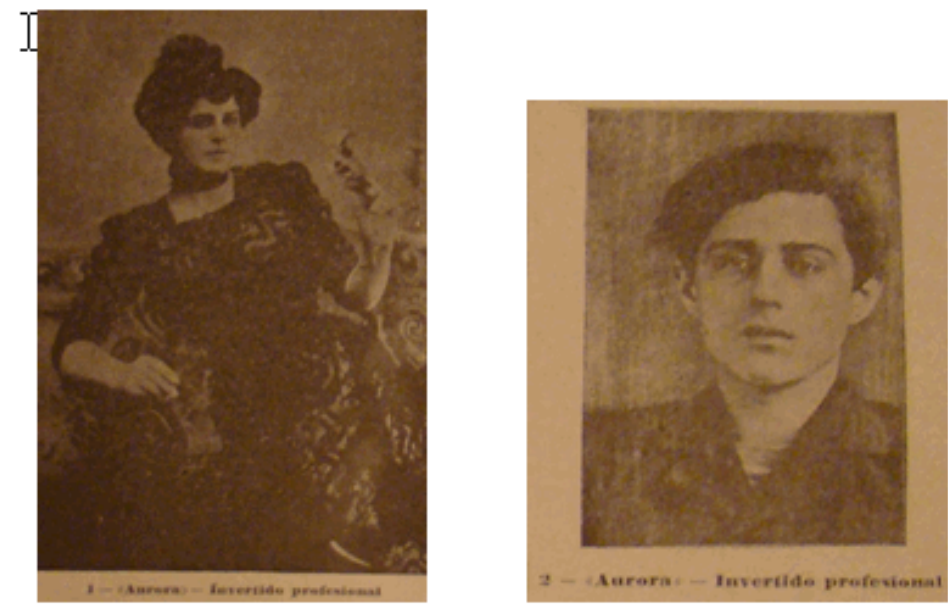

Figura 2. Aurora: ¿inversión sexual adquirida o inversión sexual congénita?

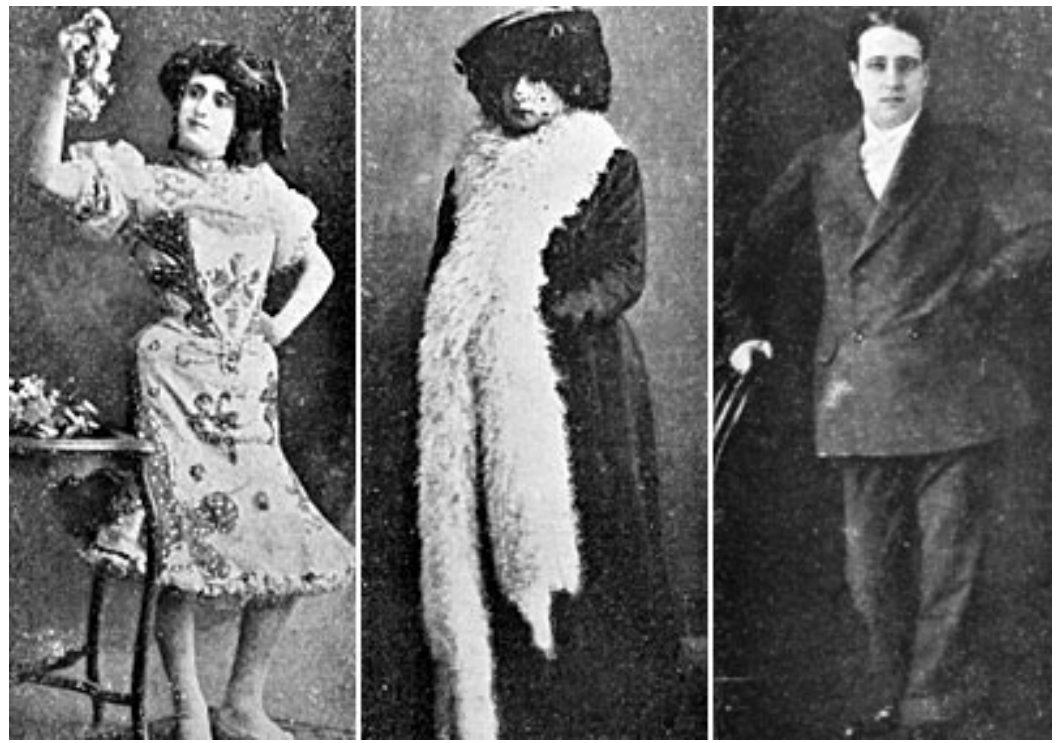

Figura 3. El célebre español Luis Fernández, conocido como "La princesa de Borbón”, luciendo varios modelos y traje 

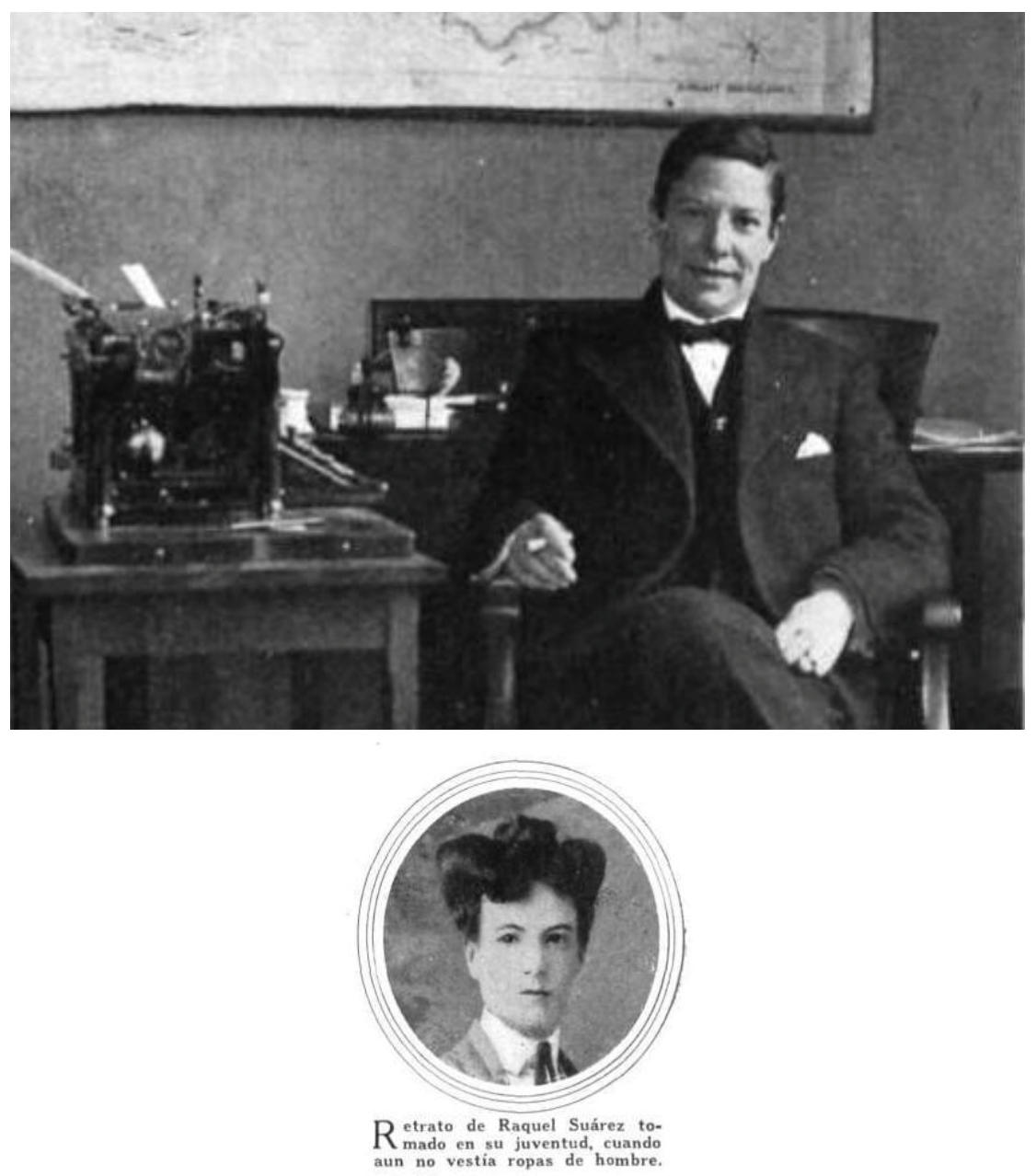

Figura 4. Raquel Suárez, usó el nombre de Raúl Suárez durante 23 años.

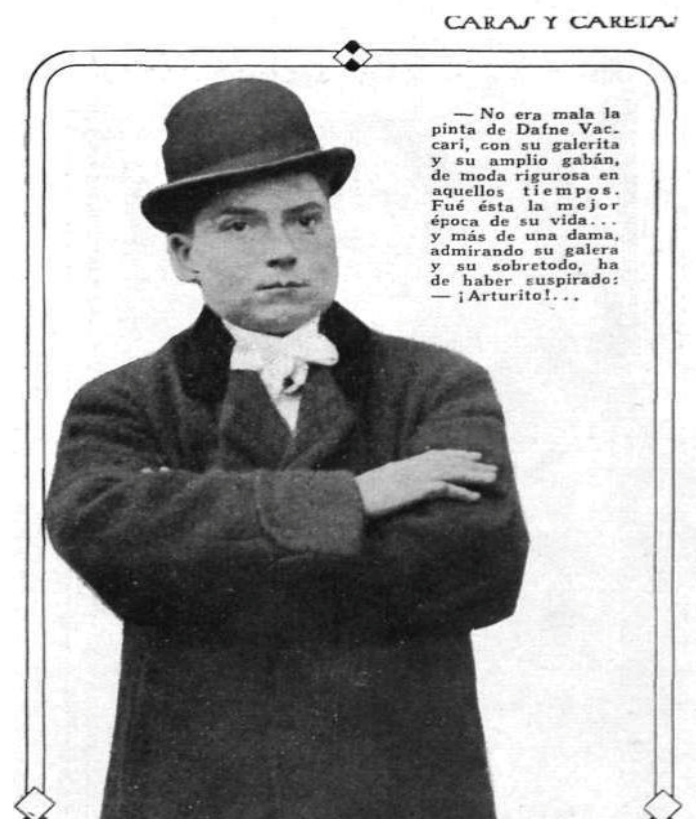

Figura 5. En el mes de mayo de 1930 murió Dafne Vaccari. (Arturo de Aragón), nacida en Sórbolo, Parma, Italia en 1906 aproximadamente. 


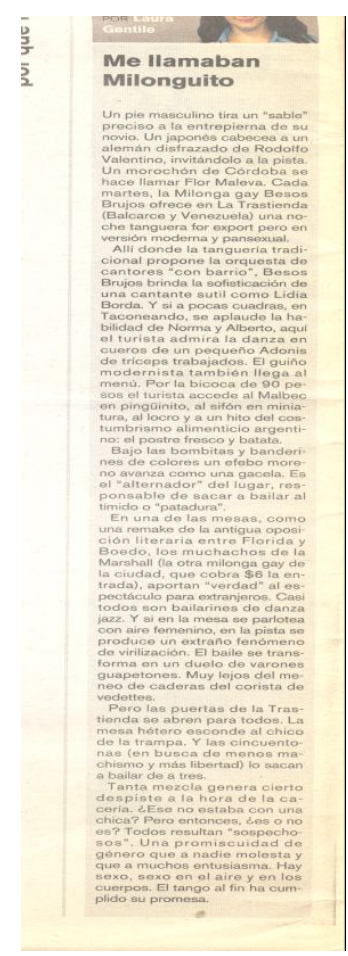

Gentile, Laura (2004, 8 de mayo). Me llamaban Milonguito. Revista de cultura Ñ. Buenos Aires: Clarín, 4.

Un pie masculino tira un "sable" preciso a la entrepierna de su novio. Un japonés cabecea a un alemán disfrazado de Rodolfo Valentino, invitándolo a la pista. Un morochón de Córdoba se hace llamar Flor Maleva. Cada martes, la Milonga gay Besos Brujos ofrece en la Trastienda (Balcarce y Venezuela) una noche tanguera for export pero en versión moderna y pansexual.

Allí donde la tangueria tradicional propone la orquesta de cantores "con barrio", Besos Brujos brinda la sostificación de una cantante sutil como Lidia Borda. Y sí a pocas cuadras, en Taconeando, se aplaude la habilidad de Norma y Alberto, aquí el turista admira la danza en cueros de un pequeño Adonis de tríceps trabajados. El guiño modernista también llega al menú. Por la bicoca de 90 pesos el turista accede al Malbec en pingüinito, el sifón en miniatura, al locro y a un hito del costumbrismo alimenticio argentino: el postre fresco y batata.

Bajo las bombitas y banderines de colores un efebo moreno avanza como una gecela. Es el "alternador" del lugar, responsable de sacar a bailar al tímido o "patadura".

En una de las mesas, como una remake de la antigua oposición literaria entre Florida y Boedo, los muchachos de la Marshall (la otra milonga gay de la ciudad, que cobra \$ 6 la entrada), aportan "verdad" al espectáculo para extranjeros. Casi todos son bailarines de danza jazz. Y si en la mesa se parlotea con aire femenino, en la pista se produce un extraño fenómeno de virilización. El baile se transforma en un duelo de varones guapetones. Muy lejos del meneo de caderas del corista de vedettes.

Pero las puertas de la Trastienda se abren para todos. La mesa hétero esconde al chico de la trampa. Y las cincuentonas (en busca de menos machismo y más libertad) lo sacan a bailar de a tres.

Tanta mezcla genera cierto despiste a la hora de la cacería. ¿Ese no estaba con una chica?. Pero entonces, ¿es o no es?. Todos resultan "sospechosos". Una promiscuidad de género que a nadie molesta y que a muchos entusiasma. Hay sexo, sexo en el aire y en los cuerpos. El tango al fin ha cumplido su promesa.

Figura 6. Flor Maleva y representación de una noticia sobre tango gay/queer

En Argentina, la Universidad de Buenos Aires y la Universidad Nacional de Río Cuarto, Córdoba, poseen Programas Queer y en 2014 se realizó en UBA a través de CaLiBiSo, el primer curso sobre Recursos de Información para la comunidad GLTTIBQ, dictado para la comunidad y público interesado, por profesional bibliotecario.

Las ciudades, como Buenos Aires, representan en muchas oportunidades, cuerpos o entes orgánicos pasibles de ser intervenidos, medidos, estudiados, etcétera, a partir de sus entornos, como es el caso concreto de que Argentina es el país elegido por numerosos extranjeros que quieren adecuar su identidad de género (Piotto, 2015). El surgimiento de las poblaciones y los problemas derivados de éstas permite leerlas en clave individual y colectiva, esto es en términos anatomopolíticos o de biopolítica de las poblaciones. Es por ello que importa, en primer lugar, la ciudad en tanto escenario material de las transformaciones urbanas, pero también como espacio donde auscultar las múltiples representaciones de índole cultural de aquellos procesos que, en diferentes registros -el literario, artístico, cinematográfico, etcétera-, se manifiestan/eclosionan y de su relación con el tiempo, el pasado y la memoria.En Argentinacomo en el resto de las sociedades latinoamericanas, las luchas sistemáticas por el 
reconocimiento de las minorías sexuales comenzaron tardíamente una vez avanzado el siglo XX, aproximadamente hacia fines de la década del cincuenta y comienzo de la década del sesenta. (Melo, 2011)

Las relaciones amatorias entre personas del mismo sexo han existido en todas las sociedades y en todos los momentos de la historia. En Argentina, bajo la dictadura del general Juan Carlos Onganía (1966-1970), la censura llegó a cosas imposibles como la prohibición de ballets, films, etcétera $\mathrm{E}$ instituciones como la policía apuntaban al control de la moral.

Entre este movimiento político y social, surge el fermento de uno de los movimientos claves: el Frente de Liberación Homosexual (FLH) que reunió sobre todo a jóvenes intelectuales homosexuales de izquierda (Bazán, 2004, Meccia, 2006). Este grupo tuvo un antecedente: "Nuestro Mundo" surgido en 1967 impulsado por Héctor Anabite, empleado militante del Partido Comunista. Esta agrupación llegó a reunir a once agrupaciones - como Católicos Homosexuales de la Argentina- y consiguió extenderse, aunque de manera tímida, en las ciudades del interior del país. Juan José Sebrelli y Manuel Puig, integraron las primeras filas del FLH, coincidiendo en esa época con la aparición de la revista Somos (1973-1976).

El FLH mantuvo estrechos vínculos con el feminismo, especialmente con dos agrupaciones, la Unión Feminista Argentina (UFA) y el Movimiento de Liberación Femenina (MLF). Fueron las activistas de este último quienes contribuyeron a la iniciativa del Grupo de Estudio y Práctica Política Sexual, cuyo principal objetivo era reflexionar sobre los caminos para derribar los preconceptos morales, denunciar los orígenes patriarcales y capitalistas de la censura del sexo y propiciar el reconocimiento de la sexualidad libre. Con la dictadura militar en 1976 extinguió la posibilidad del activismo debido a la ferocidad de la persecución desatada. Una parte de los militantes debió abandonar el país, como Manuel Puig, Héctor Anabitarte y Nestor Perlongher.

El antecedente de la década de 1970 pervivió bajo la forma de nuevas reivindicaciones, por parte de quienes asumían la identidad gay en el estreno de la recuperación democrática. Como señala Ernesto Meccia, las nuevas organizaciones gay lograron "politizar la homosexualidad" (Meccia, 2006). No exentas de tensiones, entre la necesidad de mantener el privatismo de la condición -y con esto, un estado permanente de 
"clandestinidad"-, y la acción política que daba bríos a la manifestación sin tapujos, a la politización de la vida privada, se abrieron paso a paso y poco a poco, las organizaciones demandantes de derechos humanos, hacia una estructura socio-política, enmarcada en las ciudades argentinas. Durante esta década, Argentina transitó el principio de un camino que no hacía prever las grandes transformaciones legales conseguidas con perseverancia y lucha, en los últimos años, en materia de: género, orientación sexual y sexualidades. Como parte del clima de radicalidad política que se vivió en las décadas de los 60 y 70 surgieron las primeras manifestaciones a favor de los derechos de la comunidad gay, y también la oportunidad de una tímida identificación de las mujeres lesbianas, muchas de las cuales, pertenecían a agrupaciones feministas. Pero esos fenómenos fueron reprimidos por la última feroz dictadura militar que persiguió a militantes y obligó al exilio externo e interno a reconocidos activistas argentinos.

En Argentina, entre las primeras organizaciones de homosexuales que luchó por sus derechos se encontraba Nuestro Mundo, creada en 1969 por militantes comunistas expulsados del partido por su condición sexual. Algunos de ellos confluyeron en 1971 en el Frente de Liberación Homosexual (FLH), creado en 1974, grupo que se acercó a las filas del peronismo. En el lesbianismo existió una tradición de reivindicaciones, ligada a movimientos feministas cuyos grupos paradigmáticos en la década de 1970 fueron la Unión Feminista Argentina y el Movimiento de Liberación Femenina. En 1984, luego de una fuerte razia policial se convocó a una asamblea en la discoteca Contramano, en la que se creó la Comunidad Homosexual Argentina (CHA), la que se autocalificó de organización de derechos humanos y adoptó como lema El libre ejercicio de la sexualidad es un derecho bumano. A partir de allí, muchos derechos de la comunidad GLTTIBQ han sido reconocidos.

Durante la década del 80, con el advenimiento de la democracia, la historia dio muestras de victorias para los derechos humanos, los cuales fueron reconocidos y enmarcados en la cultura nacional, dentro de la conformación socio-políticas del Estado en recuperación democrática.

Actualmente la información y el conocimiento circulan a través de internet con cursos gratuitos y pagos ofrecidos por muchas universidades del mundo, favoreciendo la difusión de los estudios GLTTIBQ. 


\subsection{Bibliotecas y comunidad GLTTIBQ}

Se puede establecer una cronología de hechos internacionales, regionales y argentinos relacionados, de la comunidad estudiada con la B/CIa partir de hechos y producciones intelectuales:

\section{Tabla 2}

Bibliotecas y Comunidad GLTTIBQ

\section{década Acontecimientos destacados}

1969: En EEUU, en consonancia con el movimiento por los derechos GLTTIBQ en ámbitos sociales y políticos, los activistas de dicha comunidad comenzaron a hacer visibles una mayor representación en las bibliotecas (Keilty, 2009). Barbara Gittings, se convirtió en 1971, en su coordinadora empujando a ALA a obtener mayor visibilidad para los gays y las lesbianas en la profesión. Se comenzó a reclama mayor representación en las bibliotecas.

1970: principios de la década la Task Force on Gay Liberation (en el seno de la ALA), realizó una campaña para reclasificar los libros que la Biblioteca del Congreso poseía sobre en la signatura HQ 71-471 ("Relaciones sexuales anormales", 1970 incluyendo "Delitos Sexuales"). En 1972, después de recibir una carta solicitando la reclasificación de dicho material, la Biblioteca del Congreso acordó hacer el cambio a una categoría recién creada, HQ 76.5 ("Homosexualidad, lesbianismoMovimiento de Liberación Gay").

1980: surgimiento de la literatura que examinó la búsqueda de información y comportamientos de usuarios de la biblioteca por gays y lesbianas. El libro The Joy of Cataloging ("El placer de catalogar" - 1981) de Sanford Berman describe las dificultades de acceso, a la información y materiales para esta comunidad (Keilty, 2009).

1980

1987: Richard Ashby escribe Library Services to Lesbian and Gay People, en el cual establece la necesidad de garantizar la igualdad de servicios para todas las personas, más allá de su género.

1988: el Task Force on Gay Liberation lanzó el "International Thesaurus of Gay and Lesbian Index Terms", que pretende estandarizar términos utilizados para la 


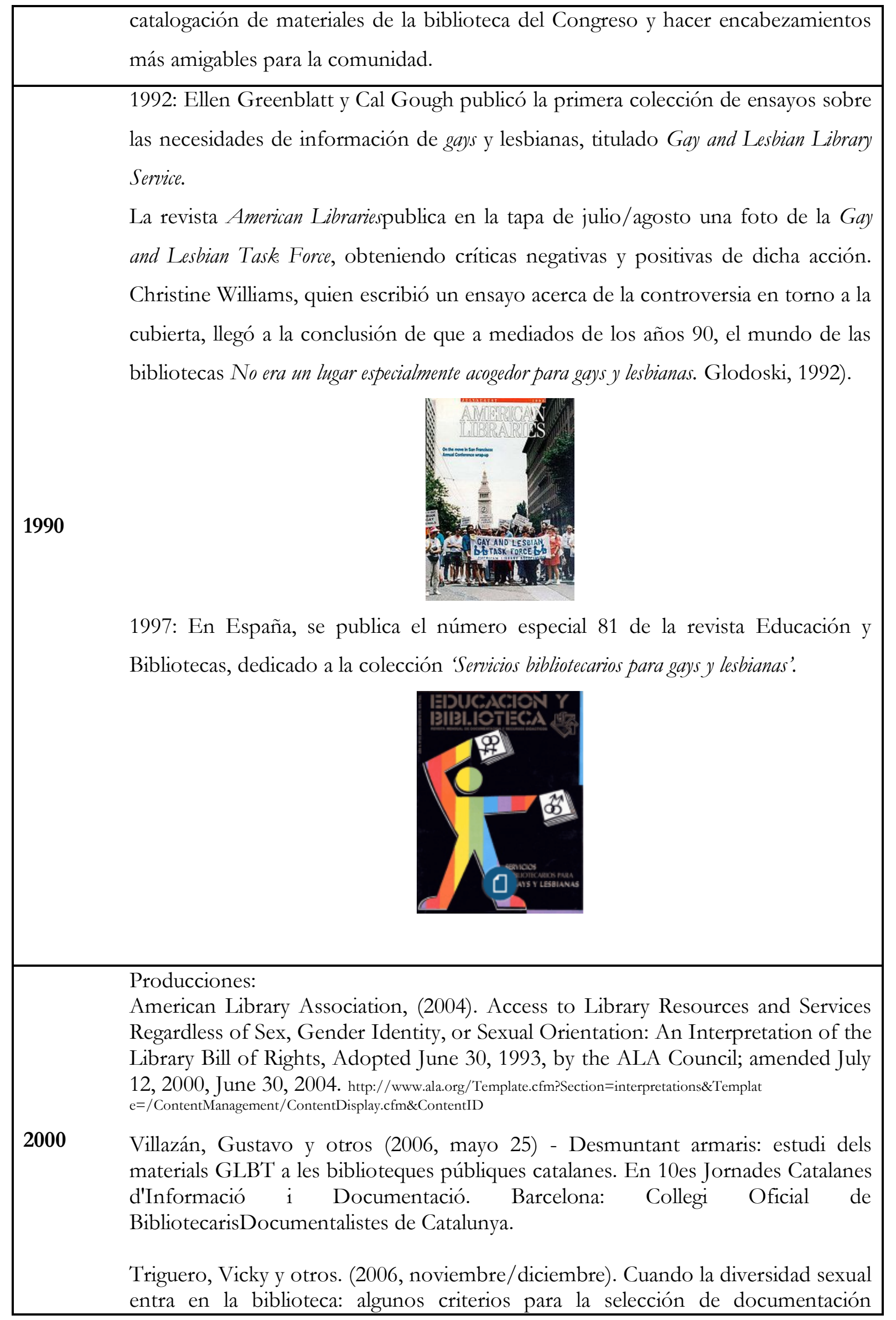


LGTB.En $3^{\circ}$ Congreso Nacional de Bibliotecas Públicas. Madrid: Ministerio de Cultura, Subdirección General de Información y Publicación. http://hdl.handle.net/10421/687

2007: El Rainbow Project Task Force (Proyecto Arco Iris) comenzó dentro de ALA a fomentar la presencia de literatura juvenil sobre temática LGTTIBQ en las colecciones de la biblioteca. El grupo ahora mantiene una bibliografía anotada de títulos para jóvenes, adolescentes y niños http://glbtrt.ala.org/rainbowbooks/

2008: Turiel, Josep M. (2008). La edición y el acceso a la literatura y los materiales GLTBQ. Scriptura 19/20: 257-280.www.raco.cat/index.php/Scriptura/article/download/189163/254763

2010: la Mesa Redonda GLBT de ALA anunció un nuevo comité, el largo de la Comisión del Arco Iris. Este comité elabora anualmente una bibliografía de libros que muestran la comunidad con una luz favorable y refleja los intereses de los adultos. Las bibliografías proporcionan orientación a las bibliotecas en la selección de materiales GLBT positivos.

2011: la Biblioteca de Investigación en el Museo de Historia de Buffalo en Nueva York se convirtió en la primera biblioteca conocida en los Estados Unidos para recoger objetos de recuerdo de la boda de parejas del mismo sexo casados legalmente.

\section{México:}

Vera-Cabañas, Martín. (2014). Las bibliotecas y la exclusión de la literatura lésbicogay: una aproximación

http://www.cisas.org.ni/story/las bibliotecas y la exclusi $\% \mathrm{C} 3 \% \mathrm{~B} 3 \mathrm{n}$ de la literatura $1 \% \mathrm{C} 3 \% \mathrm{~A} 9$ sbicogav una aproximac $\mathrm{i} \% \mathrm{C} 3 \% \mathrm{~B} 3 n$ por $\operatorname{mart} \% \mathrm{C} 3 \% \mathrm{ADn}$ vera caba $\% \mathrm{C} 3 \% \mathrm{~B} 1$ as

2014: Acedo, Alessandra Acedo. (2014, noviembre). Gênero, diversidade sexual e as lésbicas. Texto parcial da palestra apresentada durante o $7^{\circ}$ Seminário Internacional de Bibliotecas Públicas e Comunitárias, publicado com autorização da autora. http://docplayer.com.br/10979670-Genero-diversidade-sexual-e-as-lesbicas-alessandra-acedo.html

Barbara Graner, Barbara. (2014, noviembre). Gênero, sexo e sexualidade: do presumível à ressiginificação, da exclusão ao exercício integral da prática. Texto parcial da palestra apresentada durante o $7^{\circ}$ Seminário Internacional de Bibliotecas Públicas e Comunitárias, publicado com autorização da autora. siseb.sp.gov.br/arqs/INT GENERO SEXO E SEXUALIDADE Bar

\section{En Argentina: Producciones}

$47^{\circ}$ Reunión Nacional de Bibliotecarios, Buenos Aires, 2015, se presenta las líneas de investigación para la comunidad GLTTIBQ

Díaz-Jatuf, Julio. (2015, abril. Líneas de investigación de la Cátedra Libre Bibliotecología Social, Universidad de Buenos Aires, Facultad de Filosofía y Letras. En $47^{\circ}$ Reunión Nacional de Bibliotecarios Ciudad Autónoma de Buenos Aires, Argentina http://eprints.rclis.org/24957/1/Lineamientos.pdf

Díaz-Jatuf, Julio. (2015). Crítica a la ceguera de las bibliotecas argentinas por la exclusión social de la comunidad GLTTIBQ (gay, lésbica, transexual, travesti, intersexual, bisexual, queer). Crítica Bibliotecológica: revista de las Ciencias de la Información Documental, 8(1): 65-71. https://sites.google.com/site/zapopanmuela/final librarianship critique journal vol 8 no 1 jan-jun 2015.pdf 
Díaz-Jatuf, Julio. (2015, noviembre). Aportes de la Cátedra Libre Bibliotecología Social sobre necesidades y servicios de información para la comunidad GLTTIBQ (gay, lésbico, travesti, transexual, intersexual, bisexual, queer). En VII Encuentro Ibérico EDICIC 2015: "Desafíos y oportunidades de las Ciencias de la Información y la Documentación en la era digital", Madrid, España http://edicic2015.org.es/ucmdocs/actas/art/68-Diaz CaLiBiSo.pdf

Díaz-Jatuf, Julio. (2015). Servicios de Información a la Comunidad (SIC) para la población GLTTIBQ (gay, lésbica, travesti, transexual, intersexual, bisexual, queer) en Argentina/Brasil: propuesta formativa en la Maestría en Bibliotecología y Ciencia de la Información en el marco MERCOSUR. De bibliotecas y bibliotecarios: Boletín electrónico ABGR A, 7(3). http://www.abgra.org.ar/newsletter/ABGRA-Boletin-2015-A7-N3-InfoComunitaria.pdf

Díaz-Jatuf, Julio. (2015, agosto). Videos musicales: Bibliotecología Social y comunidad GLTTIBQ (gay, lésbica, travesti, transexual, intersexual, bisexual, queer). En XI Jornadas de Material Didáctico y Experiencias Innovadoras en Educación Superior, Ciudad Autónoma de Buenos Aires, Argentina. http://eprints.rclis.org/25626/

Díaz-Jatuf, Julio. (2014). LGBT thought and culture. De bibliotecas y bibliotecarios: boletín electrónico ABGRA, 4 http:/ $/$ www.abgra.org.ar/newsletter/preview.php?cat $=11 \&$ num $=38 \&$ nota $=480$

\section{España:}

Frías. José Antonio y Oliveira, Rosa. (2015, octubre). El compromiso de las bibliotecas públicas com la diversidad sexual: análisis de las iniciativas y experiencias desarrolladas en España y Portugal. En $12^{\circ}$ Congresso Nacional BAD, Évora, Portugal. http://www.bad.pt/publicacoes/index.php/congressosbad/article/viewFile/1469/pdf 72

\section{Capacitaciones:}

\section{Universidad de Buenos Aires. Cátedra Libre Bibliotecología Social}

\section{(CaLiBiSo)}

- Curso sobre Necesidades de información en la comunidad GLTTIBQ (2014)

- Curso de Servicios bibliotecarios en la comunidad GLTTIBQ (2015)

- Curso Desarrollo de la colección en bibliotecas para la comunidad GLTTIBQ

\section{Bibliotecas ESPECIALIZADAS en Argentina}

Primera Biblioteca LGTTB "Oscar Hermes Villordo", de carácter privado. Funciona en Hurlingham, y su director es el dramatugo Pietro Salemme.

Biblioteca “Alfredo Manes” dependiente de SIGLA (Sociedad de Integración Gay Lésbica Argentina)

Tabla extraída de Díaz-Jatuf, 2015, ampliada.

\subsection{Necesidades de Información}

En estos tiempos, es tangible hablar sobre la gran producción de información generada en todos los medios y la masividad de las nuevas tecnologías generadas a través de 
nuevos dispositivos y canales, que, aumentan y favorecen la comunicación interpersonal y la transferencia de la información; pero para ello es importante destacar las diferencias entre Información, Conocimiento, Necesidades de Información.

Muchos autores han publicado trabajos en los que abordan desde la teoría:

- el surgimiento de las necesidades de información, como: Taylor (1968), Paisley (1968), Wilson (1981)(Fig. 7), Blyumenau (1986), Kogotkov (1986) y Durrance (1984, 1988 y 1989); Calva-González (2006) (Fig. 8),

- otros han estudiado la búsqueda de las necesidades de información, como: Krikelas (1983))(Fig. 9),, Hill (1987), Ingwersen (1987, 1992), Kunz (1991, 1993), Prasad (1992), Fletcher y Katzer (1992), Núñez (1991, 1992), Ellis, Próchniack, Kuhlthau (1991, 1993) )(Fig. 10) Figuereido (1994), Sanz-Casado (1994), Devadason y Pratap (1997), Wilson $(1997,1999,2000)$, entre otros; y por último,

- Magaloni de Bustamante (1984), Mostert, Eloff y von Solms (1989), VerdugoSánchez (1989), Applegate (1993), Pérez-Diez (1996), Andaleeb y Patience (1998) y han abordado la satisfacción de los usuarios.

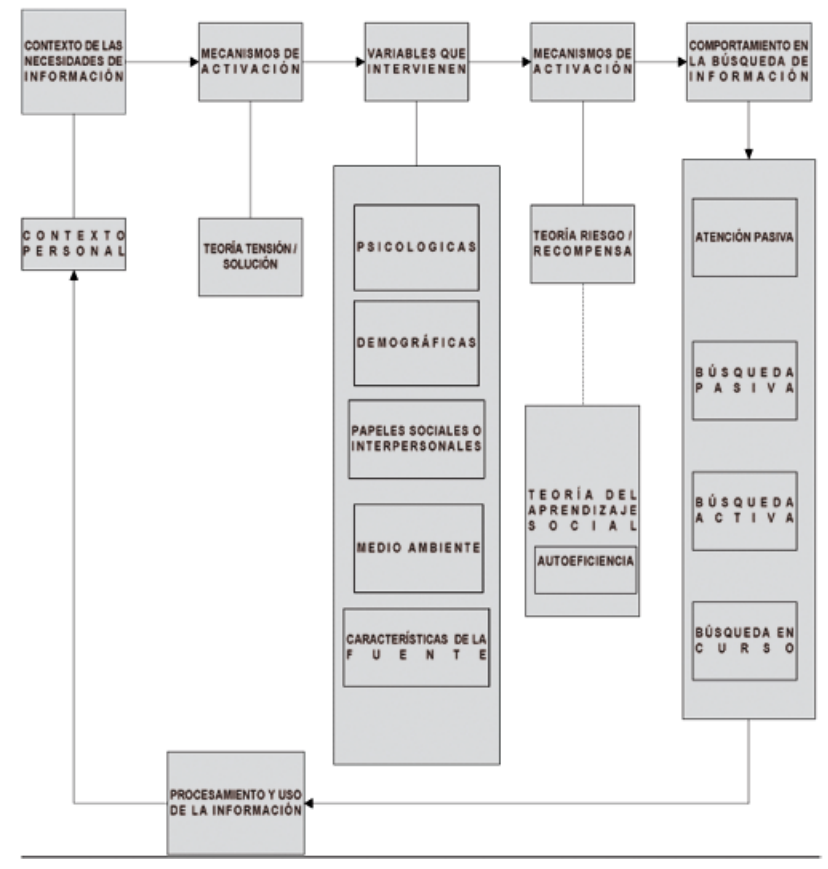

Figura 7: Modelo de comportamiento informativo de Wilson. (Fuente: Wilson. Human Information behaviour. Information Science. 


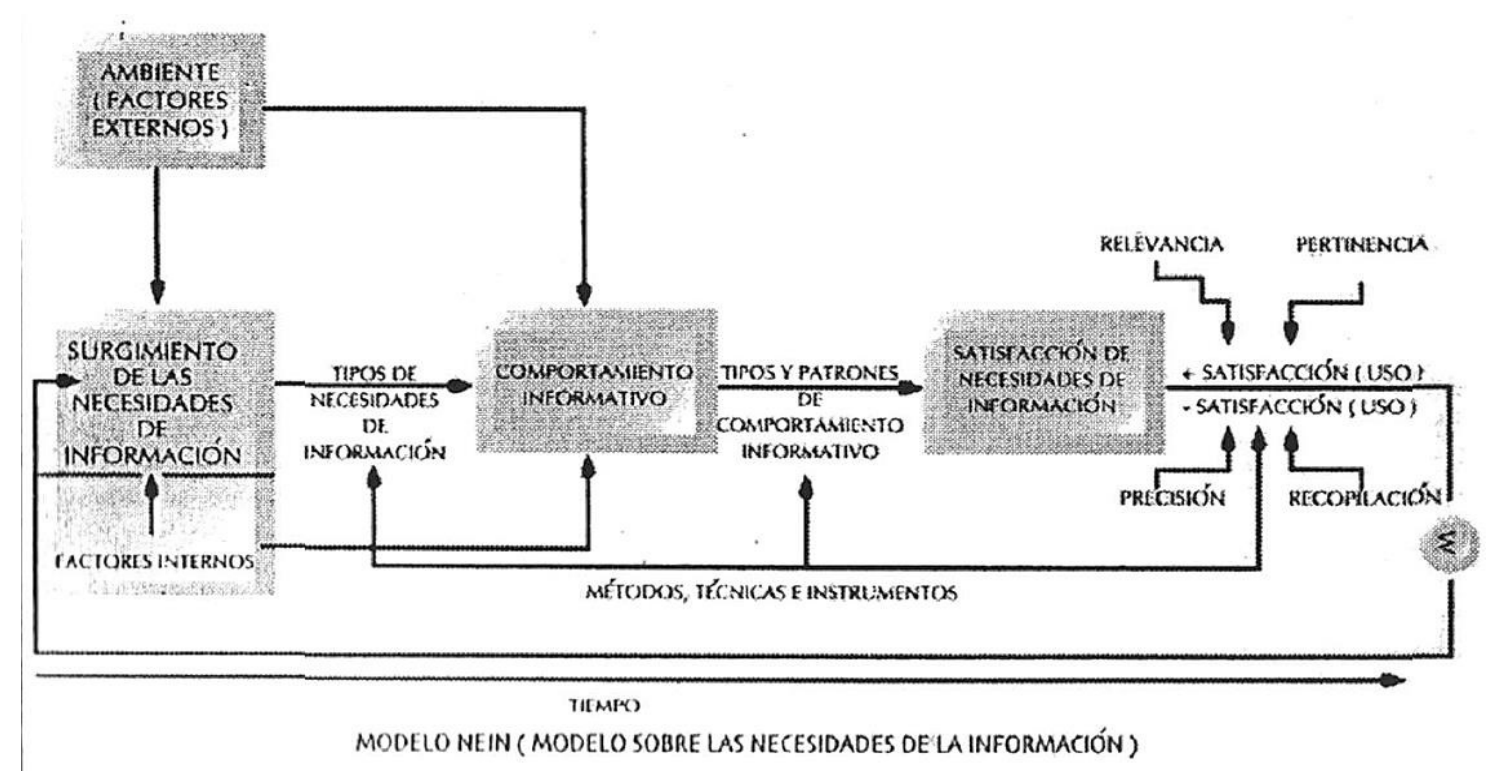

Figura 8: Modelo NEIN sobre Necesidades de Información de Calva-González. (Fuente: Calva González. Las necesidades de información: fundamentos teóricos y métodos. México: UNAM: CUIB, 2004.)

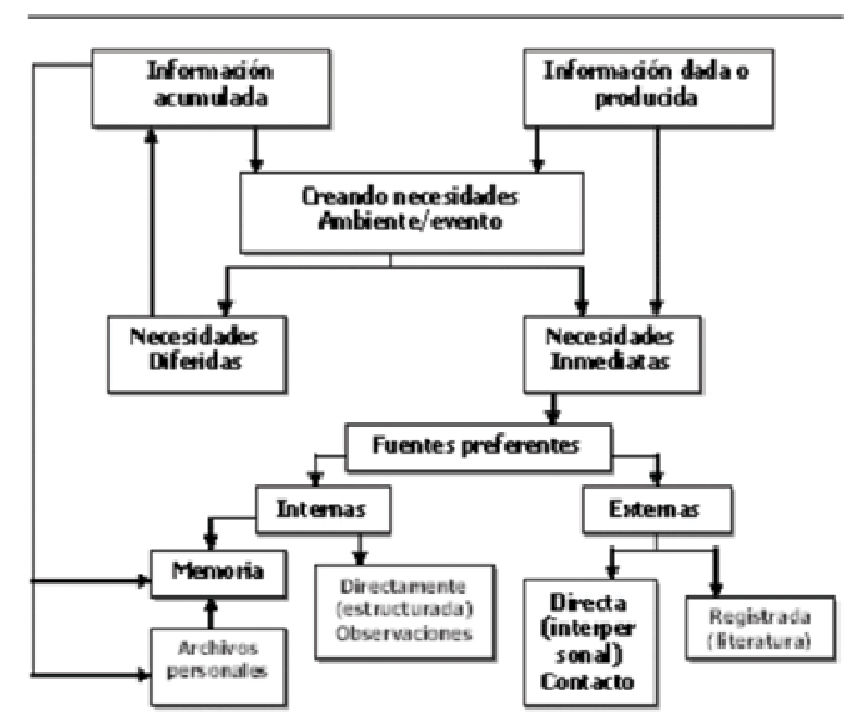

Figura 9. Modelo de comportamiento en la búsqueda de la información de Krikelas (Fuente: Krikelas. Information-seeking bahavior: patterns and concepts. Drexel Library Quaterly) 


\begin{tabular}{|c|c|c|c|c|}
\hline $\begin{array}{l}\text { Etapas durante el } \\
\text { Proceso de } \\
\text { Búsqueda de } \\
\text { Información }\end{array}$ & $\begin{array}{c}\text { Sentimientos } \\
\text { comunes para cada } \\
\text { etapa }\end{array}$ & $\begin{array}{c}\text { Pensamientos } \\
\text { comunes para cada } \\
\text { etapa }\end{array}$ & $\begin{array}{l}\text { Acciones comunes } \\
\text { para cada etapa }\end{array}$ & $\begin{array}{l}\text { Tarea apropiada } \\
\text { de acuerdo con el } \\
\text { Modelo de } \\
\text { Kuhlthau }\end{array}$ \\
\hline 1. Iniciación & Incertidumbre & General/Vago & $\begin{array}{l}\text { Búsqueda de } \\
\text { información básica }\end{array}$ & Reconocer \\
\hline 2. Selección & Optimismo & & & Identificar \\
\hline 3. Exploración & $\begin{array}{c}\text { Confusión/ } \\
\text { Frustración/ } \\
\text { Duda }\end{array}$ & & $\begin{array}{l}\text { Búsqueda de } \\
\text { información } \\
\text { relevante }\end{array}$ & Investigar \\
\hline 4. Formulación & Claridad & $\begin{array}{l}\text { Específico/ } \\
\text { Más claro }\end{array}$ & & Formular \\
\hline 5. Recopilación & $\begin{array}{l}\text { Sentido de } \\
\text { dirección/ } \\
\text { Confianza }\end{array}$ & $\begin{array}{l}\text { Incremento de } \\
\text { interés }\end{array}$ & $\begin{array}{l}\text { Búsqueda de } \\
\text { información } \\
\text { específica }\end{array}$ & Recolectar \\
\hline 6. Presentación & $\begin{array}{c}\text { Alivio/ Satisfacción } \\
\text { o Decepción }\end{array}$ & $\begin{array}{l}\text { Mayor claridad o } \\
\text { mayor especificidad }\end{array}$ & & Completar \\
\hline
\end{tabular}

Figura 10: Modelo del proceso de búsqueda de información de Kuhlthau (Fuente: Kuhlthau. Inside the search process: information seeking from the user's perspective. Journal of the American Society for Information Science)

Es posible establecer comparaciones entre algunos de esos modelos: 


\begin{tabular}{|c|c|c|c|}
\hline Modelo & $\begin{array}{l}\text { Comportamiento en la } \\
\text { búsqueda de información / J. } \\
\text { Krikelas }\end{array}$ & $\begin{array}{c}\text { Proceso de búsqueda de } \\
\text { información / C.C. Kuhlthau }\end{array}$ & $\begin{array}{l}\text { Comportamiento } \\
\text { informativo / T.D. Wilson }\end{array}$ \\
\hline Propuesta & $\begin{array}{l}\text { Cualquier actividad de un } \\
\text { individuo dirigida a identificar } \\
\text { un mensaje que satisfaga una } \\
\text { necesidad percibida como tal }\end{array}$ & $\begin{array}{l}\text { Actividad constructiva que un } \\
\text { sujeto realiza para encontrar } \\
\text { sentido a la información, con el } \\
\text { fin de aumentar su } \\
\text { conocimiento sobre un tema o } \\
\text { problema específico }\end{array}$ & $\begin{array}{l}\text { Totalidad del comportamiento } \\
\text { humano en relación a los } \\
\text { recursos y canales de } \\
\text { información, abarcando la } \\
\text { búsqueda de información, } \\
\text { activa y pasiva, y el uso de } \\
\text { información. Dentro de éste } \\
\text { incluye al comportamiento en } \\
\text { la búsqueda de información, lo } \\
\text { define como la búsqueda } \\
\text { intencional de información } \\
\text { como consecuencia de la } \\
\text { necesidad de satisfacer alguna } \\
\text { meta }\end{array}$ \\
\hline Fecha & 1983 & 1991 & 2000 \\
\hline Principio racional & Conductismo & Cognoscitivismo, & Cognoscitivismo \\
\hline En que se basa & & $\begin{array}{c}\text { Sense-making } \\
\text { Teoría de la construcción } \\
\text { personal de Nelly } \\
\text { Teoria del proceso constructivo } \\
\text { de búsqueda de información de } \\
\text { Belkin } \\
\text { Teoría de los niveles de } \\
\text { necesidades de información de } \\
\text { Taylor }\end{array}$ & $\begin{array}{c}\text { Modelo de Ellis } \\
\text { Modelo de Kuhlthau } \\
\text { Modelo anterior de Wilson }\end{array}$ \\
\hline $\begin{array}{l}\text { Elementos que } \\
\text { intervienen }\end{array}$ & $\begin{array}{l}\text { Proceso por presentación de } \\
\text { elementos: } \\
\text { Necesidades de información: } \\
\text { diferidas o inmediatas } \\
\text { Ambiente / evento } \\
\text { Información acumulada } \\
\text { Información producida } \\
\text { Fuentes Intemas } \\
\text { Fuentes Externas }\end{array}$ & $\begin{array}{l}\text { Proceso por etapas: Iniciación; } \\
\text { Selección; Exploración; } \\
\text { Formulación; Recopilación; y } \\
\text { Presentación } \\
\text { Características: afectivas, } \\
\text { cognitivas y físicas } \\
\text { Tareas apropiadas: reconocer, } \\
\text { identificar; investigar; } \\
\text { formular; recolectar, y } \\
\text { completar }\end{array}$ & $\begin{array}{c}\text { Proceso por diagrama de flujo: } \\
\text { Contexto } \\
\text { Mecanismos de activación } \\
\text { Variables } \\
\text { Mecanismos de activación } \\
\text { Comportamiento } \\
\text { Procesamiento y uso de la } \\
\text { información }\end{array}$ \\
\hline \multicolumn{4}{|c|}{ Conceptos básicos } \\
\hline Necesidad & $\begin{array}{l}\text { Capacidad del ser humano por } \\
\text { reconocer la existencia de una } \\
\text { incertidumbre }\end{array}$ & & $\begin{array}{l}\text { Es una experiencia subjetiva } \\
\text { que ocurre únicamente en la } \\
\text { mente de la persona }\end{array}$ \\
\hline $\begin{array}{c}\text { Tipos de } \\
\text { información }\end{array}$ & $\begin{array}{c}\text { Acumulada } \\
\text { Dada o producida }\end{array}$ & & \\
\hline $\begin{array}{l}\text { Necesidad de } \\
\text { Información }\end{array}$ & $\begin{array}{c}\text { Función de la incertidumbre } \\
\text { extrínseca producida por una } \\
\text { discrepancia percibida entre los } \\
\text { niveles corrientes de certeza } \\
\text { acerea de objetos importantes } \\
\text { del entomo y un estado de } \\
\text { criterio que busca alcanzar esos } \\
\text { niveles de certeza }\end{array}$ & $\begin{array}{l}\text { La brecha entre el } \\
\text { conocimiento del usuario sobre } \\
\text { el problema o tópico y lo que el } \\
\text { usuario necesita saber para } \\
\text { resolver el problema }\end{array}$ & \\
\hline $\begin{array}{c}\text { Tipos de } \\
\text { necesidades }\end{array}$ & $\begin{array}{l}\text { Necesidades diferidas } \\
\text { Necesidades inmediatas }\end{array}$ & & \\
\hline $\begin{array}{l}\text { Mecanismos de } \\
\text { activación }\end{array}$ & & & $\begin{array}{l}\text { Teonias: de tensión/solución; } \\
\text { riesgo/recompensa; y del } \\
\text { aprendizaje social }\end{array}$ \\
\hline $\begin{array}{l}\text { Procesamiento y uso } \\
\text { de la información }\end{array}$ & & & $\begin{array}{l}\text { Proceso subjetivo, no es } \\
\text { observable ya que tiene lugar } \\
\text { en la mente del individuo }\end{array}$ \\
\hline Mecanismo & $\begin{array}{l}\text { Forma vertical y unidireccional } \\
\text { de un concepto o evento a otro }\end{array}$ & $\begin{array}{c}\text { Forma lineal tanto horizontal } \\
\text { como vertical a través de las } \\
\text { etapas y de las tareas } \\
\text { apropiadas }\end{array}$ & $\begin{array}{l}\text { Teoría de tensión/solución, } \\
\text { Teoría riesgo/recompensa, } \\
\text { Teoría del aprendizaje social. }\end{array}$ \\
\hline
\end{tabular}

Figura 11: Cuadro comparativo de los modelos de Krikelas, Kuhlthau y Wilson. (Fuente: Hernández-Salazar y otros. Análisis de modelos de comportamiento en la búsqueda de la información. Ciência da Informação.)

El establecimiento de una terminología clara y el desarrollo de corrientes teóricas disciplinares, harán más eficaz los estudios de necesidades de información con el fin de ayudar a producir más conocimiento al servicio de la comunidad. 
A continuación se procede a definir los términos: Información, Conocimiento, NI, tipologías y NI en la comunidad GLT'TIBQ

\subsubsection{Información y Conocimiento}

Tom Wilson (1981), indica que el término información se usa, en el contexto de la investigación de estudios de usuarios para denotar:

1) entidad física o fenómeno $\left(\mathrm{n}^{\circ}\right.$ de libros leídos en un período de tiempo, $\mathrm{n}^{\circ}$ de suscripciones a revistas, etcétera);

2) canal de comunicación a través del que se transfieren los mensajes;

3) datos fácticos, determinados empíricamente y presentados en un documento o transmitidos oralmente.

Krikelas (1983) considera a la información como cualquier estímulo que reduce la incertidumbre

\section{Conocimiento}

Sin lugar a dudas, el concepto de estructura del conocimiento se toma de la psicología cognitiva y de la ciencia cognitiva, a la que Ingwersen (1982) califica de disciplina emergente y define como una intersección de lingüística, inteligencia artificial y psicología. Allen (1991) afirma que la investigación cognitiva en Ciencia de la Información deriva de métodos y esquemas explicativos desarrollados en la ciencia cognitiva. Esta estudia los procesos de aprender, recordar, comprender, resolver problemas y tomar decisiones. Los materiales en bruto de los procesos cognitivos son "objetos" mentales: conceptos, ideas y conocimiento.

\subsubsection{Necesidades, Búsqueda y Uso de la Información}

La biblioteca, como institución social, no debe ni puede estar exenta de las NI de la comunidad a la cual sirve; y es ella la responsable de satisfacerla. Pero para eso, conocer las necesidades de cualquier población es el primer paso que se deberá dar teniendo siempre en cuenta los derechos humanos de los individuos y el libre acceso a la información, sin discriminación alguna; para ayudar a la conformación de una sociedad más justa y equitativa. 
Las NI surgen en el individuo como una insatisfacción por la carencia de algún conocimiento e información...la influencia de un ambiente (social, político, cientifico, etcétera) y las características particulares (experiencia, conocimientos previos, etcétera) que tiene el sujeto.(Calva González, 2004) y conocerlas, permitiría:

- Desarrollar una colección de materiales documentales cuyo contenido responda con efectividad a las necesidades de información de la comunidad a la que sirve. (Negrete Gutiérrez, 1988),

- Mejorar y promover los servicios bibliotecarios, y

- A través de lo antes mencionado, satisfacer las necesidades de información específicas de la comunidad donde se encuentra inserta la biblioteca

Identificar las necesidades de información de una comunidad definida de manera clara, objetiva y profunda, es imprescindible para establecer el perfil informativo de esa comunidad - con sus complejidades, para ayudar a brindar respuestas inmediatas a las demandas de información.

Históricamente, el estudio de las NI y su uso surge de la Ciencia de la Información. Se han hecho estudios relevantes sobre el tema durante las décadas del 30 y el 40 en Bibliotecología, Comunicación y en campos específicos, como en Química, concentrándose en el uso de las fuentes, los sistemas y canales de información. Una nueva línea de estudios surgió en 1948, durante la conferencia de la Royal Society, centrado en la forma en que los científicos se mueven para obtener información y de cómo usan la literatura en sus diferentes áreas. Alrededor de la década del 50 esta área se fue desarrollando dentro de la Ciencia de la Información, estableciéndose en 1959 los Proceedings of the International Conference on Scientific Information y the Annual Review of Information Science and Technology, con su capítulo especializado "Information needs and use" desde su primer volumen en 1966 a 1984. En 1976, la Sheffield University en Inglaterra, implementó el Centre for Research on User Studies, con el objeto de desarrollar y divulgar los estudios realizados. 
Dentro de este resumen se pueden enumerar a continuación los aportes más significativos dentro de las NI, a través del tiempo:

\section{Tabla 3}

Autores más representativos sobre NI

\begin{tabular}{|c|c|}
\hline Autores & Aportes \\
\hline $\begin{array}{l}\text { Taylor, Robert S. } \\
\text { (1968). Question- } \\
\text { negotiation and } \\
\text { information } \\
\text { seeking in libraries. } \\
\text { College \& Research } \\
\text { Libraries. } 29(3) \text { : } \\
\text { 178-194. }\end{array}$ & $\begin{array}{l}\text { En 1968, Taylor, establece en su artículo que se basa en la entrevista de } \\
\text { referencia, fomentando a los referencistas que establezcan los tipos de } \\
\text { necesidades, de las cuales él la tipifica en cuatro tipos: } \\
\text { "1. Necesidad visceral. Antes que nada está la necesidad de } \\
\text { información consciente o aun inconsciente que no existe en la experiencia } \\
\text { recordada del que busca. Puede ser sólo un tipo vago de insatisfacción. } \\
\text { Probablemente sea inexpresable en términos lingüísticos. Esta necesidad } \\
\text { (realmente no es todavia una pregunta) cambiará de forma, calidad, concreción } \\
\text { y criterios cuando se agregue información, cuando sea influida por la analogía, } \\
\text { cuando su importancia crezca con la investigación. } \\
\text { 2. Necesidad consciente. En el segundo nivel existe una descripción } \\
\text { mental consciente de una mal definida área de indecisión. Probablemente será } \\
\text { una formulación ambigua y vaga. El buscador puede, en este estado, hablar } \\
\text { con alguien más para afinar su enfoque. Presumiblemente espere que sucedan } \\
\text { dos cosas en este proceso: (a) sus colegas comprenderán las ambigüedades; y (b) } \\
\text { esas ambigüedades desaparecerán gradualmente en el curso del diálogo. } \\
\text { 3. Necesidad formalizada. En este nivel un buscador puede dar } \\
\text { forma a una formulación cualificaday racional de su pregunta. Aquí describe } \\
\text { su área de duda en términos concretos, esta puede ser pensada o no dentro del } \\
\text { contexto o de las restricciones del sistema del que quiere información. Por } \\
\text { cierto, en este nivel puede ver al bibliotecario como parte del sistema antes que } \\
\text { como un colega. } \\
\text { 4. Necesidad comprometida. En el cuarto nivel la pregunta se } \\
\text { reformula en anticipación a lo que los archivos pueden proporcionar. El } \\
\text { buscador debe pensar en términos de la organización de archivosparticularesy } \\
\text { de paquetes discretos disponibles --tales como libros, informes, articulos, } \\
\text { dibujos o tablas.(Romanos de Tiratel, 2000). }\end{array}$ \\
\hline $\begin{array}{l}\text { Line, M.B (1974). } \\
\text { Draft definitions: } \\
\text { information needs, } \\
\text { wants, demands } \\
\text { and use. ASLIB } \\
\text { Proceedings. 26(2): } \\
87\end{array}$ & $\begin{array}{l}\text { Line establece la NI como: Es lo que debe tener un individuo para su trabajo, su } \\
\text { investigación, su educación, su recreación, etcétera Para el investigador es aquella que } \\
\text { llevará adelante su investigación., una necesidad puede o no ser identificada como un } \\
\text { deseo. Una necesidad es una demanda potencial. }\end{array}$ \\
\hline $\begin{array}{l}\text { Belkin, Nicholas J. } \\
\text { (1978). } \\
\text { Information }\end{array}$ & $\begin{array}{l}\text { Belkin desarrolló el concepto del estado anómalo del conocimiento } \\
\text { (Anomalous State of Knowledge - ASK) estableciendo que la la NI surge del }\end{array}$ \\
\hline
\end{tabular}




\begin{tabular}{|c|c|}
\hline $\begin{array}{l}\text { concepts for } \\
\text { information } \\
\text { science. Journal of } \\
\text { Documentation, } \\
34(1): 55-85\end{array}$ & $\begin{array}{l}\text { reconocimiento de una carencia en el estado de conocimiento del usuario } \\
\text { en relación con algún tema. }\end{array}$ \\
\hline $\begin{array}{l}\text { Belkin, Nicholas J. } \\
(1980) \text {. } \\
\text { Anomalous states } \\
\text { of knowledge as a } \\
\text { bases for } \\
\text { information } \\
\text { retrieval. Canadian } \\
\text { Journal } \\
\text { Information Science. } \\
\text { 5:133-143. }\end{array}$ & $\begin{array}{l}\text { Belkin usa el término 'anómalo como un término descriptivo y que la la } \\
\text { falta de un estado del conocimiento pueden ser de muchos tipos. }\end{array}$ \\
\hline $\begin{array}{l}\text { Wilson, Tom D. } \\
\text { (1981). On user } \\
\text { studies } \\
\text { information needs. } \\
\text { Journal } \\
\text { Documentation. } \\
\text { 37(1): } 3-15 .\end{array}$ & $\begin{array}{l}\text { El modelo que Wilson introdujo acerca de la búsqueda de información, o } \\
\text { las causas de la NI podían ser no solo cognitivas sino también afectivas, o } \\
\text { sea, podían tener un componente emocional o fisiológico. }\end{array}$ \\
\hline $\begin{array}{l}\text { Krikelas, James. } \\
\text { (1983). } \\
\text { Information } \\
\text { seeking behavior: } \\
\text { patterns and } \\
\text { concepts. Drexel } \\
\text { Library Quarterly. } \\
\text { 19: 5-20. }\end{array}$ & $\begin{array}{l}\text { En el modelo de la búsqueda de información de Krikelas considera a la } \\
\text { información como cualquier estímulo que reduce la incertidumbre, y } \\
\text { advierte sobre los problemas que posee dicho concepto. }\end{array}$ \\
\hline $\begin{array}{l}\text { Durrance, Joan C. } \\
\text { (1984). Armed for } \\
\text { action: library } \\
\text { response to citizen } \\
\text { information } \\
\text { needs.Nueva York: } \\
\text { Neal-Schuman. }\end{array}$ & $\begin{array}{l}\text { Establece que las NI son el resultado de los problemas que se le presentan } \\
\text { a un individuo en una situación específica. }\end{array}$ \\
\hline $\begin{array}{l}\text { Dervin, Brenda y } \\
\text { Michael Nilan. } \\
\text { (1986). } \\
\text { Information needs } \\
\text { and uses. Annual } \\
\text { Review of Information } \\
\text { Science and } \\
\text { Technology, 21: 3-33. } \\
\text { Durrance, Joan C. } \\
\text { (1989). } \\
\text { Information }\end{array}$ & $\begin{array}{l}\text { Esta revisión considera a la información como un constructo social creada } \\
\text { en la interacción de personas y mensajes, que conduce al uso de variables } \\
\text { de nivel organizativo y social. }\end{array}$ \\
\hline
\end{tabular}




\begin{tabular}{|c|c|}
\hline $\begin{array}{ll}\text { needs: old } & \text { song, } \\
\text { new tune. } & \text { School } \\
\text { Library } & \text { Media } \\
\text { Quaterly, } & 17(3): \\
\text { 126-130. } & \end{array}$ & \\
\hline $\begin{array}{l}\text { Kuhlthau, Carol C. } \\
\text { (1991). Inside the } \\
\text { search process: } \\
\text { information } \\
\text { seeking from the } \\
\text { user's perspective. } \\
\text { Journal of the } \\
\text { American Society for } \\
\text { Information Science, } \\
\text { 42(5): 361-371. }\end{array}$ & $\begin{array}{l}\text { Genera un modelo sobre el proceso de búsqueda de información desde la } \\
\text { perspectiva del usuario y dicha estructura se basa en las premisas del } \\
\text { sensemaking realizadas por Dervin. }\end{array}$ \\
\hline $\begin{array}{l}\text { Savolainen, Reijo. } \\
\text { (1993). The sense- } \\
\text { making theory: } \\
\text { reviewing the } \\
\text { interests of a user- } \\
\text { centered approach } \\
\text { to information } \\
\text { seeking and use. } \\
\text { Information } \\
\text { Processing } \\
\text { Management. 29(1): } \\
\text { 13-28. }\end{array}$ & $\begin{array}{l}\text { Describe la polaridad en los abordajes investigativos cuando indica que, } \\
\text { en el contexto de los estudios de la información, el investigador puede } \\
\text { elegir entre dos tipos ideales de puntos de vista, el del intermediario o el } \\
\text { del usuario (individuo) de la información. }\end{array}$ \\
\hline $\begin{array}{l}\text { Sanz Casados, } \\
\text { Elías. (1994). } \\
\text { Manual de estudios de } \\
\text { usuarios. Madrid: } \\
\text { Fundación } \\
\text { Germán Sánchez } \\
\text { Ruipérez. }\end{array}$ & $\begin{array}{l}\text { Constituye un manual que estructura y describe los métodos de } \\
\text { recolección de datos para el análisis de los estudios de usuarios desde el } \\
\text { punto de vista cuantitativo. }\end{array}$ \\
\hline $\begin{array}{l}\text { Wilson, Tom D. } \\
\text { (1997). } \\
\text { Information } \\
\text { behavior: an } \\
\text { interdisciplinary } \\
\text { perspective. } \\
\text { Information } \\
\text { Processing \& } \\
\text { Management, } \\
\text { 33(4): 551-572. }\end{array}$ & $\begin{array}{l}\text { Intenta elaborar ese modelo anterior de conducta de búsqueda de } \\
\text { información y desarrollar una estructura más general refiriéndose al } \\
\text { trabajo sobre conducta informativa que realizado en una variedad de } \\
\text { campos del conocimiento fuera de la ciencia de la información (ciencias } \\
\text { de la salud, estudios del consumidor, propaganda y publicidad) y que, } \\
\text { dada la fragmentación del conocimiento en especialidades, raramente es } \\
\text { considerado por los científicos de la información. }\end{array}$ \\
\hline $\begin{array}{l}\text { Wilson, Tom D. } \\
(1999) \text {. Models in } \\
\text { information } \\
\text { behavior research. } \\
\text { Journal of } \\
\text { Documentation. }\end{array}$ & $\begin{array}{l}\text { Según los aspectos estudiados, dentro del comportamiento informacional se establecen } \\
\text { conceptualmente diversas áreas o niveles anidados. } \\
\text { El comportamiento informacional (information behavior) puede considerarse como el } \\
\text { área de investigación más general. } \\
\text { El comportamiento de búsqueda de información (information seeking behavior) es un }\end{array}$ \\
\hline
\end{tabular}




\begin{tabular}{|c|c|}
\hline $5(3): 249-270$ & $\begin{array}{l}\text { subconjunto del anterior, y concierne concretamente a la diversidad de métodos } \\
\text { empleados por los individuos para descubrir y acceder a los recursos de información. } \\
\text { El comportamiento de búsqueda propiamente (information searching behavior) es un } \\
\text { subconjunto del comportamiento de buisqueda de información que pretende englobar las } \\
\text { interacciones existentes entre el usuario de la información (con o sin intermediario) y los } \\
\text { sistemas de información.(Romanos de Tiratel, 2000). }\end{array}$ \\
\hline $\begin{array}{l}\text { Wilson, Tom D. } \\
(2000) \text {. Human } \\
\text { information } \\
\text { behavior. } \\
\text { Information } \\
\text { Science, 3(2): } 49 \text { - } \\
55 \text {. }\end{array}$ & $\begin{array}{l}\text { Define comportamiento informativo como [...] la totalidad del } \\
\text { comportamiento humano en relación a los recursos y canales de información, abarcando } \\
\text { la búsqueda de información, activa y pasiva, y el uso de información.Incluye, tanto la } \\
\text { comunicación cara-a-cara con otros, como la recepción pasiva de información, [...].( } \\
\text { p.49). }\end{array}$ \\
\hline $\begin{array}{l}\text { Calva González, } \\
\text { Juan José. (2004). } \\
\text { Las necesidades de } \\
\text { información: } \\
\text { fundamentos } \\
\text { teóricos y } \\
\text { métodos. México, } \\
\text { DF. }\end{array}$ & $\begin{array}{l}\text { Constituye un importante aporte al estudio de los usuarios al abordar los } \\
\text { fundamentos del surgimiento de las NI, pero no desde una perspectiva } \\
\text { coyuntural con miras a establecer programas de previsión de servicios } \\
\text { bibliotecarios, sino al tratar de dilucidar los orígenes de las NI explorando } \\
\text { entre las necesidades de los seres humanos, proponiendo el modelo } \\
\text { NEIN (Fig. 8). }\end{array}$ \\
\hline
\end{tabular}

En Hispanoamérica, existen pocos textos sobre NI (Calva-González, 2013; Villaseñor, 2014), pero en América Latina, existen algunos abordajes y experiencias realizadas (Hernández-Salazar, 1997, 2004; Pérez-Giffoni y Sabelli, 2010; Sabelli y otros, 2012 y Sabelli, 2003, 2008, 2013), en los cuales también se ha planteado la necesidad de producciones revisionistas sobre el tema, por su complejidad temática y terminológica. Dicha problemática también ha sido planteada a través de eventos como los Seminarios de Usuarios de la Información (México: CUIB), desde 2004 al presente 2014 en sus nueve ediciones y sobre Alfabetización en información.'

En América Latina es importante destacar dos revisiones bibliográficas:

- Bettiol (1990), en lengua portugués, donde se plasma la literatura de estudios extranjeros sobre NI. La compiladora sugiere una visión más amplia sobre el tema, donde las NI deben estar asociadas a otras necesidades humanas básicas, divididas por los psicólogos en tres categorías que son: necesidades fisiológicas, afectiva y cognitiva. 
- La primera revisión bibliográfica, en castellano, llevada a cabo por Susana Romanos de Tiratel (2000), con la cual se cumple el objetivo de cubrir una necesidad imperiosa sobre el tema al presentar un estado de la cuestión que integra los aspectos teóricos generados en el área de los estudios de usuarios, teorizaciones generales y abordajes alternativos y definición de terminología necesaria con el objeto de conceptualizar cada uno de estos fenómenos sociales.

Un reciente libro (Tarango y otros, 2014) reúne investigaciones sobre servicios de información para migrantes donde se destaca el trabajo de Chu (2014), concentrado especialmente en grupos y asuntos multiculturales y en la necesaria inserción del investigador en la comunidad de estudio.

2.7. Antecedentes de estudios sobre Necesidades de información en Argentina

Lamentablemente y en general, hay pocos antecedentes argentinos en el área de los estudios de usuarios, referidos a las modalidades de búsqueda de información. (Romanos de Tiratel, 2000) y esto se hace extensible a los estudios sobre NI. Esta situación no ha sufrido muchas modificaciones hasta nuestros días considerando

Analizando los antecedentes mencionados, que presentan un panorama de los estudios de usuarios efectuados en el campo científico, tecnológico y educativo superior en la Argentina, se puede señalar que algunos de ellos son previos a la difusión masiva del acceso a recursos electrónicos en línea. La mayor parte se refiere a usuarios de diversas áreas pertenecientes al campo de las humanidades o al de las ciencias sociales, mientras que ninguno se dedica al ámbito de la tecnología.(Falcato, 2016).

A continuación se señalan los principales antecedentes encontrados en la literatura científica: 
Tabla 4

Principales antecedentes sobre NI en Argentina

\begin{tabular}{|c|c|c|c|c|}
\hline Año & $\begin{array}{l}\text { Tipo de } \\
\text { estudio }\end{array}$ & Autor/es & $\begin{array}{l}\text { Tipo de } \\
\text { necesidades } \\
\text { detectadas }\end{array}$ & $\begin{array}{l}\text { Notas y referencia } \\
\text { bibliográfica }\end{array}$ \\
\hline 1971 & Investigación & $\begin{array}{l}\text { Gustavo } \\
\text { Cirigliano }\end{array}$ & $\begin{array}{l}\text { Capacidad de los } \\
\text { jóvenes graduados } \\
\text { universitarios para } \\
\text { manejar fuentes de } \\
\text { información } \\
\text { bibliográfica }\end{array}$ & $\begin{array}{l}\text { Cirigliano, Gustavo F. J. } \\
\text { (1971). La conducta informativa en } \\
\text { universitarios argentinos: } \\
\text { investigación sobre la babilidad y } \\
\text { capacidad de los jóvenes graduados } \\
\text { universitarios para manejar y } \\
\text { utilizar las fuentes de información } \\
\text { bibliográfica. Buenos Aires: CIB, } \\
\text { FFyL, UBA. } \\
\text { Este trabajo } \\
\text { continuidad, pero quedó } \\
\text { inédito bajo el titulo } \\
\text { Investigación sobre la capacidad de } \\
\text { los estudiantes avanzados de las } \\
\text { universidades estatales argentinas } \\
\text { para la investigación bibliográfica, } \\
\text { conservado en la Biblioteca del } \\
\text { INIBI, FFyL, UBA (Romanos } \\
\text { de Tiratel, 2000). }\end{array}$ \\
\hline 1975 & $\begin{array}{l}\text { Ponencia de } \\
\text { Congreso }\end{array}$ & $\begin{array}{l}\text { Ángel } \\
\text { Fernández y } \\
\text { Ricardo } \\
\text { Gietz }\end{array}$ & $\begin{array}{l}\text { Análisis de } \\
\text { necesidades de } \\
\text { información y } \\
\text { satisfacción en el } \\
\text { campo de la } \\
\text { agricultura }\end{array}$ & $\begin{array}{l}\text { Fernández, Ángel y Ricardo } \\
\text { Gietz. (1975, abril 8-12). } \\
\text { Usuarios y servicios en } \\
\text { información agrícola. En } \\
\text { Cuarta Reunión Interamericana de } \\
\text { Bibliotecarios y Documentalistas } \\
\text { agrícolas, México, D.F. } \\
\text { Autores argentinos. }\end{array}$ \\
\hline 1977 & $\begin{array}{l}\text { Tesis de } \\
\text { Doctorado. }\end{array}$ & $\begin{array}{l}\text { Dominique } \\
\text { Babini }\end{array}$ & $\begin{array}{l}\text { Estudio de usuarios } \\
\text { del área de Ciencias } \\
\text { Políticas }\end{array}$ & $\begin{array}{l}\text { Babini, Dominique. (1982). } \\
\text { Política nacional de información. } \\
\text { (Tesis de Doctorado).Buenos } \\
\text { Aires: Universidad del Salvador. }\end{array}$ \\
\hline 1980 & $\begin{array}{l}\text { Ponencia de } \\
\text { Congreso }\end{array}$ & $\begin{array}{l}\text { Stella Maris } \\
\text { Fernández y }\end{array}$ & $\begin{array}{l}\text { Estudio sobre } \\
\text { usuarios de } \\
\text { información en } \\
\text { educación }\end{array}$ & $\begin{array}{l}\text { Fernández, Stella Maris y Josefa } \\
\text { Emilia Sabor.(1980, septiembre } \\
\text { 18-20). Formación de los } \\
\text { usuarios de la información }\end{array}$ \\
\hline
\end{tabular}




\begin{tabular}{|c|c|c|c|c|}
\hline & & Josefa Sabor & & $\begin{array}{l}\text { educativa. En } 2^{\circ} \text { Reunión del } \\
\text { Sistema Nacional de Información } \\
\text { Educativa, Tucumán, Argentina } \\
\text { También presentado en la } 23^{a} \\
\text { Reunión Nacional de } \\
\text { Bibliotecarios de 1987en Paraná } \\
\text { (Romanos de Tiratel, 2012) }\end{array}$ \\
\hline 1981 & $\begin{array}{l}\text { Documento } \\
\text { de trabajo }\end{array}$ & $\begin{array}{l}\text { Centro de } \\
\text { Información } \\
\text { Hídrica }\end{array}$ & $\begin{array}{l}\text { Estudio de usuarios } \\
\text { potenciales de } \\
\text { información sobre } \\
\text { recursos hídricos en } \\
\text { Argentina }\end{array}$ & $\begin{array}{l}\text { INCYTH (Instituto Nacional } \\
\text { de Ciencia y Técnica Hídricas) } \\
\text { (1981). Estudio de usuarios de } \\
\text { información sobre recursos } \\
\text { hídricos: prueba piloto. Ezeiza, } \\
\text { Buenos Aires: INCYTH. }\end{array}$ \\
\hline 1987 & $\begin{array}{l}\text { Acta de } \\
\text { Congreso }\end{array}$ & ABGRA & $\begin{array}{l}\text { Diferentes estudios } \\
\text { sobre Usuarios de la } \\
\text { Información }\end{array}$ & $\begin{array}{l}\text { ABGRA. (1986). El } \\
\text { bibliotecario y los usuarios de la } \\
\text { información. En XXIII } \\
\text { Reunión Nacional de } \\
\text { Bibliotecarios. Paraná: ABGRA } \\
\text { Contiene los siguientes trabajos: } \\
\text { Gietz, Ricardo. El servicio de } \\
\text { información frente a la } \\
\text { necesidad del usuario / Del } \\
\text { Caño, Eduardo Bibliotecas } \\
\text { hospitalarias municipales: un } \\
\text { proyecto diseñado para las } \\
\text { actuales circunstancias, en } \\
\text { función y con la participación } \\
\text { de los usuarios / Barbieri, } \\
\text { Oscar; Martínez, Ana María; } \\
\text { Tardito, Marta C; Astigarraga, } \\
\text { María F La cooperación, el } \\
\text { bibliotecario y el usuario: una } \\
\text { experiencia entre bibliotecas de } \\
\text { salud de la ciudad de La Plata / } \\
\text { Tuya, Osvaldo Los usuarios de } \\
\text { la información en bibliotecas } \\
\text { agrícolas regionales / Mansilla } \\
\text { de Riveros, María A Usuarios: } \\
\text { adiestramiento sistemático en } \\
\text { todos los niveles de enseñanza } \\
\text { / Hasenkamp de Glucklich, } \\
\text { Beatriz; Zapata, Angélica Hacia } \\
\text { un mejor conocimiento de la } \\
\text { conducta del usuario / Mariel } \\
\text { Erostarbe, Juan; Rivas, María } \\
\text { Aracelis; Cirelli Marcó, } \\
\text { Mercedes Formación del } \\
\text { usuario potencial, inclusión de }\end{array}$ \\
\hline
\end{tabular}




\begin{tabular}{|c|c|c|c|c|}
\hline & & & & $\begin{array}{l}\text { la bibliotecología en la currícula } \\
\text { primaria (una experiencia de la } \\
\text { Universidad Católica de Cuyo) } \\
\text { / Hammerly, Hernán D. El } \\
\text { equipo bibliotecario-docente en } \\
\text { la formación del usuario- } \\
\text { educando / Zabala, Horacio } \\
\text { Víctor Enseñanza de usuarios: } \\
\text { una experiencia universitaria / } \\
\text { Pasarelli, Víctor Andrés; } \\
\text { Almeida, Adolfo Gregorio Los } \\
\text { usuarios de la información ante } \\
\text { el desborde informático. } \\
\text { Discusiones sobre los avances } \\
\text { de la información cibernética. } \\
\text { Cap.1 Cuestiones acerca de la } \\
\text { actitud frente a los sistemas de } \\
\text { información.-Cap.2 Cuestiones } \\
\text { acerca de los usuarios de la } \\
\text { información / Arnau de } \\
\text { Carranza, Laura Estela Los } \\
\text { usuarios de la información, un } \\
\text { reto permanente para el } \\
\text { bibliotecario }\end{array}$ \\
\hline 1992 & $\begin{array}{c}\text { Tesis de } \\
\text { Doctorado. }\end{array}$ & Susana Soto & $\begin{array}{l}\text { Conducta informativa } \\
\text { en odontólogos }\end{array}$ & 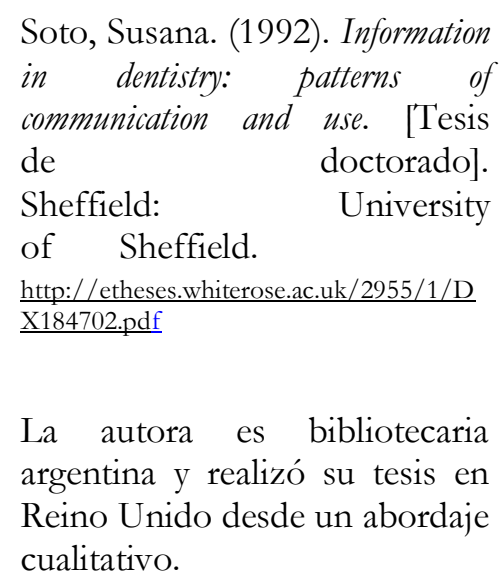 \\
\hline 1995 & $\begin{array}{c}\text { Grupo de } \\
\text { Investigación } \\
\text { dirigido por } \\
\text { Profa. Susana } \\
\text { Romanos de } \\
\text { Tiratel }\end{array}$ & $\begin{array}{l}\text { Universidad } \\
\text { de Buenos } \\
\text { Aires. } \\
\text { Facultad de } \\
\text { Filosofía y } \\
\text { Letras. } \\
\text { Departamen } \\
\text { to de } \\
\text { Bibliotecolo }\end{array}$ & $\begin{array}{l}\text { Áreas de interés: } \\
\text { necesidades, } \\
\text { búsqueda, acceso y } \\
\text { uso de la información } \\
\text { en profesionales e } \\
\text { investigadores. }\end{array}$ & $\begin{array}{l}\text { El grupo elaboró y ejecutó el } \\
\text { proyecto Procesos de búsqueda de } \\
\text { información y modalidades e } \\
\text { instancias de intervención, además } \\
\text { de los siguientes trabajos: } \\
\text { Romanos de Tiratel, Susana. } \\
\text { (1995). Modos de acceso y } \\
\text { utilización de la bibliografía en } \\
\text { los procesos de producción de } \\
\text { información. En } 29^{\circ} \text { Reunión } \\
\text { Nacional de Bibliotecarios. Buenos } \\
\text { Aires: ABGRA. } \\
\text { Romanos de Tiratel, Susana. }\end{array}$ \\
\hline
\end{tabular}




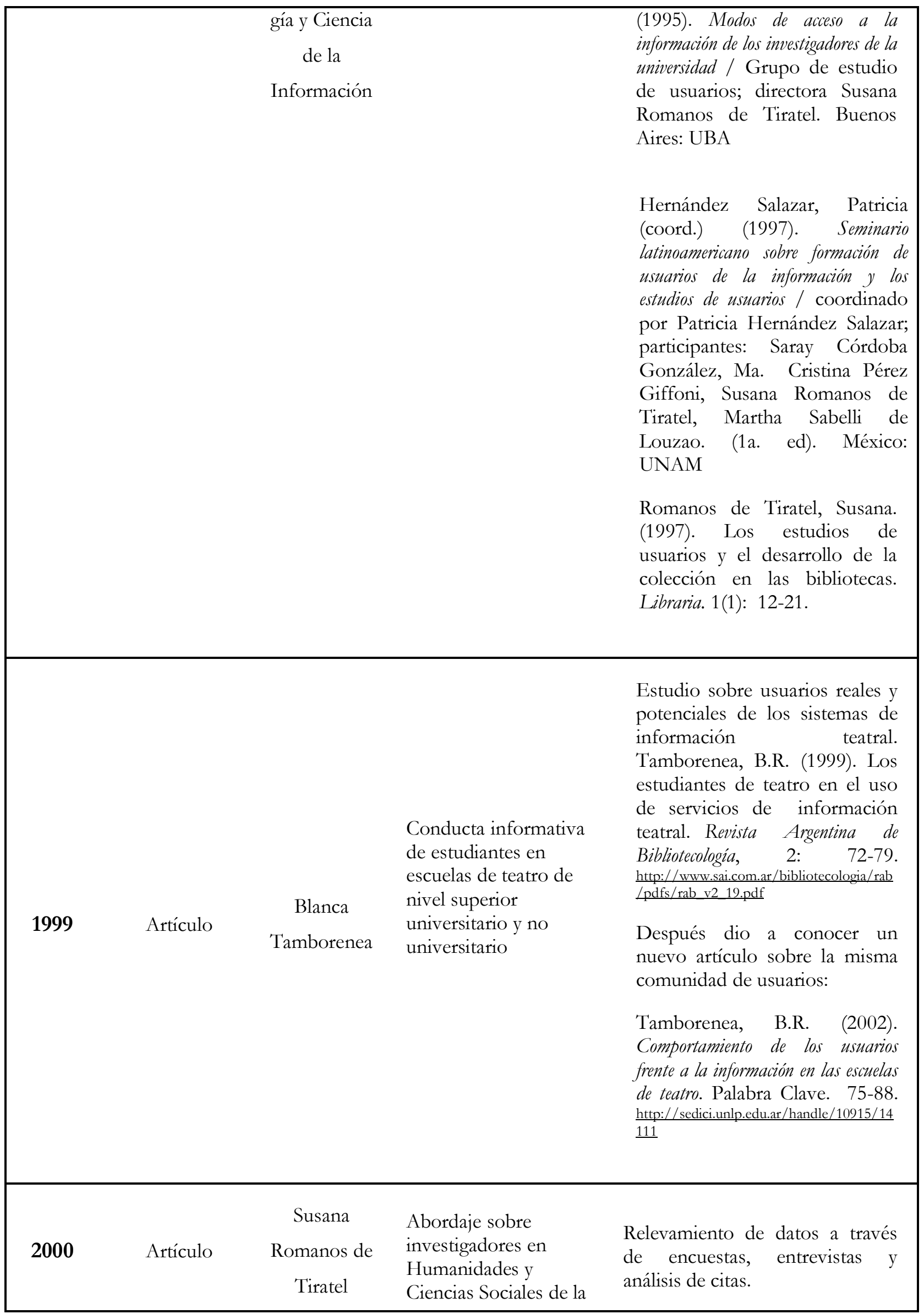




\begin{tabular}{|c|c|c|c|c|}
\hline & & & FFyL, UBA & $\begin{array}{l}\text { Romanos de Tiratel, Susana. } \\
(2000) \text {. Accessing information } \\
\text { use by humanists and social } \\
\text { scientists: a study at the } \\
\text { Universidad de Buenos Aires, } \\
\text { Argentina. Journal of Academic } \\
\text { Librarianship. 26(5): 346-354. } \\
\text { Romanos de Tiratel, Susana. } \\
\text { (2000). Conducta informativa de } \\
\text { los investigadores argentinos en } \\
\text { Humanidades y Ciencias Sociales. } \\
\text { Revista Española de Documentación } \\
\text { Cientifica. 23( 3): 268-286. } \\
\text { redc.revistas.csic.es/index.php/redc/article/d } \\
\text { ownload/324/495 }\end{array}$ \\
\hline 2001 & Artículo & $\begin{array}{l}\text { Nancy } \\
\text { Gómez }\end{array}$ & $\begin{array}{l}\text { Estudio sobre tesistas } \\
\text { de Física }\end{array}$ & $\begin{array}{l}\text { Gómez, Nancy Diana. (2001). La } \\
\text { conducta informativa de los } \\
\text { físicos: un estudio cualitativo de } \\
\text { usuarios. Información, Cultura y } \\
\text { Sociedad, } \quad \text { (4): } 23-36 . \\
\text { http://revistascientificas.filo.uba.ar/index.ph } \\
\text { p/ICS/article/view/1010 } \\
\text { Uso de la entrevista }\end{array}$ \\
\hline 2002 & $\begin{array}{c}\text { Grupo de } \\
\text { Investigación }\end{array}$ & $\begin{array}{l}\text { Departament } \\
\text { o de } \\
\text { Bibliotecologí } \\
\text { a de la } \\
\text { Facultad de } \\
\text { Humanidades } \\
\text { y Ciencias de } \\
\text { la Educación } \\
\text { de la } \\
\text { Universidad } \\
\text { Nacional de } \\
\text { La Plata }\end{array}$ & $\begin{array}{l}\text { Procedimientos de } \\
\text { búsqueda realizados } \\
\text { por investigadores } \\
\text { de la UNLP, con } \\
\text { abordaje cuantitativo } \\
\text { y uso de la } \\
\text { entrevista. }\end{array}$ & $\begin{array}{l}\text { Albornoz, Silvia y otros (2002). } \\
\text { Procedimiento de los } \\
\text { investigadores de la Universidad } \\
\text { Nacional de La Plata en la } \\
\text { búsqueda de información. } \\
\text { Información, Cultura y Sociedad. 7: } \\
\text { 110-116. } \\
\text { http://revistascientificas.filo.uba.ar/index.ph } \\
\text { p/ICS/article/view/970 } \\
\text { Albornoz, Silvia y otros (2007). } \\
\text { Búsqueda de la información y } \\
\text { uso de la Biblioteca por parte de } \\
\text { los investigadores de de } \\
\text { humanidades: un estudio de caso } \\
\text { en la Universidad Nacional de la } \\
\text { Plata. Revista Interamericana de. } \\
\text { Bibliotcología 30( 1): 73-92. } \\
\text { www.scielo.org.co/pdf/rib/v30n1/v30n1a04. } \\
\text { pdf }\end{array}$ \\
\hline 2003 & Artículo & $\begin{array}{c}\text { Irene } \\
\text { Münster }\end{array}$ & $\begin{array}{l}\text { Necesidades y } \\
\text { búsqueda de } \\
\text { información y } \\
\text { características/hábit }\end{array}$ & $\begin{array}{l}\text { Comparación con las necesidades } \\
\text { de profesores anglosajones, de } \\
\text { carácter descriptivo- cuantitativo; }\end{array}$ \\
\hline
\end{tabular}




\begin{tabular}{|c|c|c|c|c|}
\hline & & & $\begin{array}{l}\text { os de investigadores } \\
\text { en Humanidades y } \\
\text { Ciencias Sociales de } \\
\text { la Universidad de } \\
\text { San Andrés }\end{array}$ & 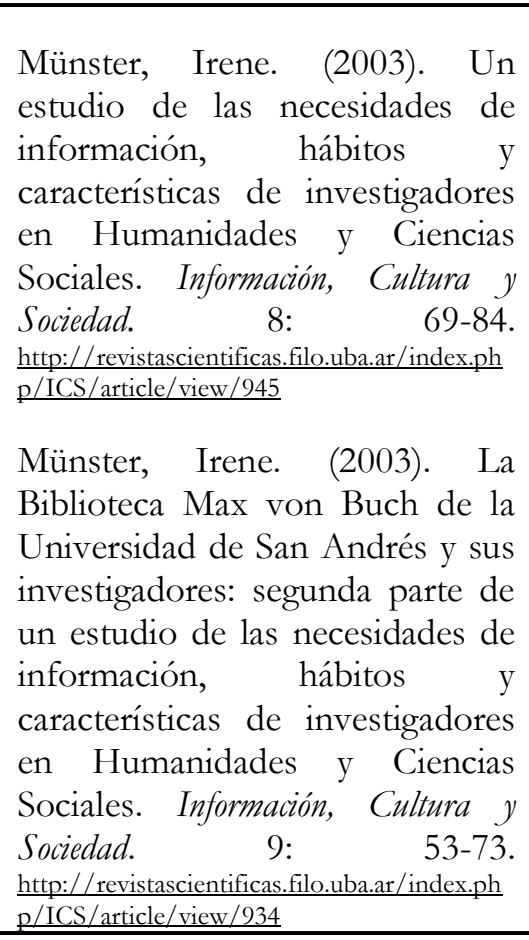 \\
\hline 2005 & $\begin{array}{c}\text { Ponencia de } \\
\text { Congreso }\end{array}$ & $\begin{array}{c}\text { Susana } \\
\text { Romanos de } \\
\text { Tiratel }\end{array}$ & $\begin{array}{l}\text { Búsqueda de } \\
\text { información en } \\
\text { relación con el } \\
\text { género. }\end{array}$ & $\begin{array}{l}\text { Primer estudio argentino sobre la } \\
\text { relación de género y búsqueda de } \\
\text { información, realizada durante las } \\
\text { 12as. Jornadas de Historia del } \\
\text { Pensamiento Científico } \\
\text { Argentino. Primer estudio sobre } \\
\text { NI y el tema de género en } \\
\text { Argentina. } \\
\text { Romanos de Tiratel, Susana. } \\
\text { (2005). La búsqueda de informacióny } \\
\text { el género. 12 En Jornadas de } \\
\text { Historia del Pensamiento } \\
\text { Científico Argentino. Actas. } \\
\text { Buenos Aires: FEPAI. }\end{array}$ \\
\hline 2009 & Artículo & $\begin{array}{c}\text { Belarmina } \\
\text { Benítez y } \\
\text { María } \\
\text { Dolores } \\
\text { Olvera Lobo } \\
\text { (2009) }\end{array}$ & $\begin{array}{l}\text { Conducta de } \\
\text { búsqueda de } \\
\text { información en la } \\
\text { Web, en docentes, } \\
\text { investigadores y } \\
\text { estudiantes de la } \\
\text { Facultad de } \\
\text { Humanidades y } \\
\text { Ciencias Sociales de } \\
\text { la Universidad } \\
\text { Nacional de } \\
\text { Misiones. }\end{array}$ & $\begin{array}{l}\text { Trabajo con aspectos cualitativos } \\
\text { y análisis estadísticos, usando } \\
\text { para la recolección de datos, } \\
\text { cuestionarios, entrevistas y el } \\
\text { análisis de búsquedas a través de } \\
\text { registros. } \\
\text { Olvera-Lobo, María- } \\
\text { Dolores;Benítez-de-Vendrell, } \\
\text { Belarmina. (2008). Aproximación } \\
\text { a las actitudes y percepciones } \\
\text { de los usuarios ante las } \\
\text { tecnologías de la información. El } \\
\text { profesional de la información 17(2): } \\
199-204 \text { halpi//www.elprofesionaldelainformacion.co } \\
\underline{\text { ht/contenidos/2008/marzo/10.pdf }}\end{array}$ \\
\hline
\end{tabular}




\begin{tabular}{|c|c|c|c|c|}
\hline & $\begin{array}{l}\text { Articulo de } \\
\text { revisión }\end{array}$ & $\begin{array}{c}\text { Susana } \\
\text { Romanos de } \\
\text { Tiratel }\end{array}$ & $\begin{array}{l}\text { Revisión } \\
\text { bibliográfica acerca } \\
\text { de las emociones } \\
\text { asociadas con los } \\
\text { procesos de } \\
\text { búsqueda y } \\
\text { utilización de la } \\
\text { información. }\end{array}$ & $\begin{array}{l}\text { Romanos de Tiratel, Susana. } \\
\text { (2010). Las emociones asociadas } \\
\text { con la conducta informativa. } \\
\text { Páginas de guarda. No. } 10 .\end{array}$ \\
\hline 2010 & Proyecto & $\begin{array}{l}\text { Alejandra } \\
\text { Nardi }\end{array}$ & $\begin{array}{l}\text { Comprensión y a la } \\
\text { utilización de las } \\
\text { TIC por parte de los } \\
\text { ingresantes a la } \\
\text { Facultad de Ciencias } \\
\text { Económicas de la } \\
\text { UNC. }\end{array}$ & $\begin{array}{l}\text { Trabajo cuantitativo con uso de } \\
\text { encuestas. } \\
\text { Nardi, Alejandra Marcela [et al.]. } \\
\text { (2010). Nivel de comprensión y } \\
\text { utilización de las Tecnologías de } \\
\text { la Información y la } \\
\text { Comunicación por parte de los } \\
\text { estudiantes que ingresan a la } \\
\text { Facultad de Ciencias } \\
\text { Económicas, UNC. Córdoba: } \\
\text { UNC } \\
\text { Untp://eprints.rclis.org/17793/7/Provecto\% } \\
\text { 20competencias\%20TiC\%20Nardi\%20et\%2 } \\
\text { lal.pdf } \\
\text { Nardi, Alejandra Marcela [et al.]. } \\
\text { (2012). Informe de Avance, junio } \\
\text { 2012. Nivel de comprensión y } \\
\text { utilización de las Tecnologías de } \\
\text { la Información y la } \\
\text { Comunicación por parte de los } \\
\text { estudiantes que ingresan a la } \\
\text { Facultad de Ciencias } \\
\text { Económicas, UNC. Córdoba: } \\
\text { UNC http://eprints.rclis.org/17864/ }\end{array}$ \\
\hline 2011 & $\begin{array}{l}\text { Ponencia de } \\
\text { Congreso }\end{array}$ & $\begin{array}{c}\text { Ezequiel } \\
\text { Fernández y } \\
\text { Julio Díaz } \\
\text { Jatuf }\end{array}$ & $\begin{array}{l}\text { Proyecto dentro de } \\
\text { la Facultad de } \\
\text { Odontología, con un } \\
\text { enfoque cuantitativo } \\
\text { descriptivo. }\end{array}$ & $\begin{array}{l}\text { Fernández, Ezequiel y Díaz Jatuf, } \\
\text { Julio. (2011). Proyecto de estudio } \\
\text { de necesidades de información } \\
\text { en la Hemeroteca de la Biblioteca } \\
\text { "Prof. Dr. José Arce" de la } \\
\text { Facultad de Odontología - } \\
\text { Universidad de Buenos Aires. En } \\
\text { Jornadas Virtuales Iberoamericanas de } \\
\text { Ciencias de la Información y la } \\
\text { Documentación (Buenos Aires; 1as.; } \\
\text { oct. } \\
\text { http://eprints.rclis.org/16243/ }\end{array}$ \\
\hline 2012 & $\begin{array}{l}\text { Póster } \\
\text { Científico }\end{array}$ & $\begin{array}{l}\text { Díaz-Jatuf, } \\
\text { Julio y }\end{array}$ & $\begin{array}{l}\text { Investigación sobre } \\
\text { NI en estudiantes } \\
\text { del curso de }\end{array}$ & $\begin{array}{l}\text { Díaz Jatuf, Julio y Ezequiel } \\
\text { Fernández. (2012, agosto). } \\
\text { Aproximación a las necesidades }\end{array}$ \\
\hline
\end{tabular}




\begin{tabular}{|c|c|c|c|c|}
\hline & & $\begin{array}{l}\text { Fernández, } \\
\text { Ezequiel }\end{array}$ & $\begin{array}{l}\text { asistentes dentales } \\
\text { en año } 2011\end{array}$ & 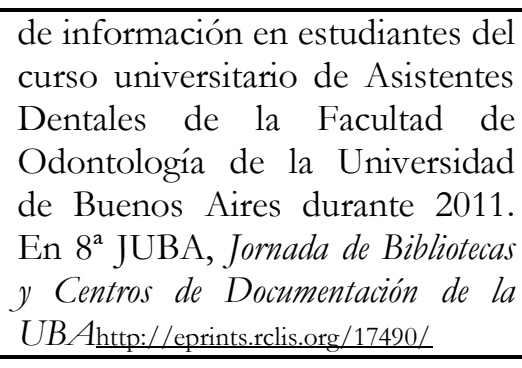 \\
\hline & & $\begin{array}{l}\text { UNCORDO } \\
\text { BA } \\
\text { Grupo de } \\
\text { Investigación } \\
\text { sobre } \\
\text { Usuarios de la } \\
\text { Información }\end{array}$ & $\begin{array}{l}\text { Estudio cuantitativo } \\
\text { sobre los docentes } \\
\text { investigadores de la } \\
\text { Facultad de Filosofía } \\
\text { y Humanidades, } \\
\text { UNC, Argentina }\end{array}$ & $\begin{array}{l}\text { Ladrón de Guevara, María del } \\
\text { Carmen y otros (2012). Los } \\
\text { docentes investigadores de la } \\
\text { Facultad de Filosofía y } \\
\text { Humanidades de la Universidad } \\
\text { Nacional de Córdoba como } \\
\text { usuarios remotos de bibliotecas } \\
\text { universitarias. Información, Cultura } \\
\text { y Sociedad, 26: 65- } \\
81 \text {.http://revistascientificas.filo.uba.ar/index } \\
\text { php/ICS/article/view/717. }\end{array}$ \\
\hline 2013 & $\begin{array}{l}\text { Póster } \\
\text { científico }\end{array}$ & $\begin{array}{l}\text { Díaz Jatuf, } \\
\text { Julio y } \\
\text { Ezequiel } \\
\text { Fernández }\end{array}$ & $\begin{array}{l}\text { Investigación sobre } \\
\text { NI en estudiantes } \\
\text { del curso de } \\
\text { asistentes dentales } \\
\text { durante los años } \\
2011-2012 \text { con } \\
\text { encuesta cerrada de } \\
11 \text { preguntas. }\end{array}$ & $\begin{array}{l}\text { Estudio comparativo entre años } \\
\text { Díaz Jatuf, Julio y Ezequiel } \\
\text { Fernández. (2013, agosto). } \\
\text { Necesidades de información en } \\
\text { estudiantes del curso } \\
\text { universitario de Asistentes } \\
\text { Dentales de la Facultad de } \\
\text { Odontología de la Universidad } \\
\text { de Buenos Aires: abordaje } \\
\text { comparativo 2011-2012. En 9a } \\
\text { JUBA, Jornada de Bibliotecas y } \\
\text { Centros de Documentación de la } \\
\text { UBAhttp://eprints.rclis.org/19938/ }\end{array}$ \\
\hline \multirow[t]{2}{*}{2014} & $\begin{array}{l}\text { Póster } \\
\text { científico }\end{array}$ & $\begin{array}{l}\text { Díaz Jatuf, } \\
\text { Julio y } \\
\text { Andrea } \\
\text { Sergui }\end{array}$ & $\begin{array}{l}\text { Seguimientos de las } \\
\text { dos necesidades } \\
\text { anteriores, a través } \\
\text { de encuesta cerrada } \\
\text { de } 11 \text { preguntas. }\end{array}$ & $\begin{array}{l}\text { Díaz Jatuf, Julio y Andrea Sergui. } \\
\text { (2014, agosto). Seguimiento de } \\
\text { las necesidades de información } \\
\text { en estudiantes del curso } \\
\text { universitario de Asistentes } \\
\text { Dentales de la Facultad de } \\
\text { Odontología de la Universidad } \\
\text { de Buenos Aires durante 2011- } \\
\text { 2013. En 10a JUBA, Jornada de } \\
\text { Bibliotecas y Centros de } \\
\text { Documentación de de } \\
\text { UBAhttp://eprints.rclis.org/23698/ }\end{array}$ \\
\hline & $\begin{array}{l}\text { Relevamiento } \\
\text { informativo }\end{array}$ & $\begin{array}{l}\text { Díaz Jatuf, } \\
\text { Julio }\end{array}$ & $\begin{array}{l}\text { Uso del cuestionario } \\
\text { para el relevamiento } \\
\text { básico sobre NI en }\end{array}$ & $\begin{array}{l}\text { Primer intento de relevamiento } \\
\text { informativo en y para la } \\
\text { comunidad GLTTIBQ en }\end{array}$ \\
\hline
\end{tabular}




\begin{tabular}{|c|c|c|c|c|}
\hline & & & $\begin{array}{l}\text { usuarios, } \\
\text { bibliotecarios, } \\
\text { estudiantes e } \\
\text { investigadores }\end{array}$ & 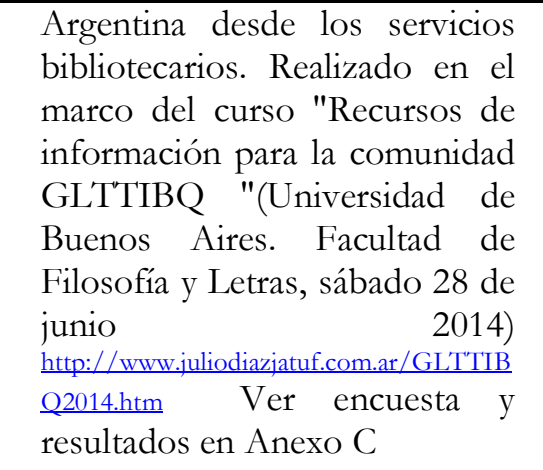 \\
\hline & $\begin{array}{c}\text { Póster } \\
\text { científico }\end{array}$ & $\begin{array}{l}\text { Díaz Jatuf, } \\
\text { Julio y } \\
\text { Samanta } \\
\text { Panzer }\end{array}$ & $\begin{array}{l}\text { Uso del cuestionario } \\
\text { como herramienta } \\
\text { didáctica para las NI } \\
\text { en alumnos de } \\
\text { pregrado. }\end{array}$ & $\begin{array}{l}\text { Díaz-Jatuf, Julio y Panzer, } \\
\text { Samanta. (2014, agosto). Uso } \\
\text { didáctico del cuestionario para } \\
\text { detectar necesidades de } \\
\text { información en } \\
\text { alumnos/usuarios de pregrado } \\
\text { de la Biblioteca "Prof. Dr. José } \\
\text { Arce" de la Facultad de } \\
\text { Odontología de la Universidad } \\
\text { de Buenos Aires. En X Jornadas } \\
\text { de Material Didáctico y } \\
\text { Experiencias Innovadoras en } \\
\text { Educación Superior, Ciudad } \\
\text { Autónoma de Buenos Aires, } \\
\text { Argentina. } \\
\text { http://eprints.rclis.org/23596/1/Necesidades.p } \\
\text { df }\end{array}$ \\
\hline 2015 & $\begin{array}{c}\text { Tesis } \\
\text { Doctoral }\end{array}$ & $\begin{array}{l}\text { Pedro } \\
\text { Falcato }\end{array}$ & $\begin{array}{l}\text { Investigación sobre } \\
\text { los procesos de } \\
\text { búsqueda de } \\
\text { información que } \\
\text { realizan los } \\
\text { tecnólogos en } \\
\text { entornos digitales y } \\
\text { la interacción con su } \\
\text { contexto (sociedad, } \\
\text { sector industrial, } \\
\text { etcétera). }\end{array}$ & $\begin{array}{l}\text { Falcato, Pedro (2015). Procesos } \\
\text { de búsqueda de información en } \\
\text { entornos digitales: un estudio de } \\
\text { usuarios del área tecnológica } \\
\text { industrial argentina. (Tesis de } \\
\text { Doctorado), FFyL, UBA. } \\
\text { http://eprints.rclis.org/30110/ }\end{array}$ \\
\hline
\end{tabular}

\subsection{Necesidades de Información en la Comunidad GLTTIBQ}

La investigación sobre las NI es de antigua data, pero recientemente se centra más en los estudios de comunidades que de usuarios individuales. Junto a los estudios de NI, 
surgieron en la década del 70, los Estudios Culturales que también centraban sus investigaciones en grupos específicos.

Con relación a la comunidad GLTTIBQ y las bibliotecas, se dio un gran inicio con el libro de Berman (1981), The Joy of Cataloging: Essays, Letters and Other Explosions, en el que se destacan las dificultades para el acceso a la información por parte de la comunidad. Luego, el libro de Greenblatt, Gay and Lesbian Library Service (1990), proporcionó la primera colección de ensayos sobre cuestiones de información para la comunidad GLTTIBQ al abordar diferentes temas (censura, desarrollo de la colección, etcétera.).

Ha habido un aumento constante en la investigación sobre NI en las últimas décadas. Sin embargo, gran parte no se ha focalizado en comunidades vulnerables específicas. Por ello este trabajo no solo tiene el compromiso de investigar un tema de escaso estudio, sino que esa carencia se convierta en referente, para especializar más el estudio. Una posible solución a esto es lo planteado por Cabañas (2014):

Si bien la labor de las bibliotecas y la acción de los bibliotecarios ha sido un rol pasivo en el mejor de los casos, es deseable que las comunidades de las llamadas sexualidades disidentes puedan colaborar ejerciendo sus derechos, a través de los espacios que ofrecen las bibliotecas. Aunque las bibliotecas no poseen el alcance que tienen los medios electrónicos de comunicación, son indudablemente uno de los espacios más valiosos donde se pueda fomentar una imagen positiva de la comunidad lésbico-gay, entendiéndola como aquélla que combate el determinismo y el esencialismo que proclama el sector conservador.

La revisión de los antecedentes de las NI a nivel local e internacional permite generar un marco teórico para los objetivos de esta tesis, constituyendo un continente para la metodología y los resultados esperados. 


\section{METODOLOGÍA}

\subsection{Introducción}

De acuerdo con el problema que se plantea en el presente estudio, los objetivos que de él se derivan y de las bases teóricas acerca del mismo, el siguiente diseño de investigación es del tipo documental, con un abordaje cuali-cuantitativo, acorde a Hernández-Sampieri y otros (2010), el enfoque cualitativo busca principalmente 'dispersión o expansión' de los datos e información, mientras que el enfoque cuantitativo pretende intencionalmente 'acotar' la información (medir con precisión las variables del estudio, tener 'foco') (p. 10). La fase cuantitativa se desplegó durante la recolección, evaluación, análisis y síntesis de los datos, con la cual se elaboró la Matriz para la compilación de datos y también se recurrió a técnicas bibliométricas: gráficos y mapas, usando el Excel y el Image Chef. El enfoque cualitativo se manifestó durante el análisis e interpretación de los contenidos del material relevado con la finalidad de construir un corpus estructurado en los resultados.

Dicha investigación posee un alcance:

Exploratorio: se realiza cuando el objetivo es examinar un tema o problema de investigación poco estudiado, del cual se tienen muchas dudas o no se ha abordado antes. (p.79)

Descriptivo: buscan especificar las propiedades, las características y los perfiles de personas, grupos, comunidades, procesos, objetos o cualquier otro fenómeno que se someta a un análisis. (p.79) y

Explicativo: se enfoca en explicar por qué ocurre un fenómeno y en qué condiciones se manifiesta. (p. 85).

Posee un método de investigación documental analítico-sintético. Dicho método ofrece los siguientes beneficios:

- Permite obtener una visión muy amplia de los conocimientos sobre el tema abordado. 
- Genera en el investigador una apreciación objetiva sobre el fenómeno, ofreciendo en la actualidad, una variedad de recursos en diferentes formatos.

- Ofrece al investigador la información pura tomada de una fuente que describe fenómenos, que en ocasiones el acceso hacia ellos es difícil, imposible o poco tratado.

- Permite al investigador crear un juicio particular sobre el fenómeno, comparando la información obtenida con las experiencias y conocimientos propios.

El análisis del contenido documental no es otra cosa que una modalidad especial de la aplicación del método cientifico en las ciencias sociales. (Sierra Bravo, 1988: 288) y permite a través del relevamiento bibliográfico, una forma de investigación técnica, un conjunto de operaciones intelectuales que buscan describir y representar los documentos de forma unificada sistemática para facilitar su recuperación. Dicho análisis, comprende el procesamiento analítico-sintético que, a su vez, incluye la descripción bibliográfica y general de la fuente, la clasificación, indización, anotación, extracción, traducción y la confección de reseñas.

Posee un enfoque de análisis comparativo sistemático de pocos casos, acorde a lo establecido por Barton y Lazarsfeld (1961), en el cual establece este tipo de investigación y análisis cuando es la única posibilidad cuando los 'casos' a estudiar son fenómenos sociales de una gran complejidad...(p. 270) además de tratarse generalmente de pocos casos disponibles de por sí.(Valles, 2007: 364). Entonces el investigador decide centrarse en algunos de ellos, en este trabajo: los relevados.

\subsection{Diseño de investigación}

El diseño de la investigación, para Hernández-Sampieri y otros (2010) refiere al plan o estrategia concebida para obtener la información que se desea. (p. 120). Constará de los siguientes pasos:

1. Búsqueda en base de datos especializada

2. Captura de los registros bibliográfico y tratamiento estadístico. 
3. Obtención de los documentos

4. Lectura y análisis de material recopilado, estudiando las referencias, notas a pie y bibliografía de los artículos identificados, a través de la variable: tema (primeros estudios/temas realizados y secuenciación cronológica de los estudios).

5. Confección del instrumento de análisis

6. Interpretación de los resultados y conclusiones

\subsection{Técnicas e instrumentos de recolección de la información}

Organizar una revisión bibliográfica sobre el tema a estudiar es una tarea compleja por su pluralidad, diversidad teórica y práctica. Los métodos que se han usado para compilar este estudio y realizar su revisión han sido los siguientes:

1. Búsquedas en la base de datos LISA (Library Information Science Abstracts, a diciembre 2015) usando la siguiente sintaxis de búsqueda a partir de los términos autorizados por el tesauro que contiene: "INFORMATION NEEDS" AND "GAY PEOPLE" AND "LIBRARIES". Recuperación: 11 registros (1 duplicado: Hart y Mfazo, 2010). El período cubierto de literatura obtenida es de 1989 a 2011.

El resultado que se obtuvo fue un número de registros accesibles para ser revisado. Sin embargo, también se han revisado algunos trabajos en lengua inglesa, a partir de las referencias bibliográficas de los artículos localizados y se buscó en portugués y español, con el objeto de corroborar información. Se procedió a la localización del material recuperado: seis referencias bibliográficas tenían acceso al texto completo a través de la base y los otros cuatro se obtuvieron por donación.

Al proceso sistemático de búsqueda y tratamiento de la información generada a partir de ella, se presentó siguiendo el estilo APA, 6th ed. Lectura y análisis del material recopilado, incluyendo el examen de las referencias, de las notas al pie de página y de las bibliografías en todos los artículos identificados para su inclusión en la revisión y en la correcta descripción bibliográfica. 


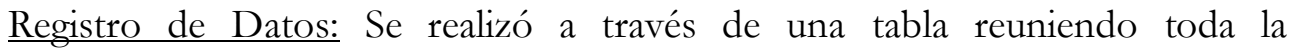
información a manera de resumen, recolectando las referencias bibliográficas ordenadas por año. (Anexo A).

Carpeta de archivos electrónicos: su utilización comprendió la acumulación de los registros localizados a través de las bases de datos o donación.

\section{Elaboración de la Matriz comparativa}

Esta técnica de la investigación documental alude a la forma de obtener y registrar datos e información mediante la elaboración de una matriz que permite recoger el producto de la indagación de la fuente investigada. Es importante su utilización para el contraste o comparación de teorías, enfoques, postulados de autores sobre temáticas especificas; registros estadísticos de indicadores económicos, sociales, educativos, estableciendo ventajas, desventajas, modelos, etcétera, sobre los cuales se generaría el análisis e interpretación de acuerdo a los propósitos de la investigación respectiva. Este instrumento proporciona los criterios necesarios para reagrupar las características de un documento en la unidad de estudio.

Para este caso se utilizó una matriz para contrastar documentos de acuerdo con siguientes variables: tipología de comunidad, métodos de investigación usados, lugar geográfico del estudio, principales NI detectadas y otros datos relevantes. (Anexo B).

3. Tratamiento estadístico de las referencias bibliográficas de los documentos recuperados.

Para ello se procedió a:

- Recuperar las referencias bibliográficas por autor.

- Compilar la cobertura temporal de la literatura referenciada y su cantidad.

- Graficación de los mismos con Excel y Image Chef para la nube de palabras. Esta representación visual permite entre otras opciones, ilustrar una presentación, web o post de un blog con un elemento 
gráfico tipográfico atractivo, identificar los términos más repetidos en un texto, discurso, noticia y cualquier otro tipo de documento, y conocer los conceptos que se han querido enfatizar; analizar la densidad de palabras clave de una página web o blog y comparar el contenido más relevante de dos o más documentos.

\subsection{Unidad de análisis}

Es el elemento mínimo de estudio observable o medible en relación con un conjunto de otros elementos que son de su mismo tipo y e encuentran constituidos por los sujetos $\mathrm{u}$ objetos de estudio y se relacionan con el planteamiento inicial de la investigación. Se debe identificar primero las unidades de análisis para la selección de la muestra.

En esta tesis la Unidad de análisis se encuentra conformada por las referencias bibliográficas existentes en la base LISA que fueron recuperadas, constituyendo dos tipos de corpus documental:

1. Para el análisis cualitativo desde la literatura citante, constituyendo el insumo intelectual principal de este trabajo, $y$

2. Para el análisis cuantitativo, desde la literatura citada en los documentos anteriores.

3.5. Diseño del estudio y análisis

Las ventajas del relevamiento bibliográfico para todo proceso de investigación es representar sistemática y sintéticamente los materiales originales, facilitando así su recuperación y consulta, además de mostrar la existencia fidedigna del documento primario utilizado y, a partir de allí, facilitar su obtención e incorporación al proceso posterior de análisis de la información. Este tipo de estudio será el comienzo para establecer las preguntas orientativas de investigación. 
En la dimensión de la investigación documental, se emplea una diversidad de técnicas e instrumentos de recolección de la información que contienen principios sistemáticos y normas de carácter práctico muy rigurosas e indispensables para ser aplicados a los materiales bibliográficos que se consultarán a través de todo el proceso de investigación, así como en la organización del trabajo escrito que se producirá al final del mismo.

Para el análisis profundo de las fuentes documentales, se utilizaron técnicas de: observación documental, presentación resumida, resumen analítico y análisis crítico. A partir de la observación documental, como punto de partida en el análisis de las fuentes, mediante una lectura general de los textos, se inició la búsqueda y observación de los hechos presentes en los materiales escritos consultados que son de interés para esta investigación. Esta lectura inicial fue continuada por numerosas lecturas rigurosas de los textos, a fin de captar sus planteamientos esenciales y aspectos lógicos de sus contenidos y propuestas, a propósito de extraer los datos bibliográficos útiles y de contenido, para el estudio que se está realizando. La aplicación de la técnica de presentación resumida de un texto permitió dar cuenta de manera fiel y, en síntesis, acerca de las ideas básicas que contienen las obras consultadas. Importa destacar que esta técnica asume un papel importante en la construcción de los contenidos teóricos de la investigación; así como en lo relativo a los resultados de otras investigaciones que se han realizado en relación al tema y sus antecedentes.

La técnica de resumen analítico se incorporó para descubrir la estructura de los textos consultados y delimitar sus contenidos básicos en función de los datos que se precisan conocer. Esta técnica contiene a los dos procedimientos anteriores e introduce su evaluación interna centrada en el desarrollo lógico y la solidez de las ideas seguidas por los autores de la literatura.

Algunas de las técnicas operacionales para el manejo de las referencias bibliográficas que se emplean, a fin de introducir los procedimientos y protocolos instrumentales de la investigación documental en el manejo de los datos ubicados en éstas, son de subrayado, registro bibliográfico, de citas y notas de referencias bibliográficas y de ampliación de texto, construcción y presentación de índices, 
presentación de cuadros, gráficos e ilustraciones, presentación del trabajo escrito, y otras.

3.6. Análisis e interpretación de resultados

El análisis e interpretación de datos tuvo en consideración la mirada integral desde la perspectiva cuali-cuantitativa de toda la información procesada.

3.7. Ventajas del abordaje

La investigación cuantitativa permitió medir y analizar datos existentes, favoreciendo la objetividad en relación con los hallazgos plasmados en la tesis. En relación con lo cualitativo, permitió que el estudio se desarrolle en un ambiente más natural al tomar información de otras fuentes, como el de las fotografías, observando el contexto y sentido social donde se desarrolla la temática dentro de las Ciencias Sociales.

\subsection{Consideraciones éticas}

Es importante hacer mención a las consideraciones que se tuvieron en cuenta en este estudio, con el objeto de cuidar y brindar las mayores garantías en el tratamiento ético dentro de la selección, análisis de la literatura de investigación y resultados.

Se abordaron principios como equidad, integralidad, beneficencia, justicia, inclusión, beneficio y respeto por todas las comunidades tratadas como se sugiere en normativas internacionales con relación a los estudios científicos. 


\section{ANÁLISIS DE DATOS Y RESULTADOS}

\subsection{Introducción}

El objetivo del análisis de datos abordado pretende:

- Darle estructura a los datos, lo cual implica organizar los documentos, categorías, temas y patrones.

- Describir las experiencias de la comunidad estudiada bajo su óptica, en su lenguaje y con sus expresiones.

- Comprender en profundidad el contexto que rodea los datos.

- Interpretar y evaluar unidades, categorías, temas y patrones.

- Explicar ambientes, situaciones, hechos, fenómenos (Hernández-Sampieri, 2010).

- Reconstruir historias.

- Encontrar sentido a los datos en el marco del planteamiento del problema (Hernández-Sampieri, 2010).

- Relacionar los resultados del análisis con la teoría fundamentada o construir teorías.

Las lecturas que se detallan a continuación fueron las recuperadas para el análisis documental acorde a su lectura según lo detallado en el aspecto metodológico. 


\section{Tabla 5}

Documentos recuperados por año

\begin{tabular}{|c|c|}
\hline año & Documento \\
\hline 1989 & $\begin{array}{l}\text { Creelman, J. E. y Harris, R. M. (1989). Coming out: the information needs } \\
\text { of lesbians. Collection Building, 10(3-4), 37-41. }\end{array}$ \\
\hline 1993 & $\begin{array}{l}\text { Whitt, A. J. (1993). The information needs of lesbians. Library \& } \\
\text { Information Science Research. } 5 \text { (3), 275-288. }\end{array}$ \\
\hline 1999 & $\begin{array}{l}\text { Norman, M. W. (1999). Out on loan: a survey of the use and information } \\
\text { needs of users of the lesbian, gay and bisexual collection of Brighton and } \\
\text { Hove Libraries. Journal of Librarianship \& Information Science, 31(4): 188-196. }\end{array}$ \\
\hline 2002 & $\begin{array}{l}\text { Taylor, Jami Kathleen. (2002). Targeting the information needs of } \\
\text { transgender individuals. Current Studies in Librarianship, 26(1/2): 85-109. }\end{array}$ \\
\hline 2005 & $\begin{array}{l}\text { Downey, Jennifer. (2005). Public library collection development issues } \\
\text { regarding the information needs of GLBT patrons. Progressive Librarian, 25: } \\
86-95 \text {. }\end{array}$ \\
\hline & $\begin{array}{l}\text { Simpson, Stacy H. (2006). Why have a comprehensive \& representative } \\
\text { collection? GLBT material selection and service in the public library. } \\
\text { Progressive Librarian, 27: 44-51. }\end{array}$ \\
\hline 2006 & $\begin{array}{l}\text { Mehra, B. y Braquet, D. (2006). A "Queer" manifesto of interventions for } \\
\text { libraries to "come out" of the closet! A study of "queer" youth } \\
\text { experiences during the Coming Out process. LIBRES: Library \& } \\
\text { Information Science Research Electronic Journal, 16(1): 1-29. }\end{array}$ \\
\hline 2007 & $\begin{array}{l}\text { Beiriger, Angie y Rose M. Jackson. (2007). An assessment of the } \\
\text { information needs of transgender communities in Portland, Oregon. Public } \\
\text { Library Quarterly, 26(1/2): 45-60. }\end{array}$ \\
\hline 2010 & $\begin{array}{l}\text { Hart, Genevieve y Ncumisa Mfazo. (2010). Places for all? Cape Town's } \\
\text { public library services to gays and lesbians. South African Journal of Libraries } \\
\text { \& Information Science, 76(2): 98-108. (aparece dos veces) }\end{array}$ \\
\hline 2011 & $\begin{array}{l}\text { Schaller, Susann. (2011). Information needs of LGBTQ college students. } \\
\text { Libri: International Journal of Libraries \& Information Services , 61(2): 100-115. }\end{array}$ \\
\hline
\end{tabular}


1. Creelman, J.E. y Harris, R.M. (1989). Coming out: the information needs of lesbians. Collection Building, 10(3-4), 37-41.

De acuerdo con Sasha Alyson, los bibliotecarios encargados del desarrollo de las colecciones tienen la responsabilidad de proveer libros que abordan las necesidades específicas de la población homosexual, estimada en un 10\%. Las bibliotecas, ofrecen privacidad a sus usuarios y albergan buenas colecciones, constituyéndose en un lugar deseable para gays y lesbianas, donde encuentran consuelo y esperanza.

2. Whitt, A.J. (1993). The information needs of lesbians. Library \& Information Science Research, (07408188), 15275-288.

Este estudio describe una encuesta de 141 lesbianas en el área metropolitana de Carolina del Norte. Evalúa el uso de la biblioteca y la satisfacción de su concurrencia así como las necesidades de información que existen dentro de los contextos de vida de estas mujeres. Los resultados indicaron que durante la etapa inicial de aceptación de identidad, cuando las mujeres no pueden tener acceso a la comunidad de lesbianas, la biblioteca se utiliza en gran medida como fuente de información. Durante las últimas etapas de la aceptación de identidad, las necesidades de información se vuelven más específicas y los recursos son consultados con más discriminación.

3. Norman, M.W. (1999). Out on loan: a survey of the use and information needs of users of the lesbian, gay and bisexual collection of Brighton and Hove Libraries. Journal of Librarianship \& Information Science, 31(4), 188196.

Informes sobre una encuesta por preguntas, de finales de 1997, a los usuarios de la LGB Collection, compartida entre la Brighton Central Library y la Hove Central Library en Gran Bretaña, determina quién utiliza la colección, las razones de su uso, qué recursos se utilizan, y los beneficios de tener una colección centralizada . Utilizando SPSS, los resultados confirman la importancia de la colección para la comunidad LGB, pero no la idea de que esas colecciones también son útiles para la comunidad en general. Se llega a la conclusión de que las colecciones separadas ayudan al acceso a la información y también que las preocupaciones sobre la "guetización" se representan como infundadas. Una colección centralizada aumenta el acceso y la disponibilidad y conduce a un mayor uso. La mayoría de los encuestados utiliza la colección LGB para uso recreativo (en particular la ficción). Se destaca un vacío en la literatura de investigación y se concluye que incluso los defensores de colecciones LGB han subestimado esta necesidad. 


\section{Taylor, J.K. (2002). Targeting the information needs of transgender}

individuals. Current Studies in Librarianship, 26(1/2), 85-109.

Este artículo explora las necesidades de información de la comunidad transgénero y cómo estas necesidades cambian con el tiempo. También se ocupa de las fuentes de información consultadas por estas personas. Los datos para este proyecto se recogieron a partir de un cuestionario distribuido a las personas trans en 2004. Los encuestados indicaron que internet y los libros fueron las fuentes de información más valiosas. Cuando se enfrentan inicialmente con su problema de identidad de género, la mayoría de las personas transgénero muestran un claro deseo de comprender su condición. Además, están muy interesados en las experiencias de otras personas transgénero. Sin embargo, para muchas personas, las necesidades de información transexual cambian con el tiempo. La aceptación y temas relacionados perdieron importancia. Algunas personas desarrollan un interés en la política pública relacionada a lo transgénero. Dentro de los subgrupos principales que componen la comunidad trans, se encontró que los travestis y transexuales, tienen diferentes necesidades de información.

5. Downey, J. (2005). Public library collection development issues regarding the information needs of GLBT patrons. Progressive Librarian, (25), 86-95.

El artículo se centra en los problemas de desarrollo de colecciones de bibliotecas públicas en relación con las necesidades de información de los usuarios transexuales (GLBT) gays, lesbianas, bisexuales. Hay muchos mitos y conceptos erróneos acerca de usuarios de la biblioteca GLBT. De hecho, uno de los mayores problemas en el servicio de biblioteca GLBT es la gran cantidad de prejuicios y la desinformación. Los bibliotecarios están a menudo mal informados o se manifiestan indiferentes con respecto a los problemas y necesidades de sus usuarios GLBT y esto a menudo se expresa en forma de explicaciones o excusas de por qué una biblioteca pública mantiene la insuficiencia de recursos de temática GLBT. Los bibliotecarios para niños a veces creen que los lectores adultos jóvenes no están interesados en cualquiera de los recursos temáticos-GLBT o están en riesgo de sufrir traumas o perjudicados por su contenido. Algunos bibliotecarios se sienten incómodos con temas GLBT y creen que evitar el tema por completo evitará controversia. Los esfuerzos de desarrollo de colecciones de temática GLBT deben ser proactivos. Los bibliotecarios tienen la obligación de desafiar los mitos y conceptos erróneos que prevalecen sobre los clientes GLBT y sus necesidades de información. 
6. Simpson, S.H. (2006). Why have a comprehensive \& representative collection? GLBT material selection and service in the public library. Progressive Librarian, (27), 44-51.

El artículo aborda la importancia de las bibliotecas y los recursos de que se dispone en ciertos segmentos de la población, tales como la comunidad GLBT. El autor afirma que las necesidades de información de toda la población deben ser atendidas con diligencia, independientemente de los obstáculos. Proporcionar una mejor recopilación de información, especialmente una colección representativa GLBT, puede ser de gran importancia para las personas y para los jóvenes. Los bibliotecarios de bibliotecas públicas necesitan tener un enfoque proactivo para proporcionar a los usuarios un servicio equitativo. Deben estudiar las colecciones públicas, recopilar información demográfica GLBT y evaluar las necesidades de la comunidad local.

7. Mehra, B. y Braquet, D. (2006). A “Queer" Manifesto of interventions for libraries to "Come Out" of the Closet! A study of "Queer" youth experiences during the coming out process. LIBRES: Library \& Information Science Research Electronic Journal, 16(1), 1-29.

Basado en un análisis cualitativo de datos recogidos durante entrevistas realizadas en profundidad sobre lo queer y experiencias juveniles con veintiún individuos, este documento es un manifiesto queer de las intervenciones de la biblioteca en apoyo de la juventud durante diversas fases del proceso de identificación. Se discuten las características importantes de "salir", sobre todo como un proceso de toda la vida para las personas queer en reconocimiento de su sexualidad y compartir ese conocimiento con los demás. Significativas preocupaciones y desafíos enfrentan los jóvenes queer durante las diferentes fases de su "salida del armario" y sus experiencias proporcionan un contexto para que refleja (y exige) que se extienden las funciones de las biblioteca tradicionales de suministro de información, así como el cumplimiento de las expectativas no tradicionales que incluyen los esfuerzos de justicia social proactivas para bibliotecas para "salir del armario" en apoyo de la juventud queer.

8. Beiriger, A. y Jackson, R.M. (2007). An assessment of the information needs of transgender communities in Portland, Oregon. Public Library Quarterly, 26(1/2), 45-60. 
Los investigadores propusieron determinar, a través de una evaluación de la comunidad, si existen necesidades específicas de información dentro de la población transgénero de un área metropolitana que no han sido identificados, oabordados adecuadamente por las bibliotecas. La información relativa a los tipos únicos de material, formato y modalidades de la accesibilidad también fueron evaluados en relación a las preferencias de la comunidad transexual local. Asimismo, se presentaron los resultados de la encuesta y sus recomendaciones en relación al desarrollo de la colección de la biblioteca.

9. Hart, G.G. y Mfazo, N.N. (2010). Places for all? Cape Town's public library services to gays and lesbians. South African Journal of Libraries \& Information Science, 76(2), 98-108.

El artículo da cuenta de una investigación de la disposición de la literatura gay y lesbiana y de servicios de información a los gays y lesbianas en las bibliotecas públicas de Ciudad del Cabo. A pesar de que, por definición, las bibliotecas públicas sirven a todos los miembros de una comunidad, la literatura internacional sugiere que descuidan las necesidades de lectura, información e intereses de los homosexuales. La Constitución de Sudáfrica considera que a los derechos de los homosexuales como los derechos humanos; sin embargo, la homofobia es frecuente en ese país. Se aplicó un cuestionario que exploró las actitudes y las prácticas de sesenta y nueve bibliotecarios responsables del desarrollo de la colección, a través de los seis distritos de la biblioteca de Ciudad del Cabo. Solo ventiséis encuestados acordaron que la biblioteca satisface las necesidades homosexuales. Además, la encuesta reveló contradicciones entre las creencias y comportamientos establecidos.

10. Schaller, S. (2011). Information Needs of LGBTQ College Students. Libri: International Journal of Libraries \& Information Services, 61(2), 100-115.

Las estadísticas han demostrado que las personas LGBTQ (Lesbianas, Gay, Bisexuales, Transgéneros y Queer) constituyen una parte relevante de cada comunidad en los Estados Unidos. Esta situación se refleja también en las universidades norteamericanas. Aunque la mayoría de los administradores tratan de ser incluidos en los servicios diseñados y ofrecidos por la universidad y las organizaciones y asociaciones en el campus respectivo, se ha puesto de manifiesto en anteriores estudios que los proveedores de información no son capaces de satisfacer las necesidades especiales de información de la comunidad LGBTQ. La investigación demostró la suposición general de que los estudiantes LGBTQ todavía representan un grupo de consumidores desatendidos crónicamente por las bibliotecas 
universitarias. La aplicación de un grupo de enfoque y entrevistas individuales con lesbianas, gays, y bisexuales estudiantes universitarios de la Universidad de Carolina del Norte en Greensboro (UNCG), reveló deficiencias de información para los estudiantes LGBTQ. Asimismo, se hizo evidente que las necesidades de información y la información del comportamiento de búsqueda de los estudiantes universitarios entrevistados (LGBTQ)son a menudo ambivalentes. Por un lado, hay una necesidad de una mayor accesibilidad y de promoción de los servicios, pero por otro lado, existe un fuerte deseo de privacidad y confidencialidad, especialmente para los estudiantes más jóvenes. Aunque fenómenos como la homofobia y el heterosexismo no eran evidentes en el campus de UNCG, la mejora de los privilegios heterosexuales sigue siendo un problema para las personas LGBTQ, ya que consideran una gran cantidad de información que sigue centrándose en las necesidades de la mayoría heterosexual. Basándose en la investigación, el documento da recomendaciones sobre cómo podrían mejorarse los servicios de información para la comunidad LGBTQ en UNCG al utilizar pantallas especializadas, exploradores, guías temáticas, aplicarse talleres especializados, o realizarse tutoriales interactivos en línea. El documento también incluye la descripción de un producto de información específica que fue diseñado y desarrollado para la comunidad LGBTQ en UNCG basado en los resultados de la investigación. 


\section{2. Abordaje cualitativo}

\section{Tabla 6}

Documentos analizados cualitativamente

\begin{tabular}{|c|c|c|c|c|c|c|}
\hline & $\begin{array}{c}\text { Referencia } \\
\text { bibliográfica }\end{array}$ & $\begin{array}{l}\text { Tipología de } \\
\text { comunidad }\end{array}$ & $\begin{array}{c}\text { Métodos de } \\
\text { investigación usados }\end{array}$ & $\begin{array}{c}\text { Lugar geográfico } \\
\text { del estudio }\end{array}$ & Principales NI detectadas & Datos relevantes \\
\hline 1 & $\begin{array}{l}\text { Creelman, } \\
\text { Janet A.E. y } \\
\text { Harris, Roma } \\
\text { M. (1989). } \\
\text { Coming out: the } \\
\text { information } \\
\text { needs of } \\
\text { lesbians. } \\
\text { Collection Building, } \\
\text { 10(3-4), 37-41. }\end{array}$ & $\begin{array}{l}50 \text { lesbianas en } \\
\text { proceso de 'salir del } \\
\text { armario'. Rango de } \\
\text { edades } 20-47 . \text { Edad } \\
\text { Promedio 28.5. }\end{array}$ & $\begin{array}{l}\text { El 'muestreo de bola de nieve' } \\
\text { es una técnica por la cual } \\
\text { a través de un grupo de } \\
50 \text { lesbianas asumidas } \\
\text { contactaron otras } \\
\text { lesbianas, que también } \\
\text { respondieron a la } \\
\text { entrevista. La entrevista } \\
\text { consistía en contar } \\
\text { momentos que hayan } \\
\text { marcado su salida del } \\
\text { closet. Si fueron } \\
\text { ayudadas y cómo. Contar } \\
\text { el evento de principio a } \\
\text { fin en una línea de } \\
\text { tiempo. Se consulta su } \\
\text { nivel educativo, edad en } \\
\text { que se asumen y el } \\
\text { tamaño de la comunidad } \\
\text { de la cual salieron.En } \\
\text { consonancia con el } \\
\text { modelo del sense- } \\
\text { making, los resultados de } \\
\text { este estudio confirman la } \\
\text { naturaleza de la situación } \\
\text { de búsqueda de }\end{array}$ & $\begin{array}{c}\text { Canadá. No } \\
\text { establece las } \\
\text { ciudades }\end{array}$ & $\begin{array}{l}\text { Se identificaron tres grandes } \\
\text { categorías en las cuales se } \\
\text { orientaron las NI: } \\
\text { - Bases de la identidad lesbiana. } \\
\text {-Compartir dicha identidad y 'salir } \\
\text { del armario' con otros } \\
\text {-Sociabilización con la } \\
\text { comunidad de lesbianas y } \\
\text { gestionar } \\
\text { las relaciones dentro de la misma }\end{array}$ & $\begin{array}{l}\text { Entre la población relevada, el } 84 \% \\
\text { respondieron que encontraron } \\
\text { información en bibliotecas. Desde los } \\
\text { soportes impresos muchas de las } \\
\text { encuestas (más de la mitad, 46\%) } \\
\text { informaron que } \\
\text { 1. no pudieron encontrar relevante } \\
\text { materiales } \\
\text { 2. los recursos se centraron en las } \\
\text { experiencias de los hombres } \\
\text { homosexuales y no en lesbianas } \\
\text { 3. los materiales consultados no } \\
\text { contenían información práctica de } \\
\text { estilos de vida, } \\
\text { 4. los materiales eran deprimente y } \\
\text { negativo. } \\
\text { El material impreso es el más } \\
\text { significativo como fuente de } \\
\text { información y la colección va } \\
\text { incrementando su valor con títulos } \\
\text { relevantes y de calidad para hombres y } \\
\text { lesbianas. } \\
\text { "El valor de esta investigación es que } \\
\text { representa el primer intento de forma } \\
\text { sistemática de evaluar las necesidades de }\end{array}$ \\
\hline
\end{tabular}




\begin{tabular}{|c|c|c|c|c|c|c|}
\hline & & & información & & & $\begin{array}{l}\text { información de una población no estudiada y } \\
\text { desatendidas" (p.37) }\end{array}$ \\
\hline 2 & $\begin{array}{l}\text { Whitt, Alisa J. } \\
\text { (1993). The } \\
\text { information } \\
\text { needs of } \\
\text { lesbians. Library } \\
\text { \& Information } \\
\text { Science Research. 5 } \\
\text { (3), 275-288. }\end{array}$ & Lesbianas & $\begin{array}{l}\text { Cuestionario enviado } \\
\text { por correo electrónico a } \\
619 \text { personas de los } \\
\text { cuales se recibieron } 141 \\
\text { respuestas. }(22,8 \%)\end{array}$ & $\begin{array}{l}\text { North Carolina, } \\
\text { EEUU }\end{array}$ & $\begin{array}{l}\text { Las principales NI encontradas } \\
\text { fue: material dobre ficción, } \\
\text { investigaciones de orientación } \\
\text { psicológicas y sociológica, poesía } \\
\text { y ética/comportamiento sexual }\end{array}$ & $\begin{array}{l}\text { Esta comunidad utiliza en gran parte la } \\
\text { biblioteca y no han encontrado } \\
\text { grandes casos de discriminación pero } \\
\text { si la mala información que se } \\
\text { demostró en algunos casos en que } \\
\text { consideran el lesbianismo como } \\
\text { "enfermedad". }\end{array}$ \\
\hline 3 & $\begin{array}{l}\text { Norman, Mark } \\
\text { W. (1999). Out } \\
\text { on loan: a survey } \\
\text { of the use and } \\
\text { information } \\
\text { needs of users } \\
\text { of the lesbian, } \\
\text { gay and bisexual } \\
\text { collection of } \\
\text { Brighton and } \\
\text { Hove Libraries. } \\
\text { Journal of } \\
\text { Librarianship \& } \\
\text { Information } \\
\text { Science, 31(4): } \\
\text { 188-196. }\end{array}$ & $\begin{array}{c}\text { Gays, Lesbianas } \\
\text { Bisexuales. Rango } \\
\text { de edades de } 20 \text { a } 70 \\
\text { años. }\end{array}$ & $\begin{array}{c}\text { Cuestionario que serían } \\
\text { depositadas en cajas } \\
\text { cerradas para asegurar } \\
\text { anonimato y } \\
\text { confiabilidad. Se } \\
\text { realizaron a } 120 \text { personas } \\
\text { de la Brighton Central } \\
\text { Library y } 30 \text { de la Hove } \\
\text { Central Library. Se } \\
\text { estudia frecuencia de } \\
\text { concurrencia a la } \\
\text { biblioteca y tipos de } \\
\text { usuarios (empleados, } \\
\text { estudiantes, jubilados, } \\
\text { etcétera) }\end{array}$ & $\begin{array}{l}\text { Brighton y Hove, } \\
\text { Reino Unido. }\end{array}$ & $\begin{array}{l}\text { Entre los materiales que más se } \\
\text { usan en la colección son: ficción, } \\
\text { educación, cultura y economía }\end{array}$ & $\begin{array}{l}\text { La colección LGTB es una valiosa } \\
\text { fuente de recursos. Su separación no } \\
\text { favorece la "guetización", sino que } \\
\text { favorece su visibilización. } \\
\text { Los bibliotecarios no fueron } \\
\text { descriptos como marginadores aunque } \\
\text { los servicios son generalmente pobres. } \\
\text { Mantener el material centralizado en } \\
\text { una biblioteca demostró ayudar al } \\
\text { acceso a la información más que } \\
\text { cuando se encuentra junto a la } \\
\text { colección general. Esta comunidad } \\
\text { consulta todos los sectores de la } \\
\text { biblioteca. }\end{array}$ \\
\hline 4 & $\begin{array}{l}\text { Taylor, Jami } \\
\text { Kathleen. } \\
\text { (2002).Targeting }\end{array}$ & $\begin{array}{l}\text { Personas } \\
\text { transgénero: } \\
\text { travesties y }\end{array}$ & $\begin{array}{l}\text { Preguntas directas con } \\
\text { garantía de anonimato } \\
\text { enviadas por correo }\end{array}$ & $\begin{array}{l}\text { Carolina del } \\
\text { Norte, EEUU }\end{array}$ & $\begin{array}{l}\text { En el caso de travestis las NI se } \\
\text { centran en sitios de la web sobre }\end{array}$ & $\begin{array}{l}\text { El término transgénero es un término } \\
\text { paragüas que alberga a dos } \\
\text { características de sexualidad que tienen }\end{array}$ \\
\hline
\end{tabular}




\begin{tabular}{|c|c|c|c|c|c|c|}
\hline & $\begin{array}{l}\text { the information } \\
\text { needs of } \\
\text { transgender } \\
\text { individuals. } \\
\text { Current Studies in } \\
\text { Librarianship, } \\
\text { 26(1/2): 85-109. }\end{array}$ & transexuales & $\begin{array}{c}\text { electrónico. } \\
\text { De } 316 \text { enviadas solo } 48 \\
\text { fueron respondidas. Se } \\
\text { estableció el origen } \\
\text { étnico y educación. } \\
\text { Trabajado con el sistema } \\
\text { SPSS. }\end{array}$ & & $\begin{array}{l}\text { maquillaje, apariencia y métodos } \\
\text { para liberarse del vello. } \\
\text { En el caso de los transexuales la } \\
\text { NI están centrados en sitios web } \\
\text { donde se plantea temas de } \\
\text { transición de sexo y uso de } \\
\text { hormonas. También sobre Leyes } \\
\text { de familia y discriminación } \\
\text { laboral. }\end{array}$ & $\begin{array}{l}\text { necesidades } \\
\text { fundamentalmente de información: } \\
\text { transexuales y travestis. } \\
\text { Este estudio fue diseñado para ayudar a las } \\
\text { bibliotecas a identificar las necesidades de } \\
\text { información de la comunidad transgénero" (p. } \\
95 \text { ) }\end{array}$ \\
\hline 5 & $\begin{array}{l}\text { Downey, } \\
\text { Jennifer. } \\
\text { (2005). Public } \\
\text { library collection } \\
\text { development } \\
\text { issues regarding } \\
\text { the information } \\
\text { needs of GLBT } \\
\text { patrons. } \\
\text { Progressive } \\
\text { Librarian, 25: 86- } \\
95 .\end{array}$ & $\begin{array}{l}\text { Gays, Lesbianas, } \\
\text { Bisexuales y } \\
\text { Transexuales }\end{array}$ & $\begin{array}{l}\text { Estudio teórico centrado } \\
\text { en la colección de las } \\
\text { Bibliotecas Públicas }\end{array}$ & California, EEUU & $\begin{array}{c}\text { Las NI coinciden con las } \\
\text { referencias bibliográficas usadas } \\
\text { en el mismo artículo, } \\
\text { encontrando dicha comunidad } \\
\text { muchos prejuicios y } \\
\text { desinformación por parte de los } \\
\text { servicios bibliotecarios. No se } \\
\text { identificó una comunidad GLTB } \\
\text { (esta apreciación tiene su origen } \\
\text { en que las personas } \\
\text { estigmatizadas por la sociedad } \\
\text { hacen todo lo posible por pasar } \\
\text { desapercibidos). y en caso de que } \\
\text { haga falta, los materiales se } \\
\text { obtienen fácilmente por préstamo } \\
\text { interbibliotecario. }\end{array}$ & $\begin{array}{l}\text { El estudio trata el tema de la "censura } \\
\text { interna". La misma se manifiesta en } \\
\text { catalogaciones erróneas lo que hace } \\
\text { que los documentos se tornen } \\
\text { invisibles. También la ubicación } \\
\text { controversial que se manifiesta } \\
\text { colocando el material en áreas poco } \\
\text { accesibles. } \\
\text { Por otra parte el estudio concluye que } \\
\text { el tamaño de la biblioteca no indica } \\
\text { una colección más apropiada para } \\
\text { estos usuarios, las bibliotecas más } \\
\text { pequeñas demostraron tener una } \\
\text { colección más adecuada y efectiva. } \\
\text { La Berkeley Public Library y la Oakland } \\
\text { Public Library fueron reconocidas como } \\
\text { proactivas en la constitución de la } \\
\text { colección. La Oakland coloca stickers } \\
\text { con los colores del arco iris en el lomo } \\
\text { para fácil identificación de los } \\
\text { materiales. } \\
\text { La Biblioteca Pública de San Francisco } \\
\text { tiene una de las más importantes y }\end{array}$ \\
\hline
\end{tabular}




\begin{tabular}{|c|c|c|c|c|c|c|}
\hline & & & & & & $\begin{array}{l}\text { mejores colecciones. } \\
\text { Se sugiere que los bibliotecarios } \\
\text { consulten recursos especializados } \\
\text { como Alternative Press Index para el } \\
\text { desarrollo de la coleccion como así } \\
\text { también el Lambda Book Report y el } \\
\text { American Library Association's Gay and } \\
\text { Lesbian Round Table Awards para } \\
\text { cumplir con el esfuerzo de dar acceso } \\
\text { a materiales alternativos a sus usuarios } \\
\text { reales y potenciales. }\end{array}$ \\
\hline 6 & $\begin{array}{l}\text { Simpson, Stacy } \\
\text { H. (2006). Why } \\
\text { have a } \\
\text { comprehensive } \\
\text { \& representative } \\
\text { collection?: } \\
\text { GLBT material } \\
\text { selection and } \\
\text { service in the } \\
\text { public library. } \\
\text { Progressive } \\
\text { Librarian , 27: } \\
\text { 44-51. }\end{array}$ & $\begin{array}{l}\text { Comunidad GLBT } \\
\text { que asisten a } \\
\text { bibliotecas públicas }\end{array}$ & $\begin{array}{c}\text { Breve experiencia en la } \\
\text { búsqueda de materiales } \\
\text { en el catálogo en línea de } \\
\text { la biblioteca Scott } \\
\text { County Public Library } \\
\text { utilizando como palabras } \\
\text { clave 'bisexual' y } \\
\text { 'bisexualidad' }\end{array}$ & Minnesota, EEUU & $\begin{array}{l}\text { Las personas GLTB poseen } \\
\text { escasa información por muchas } \\
\text { de las bibliotecas públicas, } \\
\text { cuando su función debe ser dar } \\
\text { acceso a la NI de toda la } \\
\text { población, no solo en el aspecto } \\
\text { intelectual sino también para sus } \\
\text { vidas emocionales y de salud. }\end{array}$ & $\begin{array}{l}\text { Se propone a los bibliotecarios } \\
\text { respetar la Declaración de Derechos, } \\
\text { del documento de ALA, que establece } \\
\text { que no deben excluirse materiales por } \\
\text { el origen, antecedentes y puntos de } \\
\text { vista de sus autores y que no se } \\
\text { discriminarán los materiales por el } \\
\text { sexo, la identidad de género ni la } \\
\text { orientación sexual de sus autores. } \\
\text { Estos aspectos fueron reforzados por } \\
\text { la ALA en junio } 2005 \text { en el } \\
\text { documento: "Amenazas para los } \\
\text { materiales relacionados con sexo, identidad de } \\
\text { género y orientación sexual" }\end{array}$ \\
\hline 7 & $\begin{array}{l}\text { Mehra, B. y } \\
\text { Braquet, D. } \\
\text { (2006).A } \\
\text { "Queer" } \\
\text { manifesto of } \\
\text { interventions for }\end{array}$ & $\begin{array}{c}\text { Juventud Queer que } \\
\text { ha manifestado su } \\
\text { identidad sexual en } \\
\text { sociedad. }\end{array}$ & $\begin{array}{l}\text { Análisis cualitativo en } \\
\text { discusiones informales y } \\
\text { entrevistas narrativas en } \\
\text { encuentros privados para } \\
\text { garantizar el anonimato. }\end{array}$ & Tennessee, EEUU & $\begin{array}{l}\text { Este artículo propone un } \\
\text { manifiesto para que las } \\
\text { bibliotecas diseñen servicios y } \\
\text { políticas institucionales en } \\
\text { función de mejorar las } \\
\text { colecciones y sistemas de }\end{array}$ & $\begin{array}{l}\text { Se colocaron carteles invitando a la } \\
\text { participación de la juventud en lugares } \\
\text { visibles de la Biblioteca. }\end{array}$ \\
\hline
\end{tabular}




\begin{tabular}{|c|c|c|c|c|c|c|}
\hline & $\begin{array}{l}\text { libraries to } \\
\text { "come out" of } \\
\text { the closet! A } \\
\text { study of "queer" } \\
\text { youth } \\
\text { experiences } \\
\text { during the } \\
\text { Coming Out } \\
\text { process. } \\
\text { LIBRES: Library } \\
\text { \& Information } \\
\text { Science Research } \\
\text { Electronic Journal, } \\
\text { 16(1): 1-29. }\end{array}$ & & & & $\begin{array}{l}\text { información. También propone } \\
\text { dar voz a los no representados } \\
\text { intentando bajar los índices de } \\
\text { suicidios entre la juventud queer. }\end{array}$ & \\
\hline 8 & $\begin{array}{l}\text { Beiriger, Angie } \\
\text { y Rose M. } \\
\text { Jackson. } \\
\text { (2007). An } \\
\text { assessment of } \\
\text { the information } \\
\text { needs of } \\
\text { transgender } \\
\text { communities in } \\
\text { Portland, Oregon. } \\
\text { Public Library } \\
\text { Quarterly, } \\
\text { 26(1/2): 45-60. }\end{array}$ & $\begin{array}{l}\text { Transexuales que } \\
\text { concurren a las } \\
\text { bibliotecas de } \\
\text { Portland Oregon }\end{array}$ & $\begin{array}{l}\text { Preguntas cuali- } \\
\text { cuantitativas que intenta } \\
\text { poner en conocimiento } \\
\text { si existe información } \\
\text { específica para esta } \\
\text { comunidad. } \\
\text { Se uso el correo } \\
\text { electrónico. Las } \\
\text { encuestadas tuvieron la } \\
\text { opción de no responder } \\
\text { el 100\% de las preguntas } \\
\text { y se aseguró } \\
\text { confidencialidad. Se } \\
\text { realizaron } 99 \text { encuestas. }\end{array}$ & $\begin{array}{c}\text { Portland, Oregon, } \\
\text { EEUU. }\end{array}$ & $\begin{array}{l}\text { Las principales NI detectadas está } \\
\text { en la salud fisica y mental (uso de } \\
\text { hormonas, doctores y cirugías } \\
\text { aconsejables), información legal y } \\
\text { política, general, biografías e } \\
\text { historias exitosas, listas de lugares } \\
\text { amigables. }\end{array}$ & $\begin{array}{l}\text { Implementación del TiRC } \\
\text { "Transgender/identity Resource Center" es } \\
\text { un programa que brinda educación } \\
\text { entre pares, referentes y consejeros. Se } \\
\text { les dio la posibilidad a esta comunidad } \\
\text { de participar en la sugerencia de los } \\
\text { materiales necesarios, acercándoles } \\
\text { una lista de materiales en la biblioteca. }\end{array}$ \\
\hline 9 & $\begin{array}{l}\text { Hart, } \\
\text { Genevieve y } \\
\text { Ncumisa }\end{array}$ & $\begin{array}{c}\text { Trabajo } \\
\text { investigativo sobre } \\
\text { gays y lesbianas }\end{array}$ & $\begin{array}{c}\text { Cuestionario } \\
\text { implementado en la } \\
\text { Biblioteca Pública de }\end{array}$ & $\begin{array}{c}\text { Ciudad del Cabo, } \\
\text { Sudáfrica. }\end{array}$ & $\begin{array}{l}\text { Adquieren muy poco material y el } \\
\text { mismo se marca con un triángulo } \\
\text { rosa. Gays y lesbianas son casi }\end{array}$ & $\begin{array}{l}\text { A partir de lo abordado, si bien las } \\
\text { instituciones están al tanto de las leyes } \\
\text { y digestos existentes para estas }\end{array}$ \\
\hline
\end{tabular}




\begin{tabular}{|c|c|c|c|c|c|c|}
\hline & $\begin{array}{l}\text { Mfazo. (2010). } \\
\text { Places for all? } \\
\text { Cape Town's } \\
\text { public library } \\
\text { services to gays } \\
\text { and lesbians. } \\
\text { South African } \\
\text { Journal of } \\
\text { Libraries \& } \\
\text { Information Science } \\
\text {, 76(2): 98-108. }\end{array}$ & solamente & $\begin{array}{c}\text { Cape Town para } \\
\text { bibliotecarios } \\
\text { responsables del sector } \\
\text { desarrollo de las } \\
\text { colecciones de } \\
\text { bibliotecas (69 } \\
\text { encuestados). } \\
\text { Los mismos apuntaban a } \\
\text { saber si la comunidad de } \\
\text { gays y lesbianas eran } \\
\text { incluidos en los servicios } \\
\text { de información a la hora } \\
\text { de elegir materiales y dar } \\
\text { servicios. }\end{array}$ & & $\begin{array}{c}\text { ignorados en esa comunidad y las } \\
\text { personas visibles no son bien } \\
\text { considerados e inclusive } \\
\text { socialmente son vulnerables de } \\
\text { ataque. }\end{array}$ & $\begin{array}{llll}\text { comunidades, } & \text { no } & \text { son tomadas } & \text { en } \\
\text { cuenta para } & \text { el desarrollo de la } & \text { de } \\
\text { colección } & & & \end{array}$ \\
\hline 10 & $\begin{array}{c}\text { Schaller, } \\
\text { Susann. (2011). } \\
\text { Information } \\
\text { needs of } \\
\text { LGBTQ college } \\
\text { students. Libri: } \\
\text { International } \\
\text { Journal of } \\
\text { Libraries \& } \\
\text { Information } \\
\text { Services, 61(2): } \\
\text { 100-115. }\end{array}$ & $\begin{array}{c}\text { Estudiantes } \\
\text { lesbianas, gays y } \\
\text { bisexuales de la } \\
\text { Universidad de } \\
\text { Greensboro. Rango } \\
\text { etario entre } 18 \text { y } 23 \\
\text { años. }\end{array}$ & $\begin{array}{l}\text { Grupo focal y entrevistas } \\
\text { personales, a través de } \\
\text { tres lineamientos: } \\
\text { a)Necesidad de } \\
\text { información b)La } \\
\text { Biblioteca como un lugar } \\
\text { para la comunidad } \\
\text { LGBTQ } \\
\text { c)El campus de la } \\
\text { Universidad de } \\
\text { Greensboro (UNCG) } \\
\text { como un lugar para la } \\
\text { comunidad LGBTQ }\end{array}$ & $\begin{array}{l}\text { Carolina del } \\
\text { Norte, EEUU }\end{array}$ & $\begin{array}{l}\text { Las principales NI detectadas } \\
\text { son: sobre marginalización social, } \\
\text { política y legal, religión, } \\
\text { activismo, eventos culturales y } \\
\text { sociales, mercado laboral y } \\
\text { discriminación, constitución } \\
\text { familiar y relaciones, aceptación } \\
\text { de familiares y amigos, } \\
\text { información objetiva, opiniones } \\
\text { expertas y científicas }\end{array}$ & $\begin{array}{l}\text { Por dudas sobre la confidencialidad } \\
\text { hubo pocos participantes en este } \\
\text { estudio. }\end{array}$ \\
\hline
\end{tabular}




\subsection{Abordaje cuantitativo}

Análisis bibliométrico de las referencias bibliográficas usadas en la literatura compilada

Tabla 7

Referencias bibliográficas de la literatura citada

Cita ordenadas por año descendente

Creelman, J. E. y Harris, R. M. (1989). Coming out:

the information needs of lesbians. Collection Building, 10(3-4), 37-41. cantidad

Años utilizados de las referencias

$8 \quad 1976,1978,1984,1986,1987,1988$

1977, 1978, 1979, 1981, 1984, 1985, 1986, 1987, 1990, 1991

2 lesbians. Library \& Information Science Research. 5 (3), 275-288.

Norman, M. W. (1999). Out on loan: a survey of the use and information needs of users of the lesbian, gay

3 and bisexual collection of Brighton and Hove Libraries. Journal of Librarianship \& Information Science, 31(4): 188-196.

1987, 1989, 1990, 1992, 1994, 1996, 1997, 1998

1983, 1992, 1993, 1994, 1006, 1997,

Taylor, Jami Kathleen. (2002). Targeting the information needs of transgender individuals. Current Studies in Librarianship, 26(1/2): 85-109.

$251999,2000,2001,2002,2003,2004$, 2005

Downey, Jennifer. (2005). Public library collection development issues regarding the information needs

5 of GLBT patrons. Progressive Librarian, 25: 86-95.

$221997,1999,2001,2003$

1969, 1990, 1992, 1993, 1994, 1995,

Simpson, S.H. (2006). Why have a comprehensive \& representative collection? GLBT material selection and service in the public library. Progressive Librarian, (27), 44-51.

$8 \quad 1994,2000,2001,2003,2004,2005$, 2006, 2008

1965, 1967, 1971, 1977, 1979, 1980, 1982, 1983, 1984, 1987, 1989, 1990,

Mehra, B. y Braquet, D. (2006). A "Queer" Manifesto of interventions for libraries to "Come Out" of the Closet! A study of "Queer" youth experiences during the coming out process. LIBRES: Library \& Information Science Research Electronic Journal, 16(1), 1-29.

101 1991, 1992, 1993, 1994, 1995, 1996, 1997, 1998, 1999, 2000, 2001, 2002, 2003, 2004, 2005

Beiriger, Angie y Rose M. Jackson. (2007). An

8 assessment of the information needs of transgender communities in Portland, Oregon. Public Library Quarterly, 26(1/2): 45-60.

Hart, Genevieve y Ncumisa Mfazo. (2010). Places for all? Cape Town's public library services to gays and lesbians. South African Journal of Libraries \& Information Science, 76(2): 98-108. (aparece dos veces)
1992, 1993, 1995, 1996, 1997, 1998,

35 1999, 2000, 2001, 2003, 2004, 2005, 2006, 2007, 2009, 2010
1994, 2000, 2001, 2003, 2004, 2005, 2006, 2007 
Schaller, Susann. (2011). Information needs of

LGBTQ college students. Libri: International Journal of Libraries \& Information Services, 61(2): 100-115.

1990, 1991, 1992, 2000, 2004, 2006, 2007, 2009

La transcripción de las referencias bibliográficas que figuran en cada artículo son las siguientes:

\section{Creelman, J. E. y Harris, R. M. (1989). Coming out: the information needs of lesbians.Collection Building, 10(3-4), 37-41.}

Alyson, Sasha. (1984). What librarians should know about gay and lesbian publishing. Collection Building, 5: 22-23.

Ashby, Richard. (1987). Library services to gay and lesbian people.Assistant Librarian, 80: 154.

Dervin, Brenda y Kathleen Clark. (1987). A5Q: Asking Significant Questions. Alternative tools for information need and accountability assessments for libraries. Belmont, CA: Peninsula Library System.

Dervin, Brenda y Michael Nilan. (1986). Information Needs and Uses. Annual Review of Information Science and Technology, 21:3-33.

Dervin, Brenda. (1976). The Everyday Information Needs of the Average Citizen: A Taxonomy for Analysis. En Information (or the Community, ed. Manfred Kochen and Joseph C. Donohue (Chicago: American Library Association)

Monroe, Judith. (1988). breaking the silence barrier: libraries and gay and lesbian students. Collection Building, 9: 43-46.

Parkinson, Phil. (1987). Greater expectations: services to lesbians and gay men. New Zealand Libraries, 45: 92-97.

Wyatt, Michael. (1978). Gays and libraries. New Zealand Libraries, 41: 89.

2. Whitt, A. J. (1993). The information needs of lesbians. Library \& Information Science Research. 5 (3), 275-288.

Alyson, Susan. (1986). What librarians should know about gay and lesbian publishing. En S. Berman y J. p. Danky (Eds.). Alternative Library Literature, 1984/1985: A biennial anthology (pp. 114115). Jefferson, NC: McFarland.

Bloom, Carol. (1984). Getting books on gay themes into the library: An action plan. En S. Berman \& J. p. Danky (Eds.). Alternative Library Literature, 1982/1983: A biennial anthology (p. 228). Phoenix, AZ: Oryx Press.

Creelman, Janet. A. E. y Harris, Roma. M. (1990).Coming out: the information needs of lesbians.Collection Building, 10(3/4), 37-41. 
Dervin, Brenda. (1977). Useful theory for librarianship.Drexel Library Quarterly, 13, 16-32.

Gittings, Barbara. (1978). Combatting the lies in the libraries. In L. Crew (Ed.), The gay academic (pp. 107-118). Palm Springs, CA: ETC Publications.

Lockard, Denyse. (1985). The lesbian community: An anthropological approach. Joumal of Homosexuality, 11(3/4), 83-95.

Neisen, Joseph. H. (1987).Resources for families with a gay/lesbian member.Joumal of Homosexuality, $14,239-251$.

Parkinson, Phil. (1987). Greater expectations: Services to lesbians and gay men. New Zealand Libraries, 45, 92-97.

Raaflaub, Yvonne. (1991). Problems of access to lesbian literature.RQ, 31, 19-23.

Swanson, Donald. (1979). Libraries and the growth of knowledge.Library Quarterly, 49,3-25.

Van Buskirk, Jan. (1981). On display: Presenting gay culture in a library setting. Catalys, 4 4, 111 117.

3. Norman, M. W. (1999). Out on loan: a survey of the use and information needs of users of the lesbian, gay and bisexual collection of Brighton and Hove Libraries. Journal of Librarianship \& Information Science, 31(4): 188-196.

Ashby, R. (1987). Library services to gay and lesbian people. Assistant Librarian, 80(10): 153-155.

Brett, p. (1992). Politics and public library provision for lesbians and gay men in London.International Journal of Information Research, 4(3): 195-211

Brighton Central Library.(1996). Gay men out in print.(2nded.)

Brighton Central Library.(1996). Lesbians out in print.(2nded.)

Brighton Central Library. (1996). Minutes of meeting of the LGB Consultation Group, 4/11/96

Colis, R. (1994). Out on the shelves. The Bookseller, 4618: 26-28

Creelman, J.A.E. y Harris, R.M. (1989).Coming out: the information needs of lesbians.Collection Building, 10(3/4): 37-41

Dennis, p. (1992). Daring hearts: lesbian and gay lives of 50s and 60s Brighton. Brighton: QueenSpark.

Fairbrother, p. (1998). Information provision for gay users. Community Librarian, April, 1-4.

Gough, C. y Greenblatt, E. (1992). Services to gay and lesbian patrons: examining the myths. Library Journal, 117(1): 59-63.

Greenblatt, E. (1990). AIDS information in libraries. En: Gough, C. y Greenblatt, E. (eds) Gay and Lesbian Library Service (p. 171-179). Jefferson, NJ: McFarland.

Hawkins, H. (1994). Opening the closet door. Public library services for gay, lesbian and bisexual teens. Colorado Libraries, Spring: 28-31 
Hendry, J. (1997). Freedom of information: the lesbian and gay issue. Assistant Librarian. 90(3): 3740.

Joyce, S. and Schrader, A. (1997). Hidden perceptions: Edmonton gay males and the Edmonton Public Library. Canadian Journal of Information and Library Science, 22(1): 19-37.

McMahon, S. (1996).Services to lesbians, gay men and bisexual people.An example from Brighton public library.Burning Issues Conference on library services to lesbians and gay men, 27 Jun 1996, Dulwich Library.

Montgomery, A. and Behr, A. (1988).Significant others. Assistant Librarian, 81(11): 164-168

Munt, S. (1994). In defence of heroes: lesbian literature. En: Healey, E. y Mason, A. (eds) Stonewall 25. The making of the lesbian and gay community in Britain (p. 199-209) London: Virago.

Parkinson, p. (1987) Greater expectations: services to lesbians and gay men. New Zealand Libraries, 45(5): 92-97.

Pollard, D. (1994). Gay male themed fiction: questions of publishing, readership and genre. Unpublished MA English dissertation (Sexual Dissidence), University of Sussex

Raaflaub, Y. (1991) Problems of access to lesbian literature.RQ, 31(1): 19-23.

\section{Taylor, Jami Kathleen. (2002). Targeting the information needs of transgender individuals. Current Studies in Librarianship, 26(1/2): 85-109.}

Allen, B. (1996). Information needs: A person-in-situation approach. En p. Vakkari, R. Savolainen, y B. Dervin (Eds.). Information seeking in context: Proceedings of an international conference on research in information needs, seeking and use in different contexts (p. 111 - 122). London: Taylor Graham Publishing.

American Library Association (2003).Professional etbics. Retrieved January 21, 2005, from http://www.ala.org/ala/ourassociation/governingdocs/aheadto20 $10 /$ proethics.htm

American Library Association (2004).ALA policy manual. Retrieved May 6, 2004, from http://www.ala.org/ala/ourassociation/governingdocs/policymanual/minorityconcerns.htm\#60.I

Bailey, J. M. (2003). The man who would be queen: The science of genderbending and trans-sexualism. Washington D.C.: Joseph Henry Press.

Bornstein, K. (1994). Gender outlaw. New York: Routledge.

Boylan, J. F. (2003). She's not there: A life in two genders. New York: Broadway Books.

Bullough, V. (2000).Transgenderism and the concept of gender.International Journal of Transgenderism. Retrieved July 17, 2005, from http://www.symposion.com/iit/gilbert/bullough.htm

Califia, p. (1997). Sex changes: The politics of transgenderism. San Francisco: Cleis Press.

Carroll, L., Gilroy, p. y Ryan, J. (2002). Counseling transgendered, transsexual, and gender-variant clients.Journal of Counseling and Development, 80(2), 131-139.

Conway, L. (2004). Transsexual women's successes. Retrieved May 6, 2004, from http://ai.eecs.umich.edu/people/conway/TSsuccesses/TSsuccesses.html 
Dasti, J. (2002). Advocating a broader understanding of the necessity of sex-reassignment surgery under Medicaid.New York University Law Review, 77(6), 1738.

D'Emilio, J. (1983). Sexual politics, sexual communities: The making of a homosexual minority in the United States, 1940-1970 (2nd ed.).Chicago: University of Chicago Press.

Dervin, B. (1992). From the mind's eye of the user: The sense-making qualitative-quantitative methodology. En J. D. Glazier \& R. R. Powell (Eds.), Qualitative research in information management (p. 61-84). Englewood, CO: Libraries Unlimited.

Dunne, J. (2002). Information seeking and use by battered women: A "person-in-progressivesituations" approach. Library and Information Science Research, 24(4), 343-355.

Eyler, A., \& Wright, K. (1997).Gender identification and sexual orientation among genetic females with gender-blended selfperception in childhood and adolescence.International Journal of Transgenderism, 1(1). Retrieved May 21, 2005, from http://www.symposion.com/iit/iitc0102.htm

Fikar, C., y Keith, L. (2004). Information needs of gay, lesbian, bisexual, and transgendered health care professionals: Results of an internet survey. Journal of the Medical Library Association, 92(1), 56-65.

Harry Benjamin International Gender Dysphoria Association.(2001). Standards of care for gender identity disorders, Sixth version. Retrieved May 21, 2005, from http://www.hbigda.org/soc.cfm

Lombardi, E., Wilchins, R., Priesing, D., \& Malouf, D. (2001). Gender violence: Transgender experiences with violence and discrimination. Journal of Homosexuality, 42(l), 89- 101.

Miller, T., y Kobayashi, M. M. (2000).Citizen surveys: How to do them, how to use them, what they mean ( $2^{\text {nded.). }}$. Washington DC: ICMA.

Norman, M. W. (1999). Out on loan: A survey of the use and information needs of users of the lesbian, gay and bisexual collection of Brighton and Hove Libraries. Journal of Librarianship and Information Science, 31(4), 188-196.

Osborne, D., \& Gaebler, T. (1993).Reinventing government: How the entrepreneurial spirit is transforming the public sector. New York: Plume.

Ridinger, R. B. M. (1996).Internet resources in gay and lesbian studies.College and Research Library News, 57(10). Retrieved May 6, 2004, from http://www.ala.org/ala/acrl/acrlpubs/crlnews/backissues 1996/november $\mathrm{i} /$ internetresources.htm

Rudacille, D. (2005). The riddle of gender: Science, activism and transgender rights. New York: Pantheon Books.

Seiss, J. (2003). Library surveys.One-Person Library, 20(4), 7-8.

United States Census Bureau.United States C United States Census 2000. Retrieved May 6, 2004, from http://www.census.gov

\section{Downey, Jennifer. (2005). Public library collection development issues regarding the information needs of GLBT patrons. Progressive Librarian, 25: 86-95.}

Donovan, John. (1969).I'll Get There, it Better be Worth the Trip. London: HarperCollins Juvenile Books. 
Gough, Cal. (1990). Key Issues in the Collecting of Gay/Lesbian Library Materials.Gay and Lesbian Library Service.Ed. Ellen Greenblatt \& Cal Gough. Jefferson, N.C.: McFarland.

Jenkins, Christine. (1990). Gay and Lesbian Issues for School Libraries and Librarians.Gay and Lesbian Library Service.Ed. Ellen Greenblatt \& Cal Gough. Jefferson, N.C.: McFarland.

Tsang, Daniel. (1990). Censorship of Lesbian and Gay Materials by Library Workers. Gayand Lesbian Library Service.Ed. Ellen Greenblatt \& Cal Gough. Jefferson, N.C.: McFarland.

Garden, Nancy. (1992). Annie on my Mind. New York: Farrar, Straus \& Giroux.

Whitt, Alisa. (1993). The Information Needs of Lesbians. Library \& Information Science Research 15: 275-288.

Greenblatt, Ellen. Lesbian, Gay, Bisexual, Transgender Library Users: Overcoming the Myths. Colorado Libraries 29.4: 21-25.

Bledsoe, Lucy Jane. (1995). Letter from the Bay Area.Lambda Book Report 4.8: 8-10.

Sweetland, James y Peter Christensen. (1995). Gay, Lesbian and Bisexual Titles: Their Treatment in the Review Media and Their Selection by Libraries. Collection Building 14.2: 32-41.

Joyce, Steven y Alvin Schrader. (1997). Hidden Perceptions: Edmonton Gay Males and the Edmonton Public Library. Canadian Journal of Information and Library Science 22.1: 19-37.

Joyce, Steven. (1997). Lesbian, Gay, and Bisexual Library Service: A Review of the Literature. Public Libraries 39.5: 270-279.

Loverich, Patricia y Darrah Degna (1999). Out on the Shelves? Not Really: Gay, Lesbian, Bisexual Books in Short Supply. Library Journal 124.11 (1999): 55.

Berman, Sanford. (2001). 'Inside' Censorship.Progressive Librarian 18: 48-63.

Clyde, Laurel y Marjorie Lobban.A Door Half Open: Young People's Access to Fiction Related to Homosexuality.School Libraries Worldwide 7.2: 17-30.

Hughes-Hassell, Sandra y Alissa Hinckley. (2001). Reaching Out to Lesbian, Gay, Bisexual, and Transgender Youth. Journal of Youth Services in Libraries 15.1: 39-41.

Ritchie, Catherine. (2001). Collection Development of Gay/Lesbian/Bisexual-Related Adult NonFiction in Medium-Sized Illinois Public Libraries.Illinois Libraries, 83.2: 39-70.

Levithan, David. (2003). Boy Meets Boy. New York: Knopf Books for Young Readers.

Mulholland, Rick. (2003). Gay and Lesbian Fiction: A History and a Review of Canadian Fiction Materials. Resource Links 8.4: 55-58.

Oberg, Larry y Gary Klein. (2003). Gay-Themed Books in Oregon Public and Academic Libraries: A Brief Historical Overview. OLA Quarterly 9.2: 8-12.

Pavao, Kate. (2003). Out of the Closet.Publisher's Weekly 250.48: 23-25.

Sanchez, Alex. (2003). Rainbow Boys. New York: Simon Pulse. 
Sanchez, Alex. (2003). Rainbow High. New York: Simon \& Schuster Children’s Publishing.

6. Simpson, S.H. (2006). Why have a comprehensive $\&$ representative collection? GLBT material selection and service in the public library. Progressive Librarian, (27), 44-51.

American Library Association, "Access to Library Resources and Services Regardless ofSex, Gender Identity, or Sexual Orientation: An Interpretation of the Library Bill ofRights," Adopted June 30, 1993, by the ALA Council; amended July 12, 2000, June 30,2004. [accessed at http: $/ /$ www.ala.org $/$ Template.cfm?Section=interpretations\&Template $=/$ ContentManagement $/$ ContentDisplay.cfm\&ContentID $=31878$ December 2, 2005]

American Library Association, "Resolution on Threats to Library Materials Related to Sex,Gender Identity, or Sexual Orientation," adopted by the ALA Council on June 29, 2005[accessed at www.ala.org/ala/oif/statementspols/ifresolutions/threats.htm on December 2, 2005]

Curry, Ann, "If I Ask, Will They Answer? Evaluating Public Library Reference Service to Gay/Lesbian Youth": 1. [accessed December 2, 2005 at http://www.slais.ubc.ca/RESEARCH/currentresearch/curry/GLBT 200506 22.pdf ]. Note: This manuscript was published in Reference \& User Services Quarterly, 45 (Fall 2005): 65-75.

Downey, Jennifer. "Public Library Collection Development Issues Regarding the Information Needs of GLBT Patrons.” Progressive Librarian, no 25 (Summer 2005): 86-95. [WilsonWeb online database]

Goldberg, Beverly. “Officials Silence Risqué Read-Aloud” American Libraries, 32 no. 5 (May 2001): 31.

Greenblatt, Ellen. "Barriers to GLBT Library Service in the Electronic Age." Information for Social Change, no.12 (2001) (posted November 26 2005) [accessed at http://www.libr.org/ISC/articles/12Greenblatt.html on December 2, 2005

Howard, Vivian, "Out of the Closet...but Not on the Shelves? An analysis of Canadian public libraries' holdings of gay-themed picture books." Progressive Librarian, no. 25 (Summer 2005): 6275.

Janus, Samuel S. and Cynthia L. Janus, The Janus Report (New York: John Wiley and Sons Inc., 1993), p. 70. [As cited by Burleson, William. Bi America: Myths, Truths, and Struggles of an Invisible Community. New York: Harrington Park Press, 2005. Page 50.]

7. Mehra, B. y Braquet, D. (2006). A “Queer” Manifesto of interventions for libraries to "Come Out" of the Closet! A study of "Queer" youth experiences during the coming out process. LIBRES: Library \& Information Science Research Electronic Journal, 16(1), 1-29.

Abinati, A. (1994). Legal challenges facing gay and lesbian youth. En T. DeCrescenzo (Ed.), Helping gay and lesbian youth: New policies, new programs, new practice. New York: Harrington Park.

AIDS Education and Research Trust (AVERT). (2003). Talking about homosexuality in the secondary school (2nd ed.). Sussex, UK: AVERT. Retrieved July 15, 2005, from http://www.avert.org/media/pdfs/homosexualityinschool.pdf 
Anderson, K. (1993). Sources of coming out self-efficacy for lesbians.Unpublished doctoral dissertation, Michigan State University, Lansing.

Argus and Cox. (1999). Queer in the 21st century: Perspectives on assimilation and integration. Brisbane, Australia: The Gay and Lesbian Welfare Association Inc.

Atkinson, J. D., III, y Figueroa, M. (1997). Information seeking behavior of business students: A research study. The Reference Librarian, 58, 59-73.

Beaty, L. A. (1999).Identity development of homosexual youth and parental and familial influences on the coming out process. Adolescence, 34(135), 597-601.

Beheshti, J. (1989). Cross-sectional study of the use of library books by undergraduate students. Information Processing \& Management, 25(6), 727-735.

Ben-Ari, A. (1995). The discovery that an offspring is gay: Parents', gay men's and lesbians' perspectives. Journal of Homosexuality, 30, 89-112.

Bilal, D. (2002). Children's use of the Yahooligans! Web search engine: III. Cognitive and physical behaviors on fully self-generated tasks. Journal of the American Society for Information Science \& Technology, 53(13), 1170-1183.

Bishop, K., \& Bauer, p. (2002). Attracting young adults to public libraries: Frances Henne/YALSA/VOYA Research Grant results.Journal of Youth Services in Libraries, 15(2), 36-44.

Blasius, M. (Ed.) (2001). Sexual identities, queer politics. NJ: Princeton University.

Blumenfeld, Warren J. (Ed.). (1992). Homophobia: How we all pay the price. Boston: Beacon.

Borgman, C. L., Hirsh, S. G., Walter, V. A., \& Gallagher, A. L. (1995). Children's searching behavior on browsing and keyword online catalogs: The science library catalog project. Journal of the American Society for Information Science (JASIS), 46(9), 663-684.

Bott, C. J. (2000).Fighting the silence: How to support your gay and straight students. Voice Youth Advocates, 23(1), 22-26.

Cain, R. (1991). Relational contexts and information management among gay men.Families in Society.The Journal of Contemporary Human Services, 72, 344-352.

Carter, J. (2005). United States: Reaching out with library services for GLBTQ teens. Buffalo, NY: Hawthorn.

Cass, V. C. (1979). Homosexual identity development: A theoretical model. Journal of Homosexuality, 4(3), 219-235.

Cass, V. C. (1984). Homosexual identity formation: Testing a theoretical model. Joumal of Sex Research, 20(2), 143-167.

Chelton, M. K., \& Cool, C. (2004).Youth information seeking behavior: Theories, models, and issues. New York: Scarecrow.

Cianciotto, J., \& Cahill, S. (2003). Education policy: Issues affecting lesbian, gay, bisexual, and transgender youth. New York: The National Gay and Lesbian Task Force Policy Institute. 
Coleman, E. (1982). Developmental stages of the coming out process. En Paul, W., Weinrich, J. D., Gonsioreck, J.C., \& Hotvedt, M. E. (Eds.), Homosexuality: Social, psychological and biological issues (p. 149-158). Beverly Hills, Ca: Sage.

Coleman, E. (1982). Developmental stages of the coming out process. Journal of Homosexuality, 7(23), 31-43.

Connexions (2002/2003).Information and guidance on engaging young lesbian, gay and bisexual people. Nottingham, UK: DfES. Retrieved July 15, 2005, from http://www.connexions.gov.uk/partnerships/publications/uploads/cp/ LGBreprintfinal03.04.pdf

Crowley, p. (2004). Homosexuality and the counsel of the cross.Theological Studies, 65(3), 500-529.

D’Augelli, A. R. (1994). Lesbian and gay male development: Steps toward an analysis of lesbians' and gay men's lives. En Greene, B., \& Herek, G. M. (Eds.), Psychological perspectives on lesbian and gay issues: Lesbian and gay psychology: Theory, research, and clinical applications (Vol. 1, pp. 118-132). Thousand Oaks, CA: SAGE.

Danesi, M. (2003).My son is an alien: A cultural portrait of today's youth. Lantham: Rowman \& Littlefield.

Dank, B. M. (1971).Coming out in the gay world.Psychiatry, 34, 180-197.

Dorais, M., \& Lajeunesse, S. L. (2003).Dead boys can't dance: Sexual orientation, masculinity, and suicide (p. Tremblay, Trans.). Montreal, Canada: McGill-Queen's University Press.

Dresang, E. T., Gross, M., \& Holt, L. E. (2003). Project CATE: Using outcome measures to assess school-age children's use of technology in urban public libraries: A collaborative research process. Library \& Information Science Research, 25, 19-43.

Egan, J. p. (2004). Not str8: The construction of queer male identity in Sydney, Australia. In Clover, D. E., Shinaba, J., \& Etmanski, C. (Eds.), Adult education for democracy, social justice and a culture of peace: Proceedings of the Joint International Conference of the Adult Education Research Conference (AERC) (45th National Conference) and the Canadian Association for the Study of Adult Education (CASAE), l'Association Canadienne pour l'etude de Feducation des Adultes (ACEEA) (23rd National Conference) (pp. 125-130). Victoria, Canada: National Library of Canada Cataloging in Publication.

Farmer, L. (2003). Electronic reference service.Knowledge Quest, 32(1), 22-23.

Fassinger, R. R., \& Miller, B. A. (1996).Validation of an inclusive model of sexual minority identity formation on a sample of gay men.Journal of Homosexuality, 32(2), 53-78.

Fikar, C. R., y Koslap-Petraco, M. (1991). Pediatric forum: What about gay teenagers? American Journal of Diseases of Children, 145(3), 252.

Flint, C. (2004). Space of hate: Geographies of discrimination and intolerance in the U.S.A. New York: Routledge.

Foucault, M. (1980). The bistory of sexuality (Vol. 1). New York: Vintage.

George, K. D., \& Behrendt, A. E. (1987). Therapy for male couples experiencing relationship problems and sexual problems. Journal of Homosexuality, 17, 77-88. 
Glaser, B. G., \& Strauss, A. L. (1967). The discovery of grounded theory: Strategies for qualitative research. Chicago: Aldine.

Gough, C. (1990). Making the library more user-friendly for gay and lesbian patrons. In Gough, C. \& Greenblatt, E. (Eds.), Gay and lesbian library service (p. 109-139). Jefferson, NC: McFarland.

Gough, C., \&. Greenblatt, E. (Eds.). (1990). Gay and lesbian library service. Jefferson, NC: McFarland.

Greenblatt, E., \& Gough, C. (1994). Gay and lesbian library users: Overcoming barriers to service. In Hill, K. H. (Ed.), Diversity and multiculturalism in libraries (p. 227-233). New York: JAI.

Greenblatt, G. (2001). Barriers to GLBT library service in the electronic age. Information for Social Change, Number 12. Retrieved July 15, 2005, from http://www.libr.org/ISC/articles/12-Greenblatt.html

Greene, B. (1994). Lesbian and gay male development: Steps toward an analysis of lesbians' and gay men's lives. In Greene. B., \& Herek, G. M. (Eds.), Psychological perspectives on lesbian and gay issues: Lesbian and gay psychology: Theory, research, and clinical applications (Vol. 1, pp. 118-132). Thousand Oaks, CA, US: SAGE.

Gross, L., \& Woods, J. D. (Eds.). (1999). The Columbia reader on lesbians and gay men in media, society, and politics. New York: Columbia University.

Hawkins, H. (1994). Opening the closet door: Public library services for gay, lesbian, \& bisexual teens.Colorado Libraries, 20(1), 28-31.

Herdt, G. (1989). Gay and lesbian youth.Journal of Homosexuality, 17(1-2), 1-42.

Herdt, G. (1992). Gay culture in America: Essays from the field. Boston: Beacon Press.

Herdt, G., \& Boxer, A. (1993). Children of horizons: How gay and lesbian teens are leading a new way out of the closet. Boston: Beacon.

Herek, G. M., Jobe, J. B., \& Carney, R. M. (1996).Out in force: Sexual orientation and the military. Chicago, IL: University of Chicago.

Hooker, E. (1965). Male homosexuals and their world. In Marmor, J. (Ed.), Sexual inversion: The multiple roots of homosexuality (pp. 83-107). New York: Basic Books.

Howrey, M. M. (2000). A case study of library/community agency coordination and bealth information partnering practices: The Teen CARE Network (Illinois). Unpublished doctoral dissertation, Northern Illinois University, Dekalb.

Human Rights Campaign Foundation (HRCF).(2004). Resource guide to coming out for gay, lesbian, bisexual and transgender Americans. Washington, D.C.: HRCF. Retrieved July 15, 2005, from http:/ $/$ www.hrc.org/Template.cfm?Section=Resources2\&Template $=/$ ContentManagement $/$ ContentDisplay.cfm\&ContentID $=22631$

Joyce, S. L. (2000). Lesbian, gay and bisexual library service: A review of the literature. Public Libraries, 39(5), 270-279.

Joyce, S. L. (2003). The discursive construction of lesbian, gay, and bisexual identity: How symbolic violence and information capital mediate the coming-out process. Unpublished doctoral dissertation, University of Western Ontario, London, ON. 
Joyce, S. L., \& Schrader, A. (1997). Hidden perceptions: Edmonton gay males and the Edmonton Public Library. Canadian Journal of Information and Library Science 22, 19-37.

Julien, H. E. (1999). Barriers to adolescents' information seeking for career decision making. Journal of the American Society for Information Science, 50(1), 38-48.

Kafai, Y., \& Bates, M. J. (1997). Internet web-searching instruction in the elementary classroom: Building a foundation for information literacy. School Library Media Quarterly, 25, 103-111.

Kaufman, G., \& Raphael, L. (1996).Coming out of shame: Transforming gay and lesbian lives. New York: Random House.

Kester, N. G. (1997). Liberating minds: The stories and professional lives of gay, lesbian and bisexual librarians and their advocates. Jefferson, NC: McFarland.

Kirsch, M. H. (2001). Queer theory and social change. London, UK: Routledge.

Kubler-Ross, E. (1993). On death and dying. New York: Collier Books.

LaBarbera, p. (1996). The gay youth suicide myth. Leadership U. Retrieved July 15, 2005, from http://www.leaderu.com/jhs/labarbera.html

LaSala, M. C. (2000). Lesbians, gay men, and their parents: Family therapy for the coming-out crisis. Family Process, 39(1), 67-81.

Laumann, E. O., Ellingson, S., Mahay, J., Paik, A., \& Youm, Y. (2004). The Sexual Organization of the City. Chicago, IL: University of Chicago.

Lee, J. A. (1977). Going public: A study in the sociology of homosexual liberation. Journal of Homosexuality, 3, 49-78.

Levin, D., \& Arafeh, S. (2002). The digital disconnect: The widening gap between Internet-savvy students and their schools. Pew Internet \& American Life Project Report. Retrieved May 9, 2004, from http://www.pewinternet.org/PPF/r/67/report_display.asp

MacDonald, G. B. (1983). Exploring sexual identity: Gay people and their families.Sex Education Coalition News, $5(1), 4$.

Machado, J., Lentz, B, \& Wallace, R. (2000). A survey of best practices in youth services around the country: A view from one library. Journal of Youth Services in Libraries, 13(2), 30-35.

Martin, D. (1982). Learning to hide: The socialization of the gay adolescent. Adolescent Psychiatry, 10, 52-65.

Maylon, A. (1982). Biphasic aspects of homosexual identity information. Psychotherapy: Theory, research, and practice, 19, 335-340.

McDowell, S. (2000). Library instruction for lesbian, gay, bisexual, and transgendered college students. In. Jacobson, T. E, \& Williams, H. C. (Eds), Teaching the new library to today's users: Reaching international, minority, senior citizens, gay/lesbian, first generation, at-risk, graduate and returning students, and distance learners (pp. 71-86). New York: Neal-Schuman. 
Mehra, B. (2005). A phase-model of the cross-cultural learning process of LIS international doctoral students: Characteristics and interventions. Proceedings of the American Society for Information Science \& Technology 2005 Annual Meeting: Sparking Synergies: Bringing Research and Practice Together@ASIST'05.

Minton, H., \& McDonald, G. (1984).Homosexual identity formation as a developmental process. Journal of Homosexuality, 9, 91-104.

Morris, J. F. (1997). Lesbian coming out as a multideimensional process. Journal of Homosexuality, $33(2), 1-22$.

Pascoe, p. (2004). Why the ugly rhetoric against gay marriage is familiar to this historian of miscegenation. History News Network. Retrieved July 15, 2005, from http://hnn.us/articles/4708.html

Perrin, E. C., Cohen, K. M., Gold, M., Ryan, C., Savin-Williams, R. C., \& Schorzman, C. M. (2004). Gay and lesbian issues in pediatric health care. Current Problems in Pediatric Adolescent Health Care, 34(10), 355-398.

Rankin, S. R. (1999). Queering campus: Understanding and transforming climate. Metropolitan Universities: An International Forum, 9(4), 29-38.

Rivers, I. (1997). Violence against lesbian and gay youth and its impact. In Schneider, M. S. (Ed.), Pride \& prejudice: Working with lesbian, gay and bisexual youth, Toronto, ON: Central Toronto Youth Services.

Russell, S. T. (2003). Sexual minority youth and suicide risk. American Behavioral Scientist, 46(9), 1241-1257.

Savin-Williams, R. (1990). Gay and lesbian youth: Expressions of identity. New York: Hemisphere.

Scasta, D. (1998). Issues in helping people come out. Journal of the Gay \& Lesbian Psychotherapy, 2(4), 87-98.

Schwandt, T.A. (1994). Constructivist, interpretivist approaches in qualitative research. In Denzin, N., \&. Lincoln, Y. (Eds.), The handbook of qualitative research (pp. 118-137). Thousand Oaks: SAGE.

Sears, J. (1987). Peering into the well of loneliness: The responsibilities of educators to gay and lesbian youth. In Molnar, E. (Ed.), Social issues and education: Challenge and responsibility. East Lansing, MI: National Center for Research on Teacher Learning.

Sedgwick, E. K. (1990). Epistemiology of the closet. Berkeley, CA: University of California.

Seidel, K. (1998). The "Invisibles": Lesbian women as library users. Progressive Librarian, No.14, 34-40.

Shenton, A. K., \& Dixon, p. (2002).Youngsters' use of and attitudes to their school libraries. The School Librarian, 50(4), 176-178.

Spielberger, J., Horton, C., Michels, L., \& Halpren, R. (2004). New of the shelf: Teens in the library-Findings from the evaluation of public libraries as partners in youth development. Chicago, IL: Chapin Hall Center for Children, University of Chicago. 
Stenback, T. L., \& Schrader. A. M. (1999). Venturing from the closet: A qualitative study of the information needs of lesbians. Public Library Quarterly, 17(3), 37-50.

Strauss, A., and Corbin, J. (1994).Grounded theory methodology. In Denzin, N., and Lincoln, Y. (Eds.), The handbook of qualitative research (pp. 273-285). Thousand Oaks: Sage Publications.

Swigonski, M. E., Mama, R. S., \& Ward, K. (2001). From hate crimes to human rights: A tribute to Matthew Shepard. New York: Haworth Press.

Taraba, S. (1990).Collecting gay and lesbian materials in an academic library. In Gough, C., \& and Greenblatt, E. (Eds.), Gay and lesbian library service (pp. 25-37). Jefferson, NC: McFarland.

Temes, R. (1980). Living with an empty chair: A guide through grief, (2nd ed.). New York: Irvington.

Todd, R. J. (1999). Utilization of heroin information by adolescent girls in Australia: A cognitive analysis. Journal of the American Society for Information Science, 50(1), 10-23.

Troiden, R. R. (1979). Becoming homosexual: A model of homosexual identity acquisition. Psychiatry, 42, 363-373.

Uribe, V., \& Harbeck, K. M. (1992).Addressing the needs of lesbian, gay, and bisexual youth: The origins of Project 10 and school-based intervention. In. Harbeck, K. M. (Ed.), Coming out of the classroom closet: Gay and lesbian students, teachers and curricula. New York: Haworth.

Utter, G. H., \& True, T. L. (2004). Conservative Christians and political participation: A reference handbook. Santa Barbara, CA: ABC-CLIO.

Waldner, L. K., \& Magruder, B. (1999).Coming out to parents: Perceived resources and identity expression as predictors of identity disclosure for gay and lesbian adolescents. Journal of Homosexuality, 37(2)83-100.

Walter, V. A. (2003). Public library service to children and teens: A research agenda. Library Trends, 51(4), 571-589.

Westheimer, R.K. (1995). Sex for dummies. Foster City, CA: IDG Books.

Whitman, J. S., Cormier, S., \& Boyd, C. J. (2000). Lesbian identity management at various stages of the coming out process: A qualitative study. International Journal of Sexuality and Gender Studies, $5(1), 3-18$.

Willett, H. G. (1995). Public library youth services. Westwood, CT: Greenwood.

Winston, M., \& Paone, K. L. (2001).Reference and information services for young adults. Reference \& User Services Quarterly, 41(1), 45-51.

8. Beiriger, Angie y Rose M. Jackson. (2007). An assessment of the information needs of transgender communities in Portland, Oregon. Public Library Quarterly , 26(1/2): 45-60.

Beiriger, A. and Jackson, R. (2006, April).Transgender health issues.MLA News, 16. 
Boon, M. and Howard, V. (2004). Recent lesbian/gay/bisexual/transgender fiction forteens: Are Canadian public libraries providing adequate collections? Collection Building, 23(3), 133-138.

Downey, J. (Summer, 2005). Public library collection development issues regarding the information needs of GLBT patrons. Progressive Librarian, 25, 86-95.

Garnar, M. (December, 2000). Changing times: Information destinations of the Lesbian, Gay, Bisexual, and Transgender community in Denver, Colorado.Information for Social Change.Retrieved January 14, 2006, from http://www.libr.org/ISC/articles/12-Garnar.html.

Greenblatt, E. (Winter, 2003). Lesbian, gay, bisexual, transgender library users: Overcoming the myths. Colorado Libraries, 29(4), 21-25.

The American Library Association. (1994, June 30). Access to Library Resources and Services Regardless of Sex, Gender Identity, or Sexual Orientation Policy.Retrieved March 13, 2006, from http://www.ala.org/Template.cfm?Section=interpretations\&Template=/ContentManagement $/$ Co ntentDisplay.cfm\&ContentID $=31878$.

The Gay, Lesbian, Bisexual, and Transgender Roundtable of the American Library Association. (2005). TRANScending Identities: A Bibliography of Resources on Transgender and Intersex Topics. Retrieved November 13, 2005, from http://isd.usc.edu/ trimmer/glbtrt/biblist.htm.

The Gay, Lesbian, Bisexual, Transgender Wellness Project of Ottawa-Carlton Survey.(n.d.). Retrieved August 18, 2005, from http://www.pinktriangle.org/wellness/survey.pdf.

The LGBT Health Channel. (2005, February 08). Transgender Health. Retrieved October15, 2005, from http://www.gayhealthchannel.com/transgender/index.shtml.

U.S. Census Bureau. (2006, January 12). Oregon Quick Facts. Retrieved January 14, 2006, from http://quickfacts.census.gov/qfd/states/41000

Witeck-Combs Communications and Harris Interactive. (2001, February 20). Gay and Lesbian ECommerce Activity Beats That of Non-Gay Web Users. Retrieved January 30, 2006, from http://www.harrisinteractive.com/news/allnewsbydate.asp?NewsID=236.

\section{Hart, Genevieve y Ncumisa Mfazo. (2010). Places for all? Cape Town's public library services to gays and lesbians. South African Journal of Libraries \& Information Science, 76(2): 98-108.}

Boon, H \& Howard, V. 2004. Recent lesbian/gay/bisexual/transgender fiction for teens: are Canadian public libraries providing adequate collections? Collection Building, 23(3): 133-1 38.

Carrlgan, DP 1995. Toward a theory of collection development. Ubrary Aequisitions Practice and Theory, 19( I ): 97-106.

City of Cape Town Library and Information Services Task Team on Staffing Standards. 2006. Report on interim staffing standards. February 2006. Unpublished report. Cape Town: COCTLIS.

Clyde, LA \& Lobban, M. 2001. A door half open: young people's access to fiction related to homosexuality. Sehool Ubraries Worldwide, 7(2): 17-80. 
Curry, A. 2000. Collection management of gay/ lesbian materials in the U.K. and Canada. Ubri, 50(1): 14-25.

Curry, A. 2005. If I ask, will they answer? Evaluating public library reference service to gay and lesbian youth. Referenee and User Services Quarterly, 45(2): 65-74.

Department: Public Service and Administration Republic of South Africa, nd. Batho Pele: together beating the drum for servicedelivery. [Online].http://www.dpsa.gov.za/batho-pele/Principtes.asp(Accessed 16 September 2010).

Farrelly, MG. 2007.More on serving gay youth. Pub//c Ubraries, May/June: 38-39.

Garnar, M. 2000. Changing times: information destinations of the lesbian, gay, bisexual, and transgender community in Denver, Colorado. Information for Social Change, 12:9-14.

Gold Coast Convention \& Exhibition Centre, Queensland, Australia.[Online], http://conferences.alio.org.au/alia2004/pdfs/moody.k.paper.pdf (Accessed 31 June 2009).

Goldthorp, J 2006. The social inclusion of lesbians as borrowers from Scottish Public Libraries, explored through the visibility of lesbian fiction. M.Sc.Dissertation. Robert Gordon University, Aberdeen.

Gough, C \& Greenblatt, E. 1992. Services to gay and lesbian patrons: examining the myths. Library Journal, I 17( I ):59-63.

Hamer, J S. 2003. Coming-out: gay males' information seeking. Sehoot Ubraries Wortdwide, 9(2): 73-89.

Hart, G. 1999. Ready for the information society?A study of Cape Town's children's librarians. New Review of Chitaren's Uterature and Ubrarianship, 5: 169-188.

IFLA/UNESCO public library manifesto.2004. [Online]. http://www.ifla.org/Vil/s8/uneswco/eng.htm . (Accessed 31 May 2008).

International Gay and Lesbian Human Rights Commission. 2007. What we do and why. [Online], http://www.iglhre.org/site/iglhre/ section.php?id=25. (Accessed 2 April 2008).

Joyce, SL. \& Schrader, AM. 1997. Hidden perceptions: Edmonton gay males and the Edmonton public library. Canadian journal of Information and Library Science, 22: 19-37.

Kingston, M. 1998. The information needs of LGBT college students. Journo/ of Librarianship, 35: 141-152.

LGBT literature: chronological survey. 2007. [Online], http://iclarkmedia.com/garbooks/chronologiealsun/ev.html (Accessed 20 May 2008).

Loverich, P \& Darrah, D. 1999. Out on the shelves? Not really library journal, 124 (11): 55.

Martin, A, Kelly, A, Turquet, L \& Ross, S. 2009. Hate crimes: the rise of "corrective" rape in South Africa. London: Action Aid. [Online], www.actionaid.org.uk(Accessed 13 September 2010). 
Mehra, B. \& Braquet, D. 2006. A "queer" manifesto of interventions for libraries to "come out" of the closet: a study of "queer" youth experiences during the out process. Library and Information Science Research Electronic journal, 16(1): I -29.

Moody, K. 2004. Opinions and experiences of Queensland-based public librarians with regard to censorship of materials in public library collection: an exploratory analysis. In: ALIA 2004 Biennial Conference: Challenging Ideas, 21-24 September 2004,

Norman, M. 1999. Out on loan: survey of the use and information of users of the lesbian, gay and bisexual collection of Brighton and Hove Libraries. Information Retrieval and Ubrary Automation, 31 (4): 188-196.

Reitz, JM. 2004. Dictionary for library and information science. New York: Greenwood Publishing.

Ritchie, CJ. 2006. Collection development of gay/ lesbian/bisexual related adult non fiction in medium-sized Illinois public libraries. Illinois Libraries, 83(2): 53-70.

Rothbauer, P \& McKechnie, L. 1999. Gay and lesbian fiction for young adults: a survey of holdings in Canadian public libraries. Collection Building, 18(1): 32-39.

Rothbauer, P \& McKechnie, L. 2000. The treatment of gay and lesbian fiction for young adults in selected prominent reviewing media. Collection Building, 19:5-16.

Sachs, A. 2010.The strange alchemy of life and law. Oxford: Oxford University Press.

Schrader, A \& Wells, K. 2005. Queer perspective on social responsibility in Canadian schools and libraries: analysis and resources. Canadian journal, 24(4): 1-50.

South Africa. 1996. Constitution of the Republic of South Africa. 1996. Act 108 of 1996. Cape Town: Constitution Assembly.

Stenback, TL \& Schrader, AM. 1999. Venturing from the closet: qualitative study of the information needs of lesbians. Public Library Quarterly, 17(3): 37-50.

The Public library service: guidelines for development. 2001. München: IFLA/Saur

The Public Library service: IFLA/ UNESCO guidelines for development. 2001. München: K.G. Saur

Vincent, J. 1999. Lesbian, bisexual, gay men and transgendered people. Leeds: Leeds Metropolitan University.

Whitt, AJ. 1993. The information needs of lesbians. Ubrary and Information Science Research, 15: 275-288.

10. Schaller, Susann. (2011). Information needs of LGBTQ college students. Libri: International Journal of Libraries \& Information Services, 61(2): 100-115.

Buschman, J. 2007. The Library as Place: History, Community, and Culture. Westport Conn.: Libraries Unlimited. 
Garnar, M. 2000. Changing Times: Information Destinations of the Lesbian, Gay, Bisexual, and Transgender Community in Denver, Colorado. Information for Social Change Journal.Accessed May 23, 2010.http://libr.org/isc/articles/12-Garnar.html

Gates, G. 2004. The Gay \& Lesbian Atlas. Washington D.C.: Urban Institute Press.

Gough, C. 1990. Gay and Lesbian Library Service. Jefferson N.C.: McFarland.

Gough, C., and E. Greenblatt. 1992. Services to Gay and Lesbian Patrons: Examining the Myths" Library Journal 117 (1): 59-63.

Hawley, J.C., ed. 2009. LGBTQ America Today: An Encyclopedia. Westport Conn.: Greenwood Press.

McDowell, S. 2000. Library Instruction for Lesbian, Gay, Bisexual, and Transgendered College Students. In Teaching The New Library Top Today's Users, edited by T.E. Jacobson, 71-86. New York: Neil-Schuman Publishers

Morrow, D. 2006. Sexual Orientation and Gender Identity Expression. In Sexual Orientation and Gender Expression in Social Work Practice: Working with Gay, Lesbian, Bisexual, and Transgender People, edited by D. Morrow, 3-17. New York: Columbia University Press.

Rothbauer, p. 2007. Locating the Library as Place among Lesbian, Gay, Bisexual, and Queer Patrons. In The Library as Place, edited by J. Buschman, 101-115. Westport Conn.: Libraries Unlimited.

Student Health Services at the University of North Carolina, Greensboro. [n.d.]. Safe Zone: Jackson Library. Accessed September 25, 2009.http://www.uncg.edu/shs/wellness/safezone/library/

Taraba, S. 1990. Collecting Gay and Lesbian Materials in an Academic Library. In Gay and Lesbian Library Service, edited by C. Gough, 25-37. Jefferson N.C.: McFarland.

Taylor, J. K. 2004. Targeting the Information Needs of Transgender Individuals. Unpublished student paper, Department of Library and Information Sciences, University of North Carolina at Greensboro.

Taylor, R. S. 1991. Information Use Environments. In Progress in Communication Sciences, edited by B. Derwin, 217-255. Norwood, NJ: Ablex.

Williamson, K. 2006. Research in Constructivist Frameworks Using Ethnographic Techniques. Library Trends 55(1): 83-101.

Windmeyer, S. 2006. The Advocate College Guide for LGBT Students: A Comprehensive Guide to Colleges and Universities with the Best Programs, Services, and Student Organizations for LGBT Students. New York: Alyson Books. 


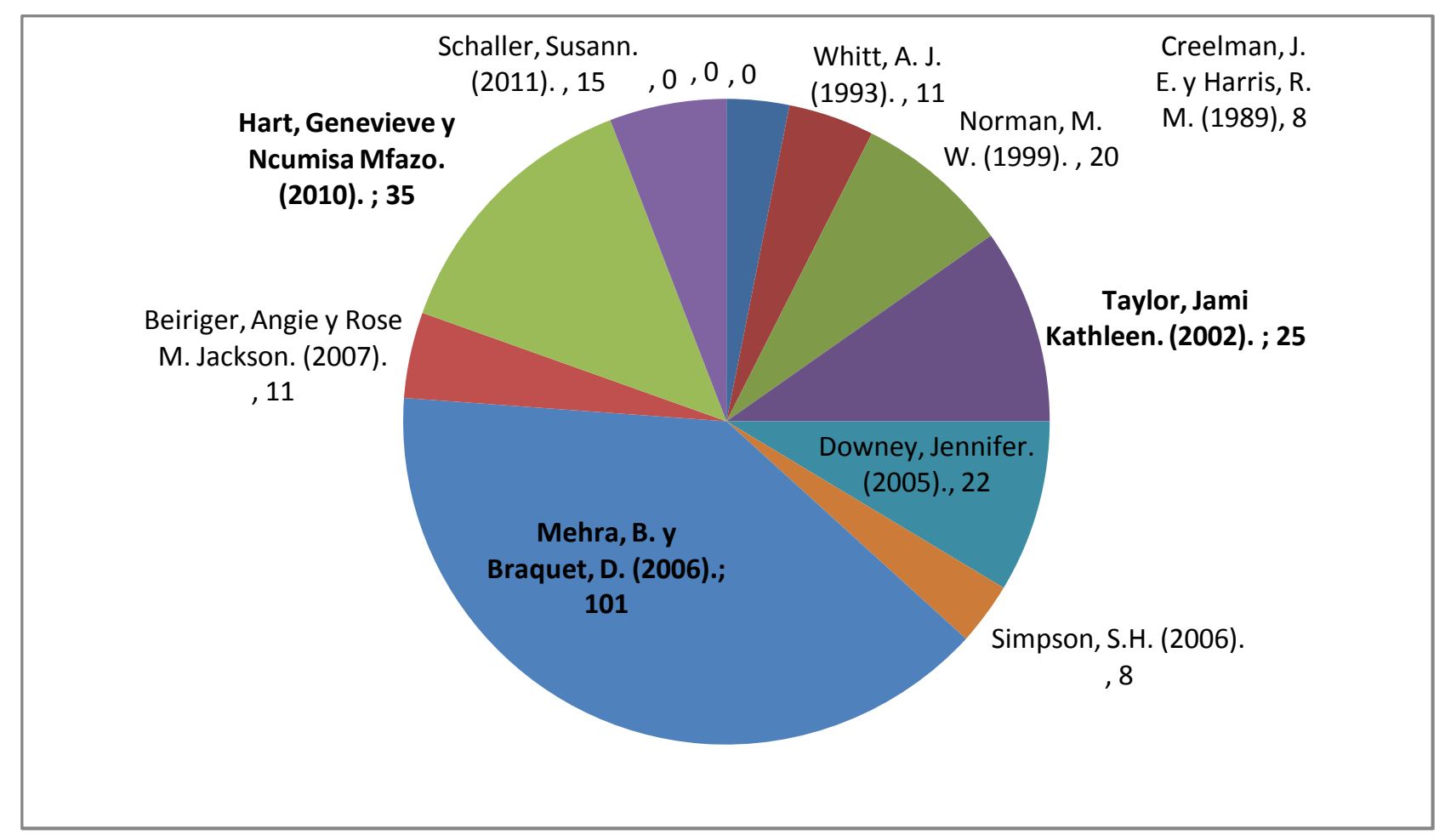

Gráfico 1. Cantidad de referencias bibliográficas por documentos relevados

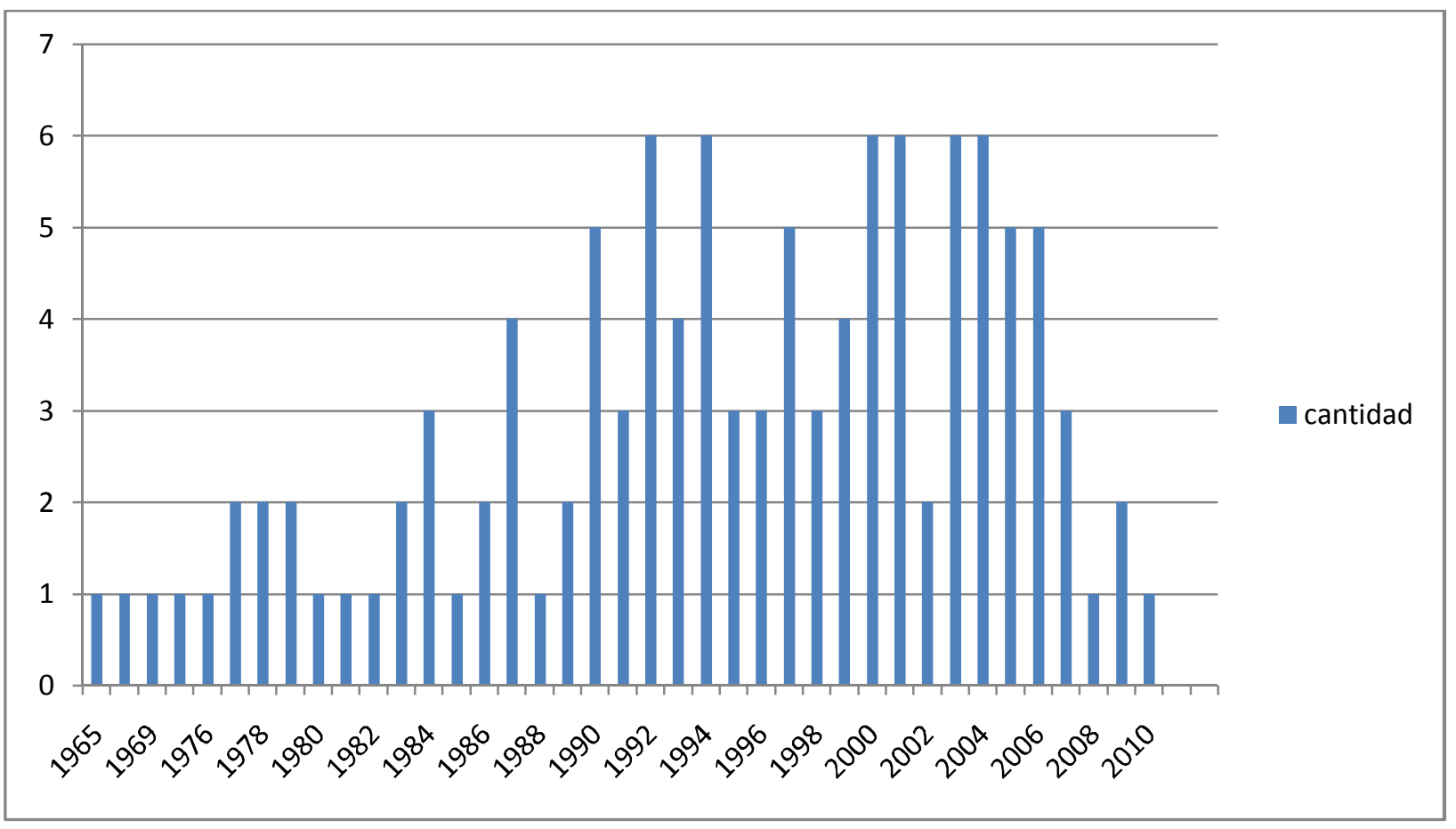

Gráfico 2.Cantidad de referencias bibliográficas por año de los documentos 
Tabla 8

Cantidad de referencias bibliográficas por año

\begin{tabular}{|c|c|}
\hline Año & $\begin{array}{c}\text { Cantidad } \\
\text { RB }\end{array}$ \\
\hline 1965 & 1 \\
\hline 1967 & 1 \\
\hline 1969 & 1 \\
\hline 1971 & 1 \\
\hline 1976 & 1 \\
\hline 1977 & 2 \\
\hline 1978 & 2 \\
\hline 1979 & 2 \\
\hline 1980 & 1 \\
\hline 1981 & 1 \\
\hline 1982 & 1 \\
\hline 1983 & 2 \\
\hline 1984 & 3 \\
\hline 1985 & 1 \\
\hline 1986 & 2 \\
\hline 1987 & 4 \\
\hline 1988 & 1 \\
\hline 1989 & 2 \\
\hline 1990 & 5 \\
\hline 1991 & 3 \\
\hline 1992 & 6 \\
\hline 1993 & 4 \\
\hline 1994 & 6 \\
\hline 1995 & 3 \\
\hline 1996 & 3 \\
\hline 1997 & 5 \\
\hline 1998 & 3 \\
\hline 1999 & 4 \\
\hline 2000 & 6 \\
\hline 2001 & 6 \\
\hline 2002 & 2 \\
\hline 2003 & 6 \\
\hline 2004 & 6 \\
\hline 2005 & 5 \\
\hline 2006 & 5 \\
\hline 2007 & 3 \\
\hline 2008 & 1 \\
\hline 2009 & 2 \\
\hline 2010 & 1 \\
\hline
\end{tabular}




\section{american-library-association \\ dervin-b \\ -no gough-c greenblatt-e - joyce-s s schrader-a.}

Figura 12. Nube de palabras: Diez autores, personales e institucionales, más representativos en las referencias bibliográfica de los documentos relevados 


\section{COROLARIO, RECOMENDACIONES Y CONCLUSIONES}

A partir de lo analizado se pueden establecer los siguientes puntos:

\subsection{Corolario}

\section{Desde lo cualitativo:}

El primer estudio realizado sobre NI en la comunidad GLTTIBQ es el de Creelman y Harris (1989) sobre mujeres lesbianas, y representa el primer intento de forma sistemática de evaluar las necesidades de información de una población no estudiada y desantentida (p. 37). Sobre bisexuales se encuentra el de Norman (1999) en el cual las NI están muy relacionadas con el uso de la colección. Respecto de la población transexual, el estudio de Taylor (2002) concluye que dicha población usa más la web para canalizar sus NI. Mehra y Braquet (2006) se ocupa de la juventud Queer y propone una acción concreta, a través de un Manifiesto con el objeto de diseñar servicios y políticas inclusivas para esa comunidad. Resulta relevante destacar y tener en cuenta estas primeras investigaciones como antecedentes de la producción bibliográfica y para servicios bibliotecarios que se realicen en el futuro.

Todos los estudios vienen de países de habla inglesa y los principales son producidos en EEUU (Whitt, 1993; Taylor, 2002; Downey, 2005; Simpson, 2006; Mehra y Braquet, 2006; Beiriger, 2007, Schaller, 2011), Canadá (Creelman y Harris, 1989), Reino Unido (Norman, 1999) y Sudáfrica (Hart y Ncumiza, 2010).

Los métodos más usados para el relevamiento de NI fueron el cuestionario (Whitt, 1993; Norman, 1999; Taylor, 2002, Beiriger, 2007 y Hart y Ncumiza, 2010), la entrevista (Mehra y Braquet, 2006), el grupo focal (Schaller, 2011),el abordaje teórico(Downey, 2005), las experiencias prácticas (Simpson, 2006) y el muestreo de bola de nieve (Creelman y Harris, 1989).

En el análisis realizado se encontraron dos tipos de estudios: 
- El que aborda el estudio de los usuarios y sus NI en relación a la satisfacción con los servicios de la biblioteca y otro sobre

- Prácticas, abordajes y servicios de bibliotecas públicas en la comunidad GLTTIBQ. En este último se observan, principalmente, criterios y actitudes relacionados sobre el tema de 'Desarrollo de la Colección' (Creelman y Harris, 1989; Norman, 1999; Downey, 2005; Hart y Mfazo, 2010), relacionado al mismo colectivo. En este tipo de grupo se examina principalmente el tema de la 'selección' de materiales en un intento de explorar las percepciones de sus servicios.

Si bien ningún estudio cubre las NI en adultos mayores o relacionados a la salud de dicha comunidad, si se abarcan en jóvenes (Mehra y Braquet, 2006) y universitarios/as (Schaller, 2011).

El compromiso percibido desde la actitud profesional, social, ético y profesional lo establecen los artículos de Progressive Librarian. Al respecto, Downey (2005) se interesa en sucesos de "censura interna", catalogaciones erróneas, que provocan que los documentos se tornen invisibles, como así también la ubicación controversial que se manifiesta al colocar el material en áreas poco accesibles. El autor sugiere a los profesionales que consulten fuentes alternativas de información (Alternative Press Index) para el Desarrollo de la Colección. Asimismo, Simpson (2006) hace hincapié en el compromiso que el profesional bibliotecario debe tener para respetar la Declaración de Derechos del documento de ALA, el cual establece que no deben excluirse materiales por el origen, antecedentes e ideología de sus autores.

\section{Desde lo Cuantitativo:}

Desde la literatura citada

Todos los estudios vienen de países de habla inglesa y los principales son de EEUU (7), Canadá (1), Reino Unido (1), Sudáfrica (1). Completando 10 en total. 
Los métodos más usados para el relevamiento de NI fueron el del cuestionario (5), la entrevista (1), el grupo focal (1), el abordaje teórico (1), las experiencias prácticas (1) y el muestreo de bola de nieve (1).Suman 10 en total.

Desde la literatura citante

En los 10 documentos analizados, se citarón 256 referencias bibliográficas en total, que representan 20 años (1965 a 2010).

El documento que contenía más referencias bibliográficas es el de Mehra y Braquet (2006), con 101. Creelman y Harris (1989) y Simpson (2006) presentaron menor cantidad de referencias.

En el conjunto de citas los tres autores más referenciados fueron Greenblatt, E. (9), Gough, C (8) y Joyce, S (6).

\subsection{Recomendaciones}

El estado de la situación que plasman Hart y Mfazo (2010): la literatura internacional sugiere que se descuidan las necesidades de lectura, información e intereses de los gays y lesbianas, lamentablemente sigue en vigencia. Resulta imperioso que los profesionales reviertan esa situación a partir de plasmar experiencia por parte de bibliotecas y bibliotecarios, especialmente en español y desde las experiencias latinoamericanas.

En relación a lo cuantitativo de este estudio se recomienda a futuro profundizar la información que este relevamiento emana desde la óptica de lo cualitativo, y que no representa el objetivo de esta tesis, pues los datos son cuantificables pero no así su 
significación. Se recomienda analizar la relación de los contextos sociales emergentes en determinados períodos históricos que dieron origen a esa literatura, los autores bases que ayudan a conformar el marco teórico del tema GLTTIBQ dentro de la B/CI, la relación existentes entre las citaciones de los autores con su mapa de relación y las líneas temáticas emergentes, entre otros temas analizables.

\subsection{Conclusiones}

Los estudios sobre NI en la comunidad GLTTIBQ comienzan en la década del 80, pero esta investigación detalla la total ausencia de documentos producidos en lengua española por autores hispanos-latinoamericanos y sobre experiencias en bibliotecas representadas en la base de datos LISA.

Las bibliotecas deben constituir siempre un servicio público para el correcto ejercicio de la democracia. Al respecto, deben asegurar la igualdad de acceso a la lectura y a los recursos informativos para permitir el correcto ejercicio de la ciudadanía de todos los individuos, sin discriminación alguna para contribuir al progreso de la sociedad.

El profesional de la información no puede ni debe ignorar que se deben llevar a cabo, como servicios de las bibliotecas, acciones inequitativas para tratar de alcanzar la igualdad de los individuos y que dichas bibliotecas son y deberán ser portadoras de un conjunto de valores para la cohesión social.

Conocer las NI de la comunidad GLTTIBQ es lo primero que hay que plantear en todo servicio bibliotecario pues ellas constituyen la razón de ser de las bibliotecas. La construcción de servicios para dicho colectivo es tarea siguiente y comprende brindar una oferta de 
colección acorde a las necesidades estudiadas en espacios presenciales y virtuales inclusivos, favorecer los modos de comunicación/difusión de la información/conocimiento y generar prácticas inclusivas de estrategias de recepción y acercamiento de dicha comunidad a las bibliotecas. Se deberán llevar a cabo acciones concretas de ejecución obligatoria, para modificar la realidad vigente en muchas bibliotecas $\mathrm{y}$, especialmente, paliar la ceguera de las bibliotecas argentinas por la exclusión social de la comunidad GLTTIBQ (Díaz-Jatuf, 2015). 


\section{Anexo A}

Documentos recuperados de la base de datos LISA en texto completo y en referencia bibliográfica

Documentos recuperado

1 Schaller, Susann. (2013). Information needs of LGBTQ college students. Libri: International Journal of Libraries \& Information Services, 61(2): 100-115.

2 Hart, Genevieve y Ncumisa Mfazo. (2010). Places for all? Cape Town's public library services to gays and lesbians. South African Journal of Libraries \& Information Science, 76(2): 98-108. (aparece dos veces)

3 Beiriger, Angie y Rose M. Jackson. (2007), An assessment of the information needs of transgender communities in Portland, Oregon. Public Library Quarterly, 26(1/2): 45-60.

4 Mehra, B. y Braquet, D. (2006). A "Queer" manifesto of interventions for libraries to "come out" of the closet! A study of "queer" youth experiences during the Coming Out process. LIBRES: Library \& Information Science Research Electronic Journal, 16(1): 1-29.

5 Simpson, Stacy H. (2006) Why have a comprehensive \& representative collection? GLBT material selection and service in the public library. Progressive Librarian, 27: 44-51.

6 Downey, Jennifer. (2005). Public library collection development issues regarding the information needs of GLBT patrons. Progressive Librarian, 25: 86-95.

7 Taylor, Jami Kathleen. (2002) Targeting the information needs of transgender individuals. Current Studies in Librarianship, 26(1/2): 85-109.

\section{Texto completo}

Referencia bibliográfica

$\mathbf{x}$ 


\section{Anexo B}

Matriz para el relevamiento de los documentos recuperados

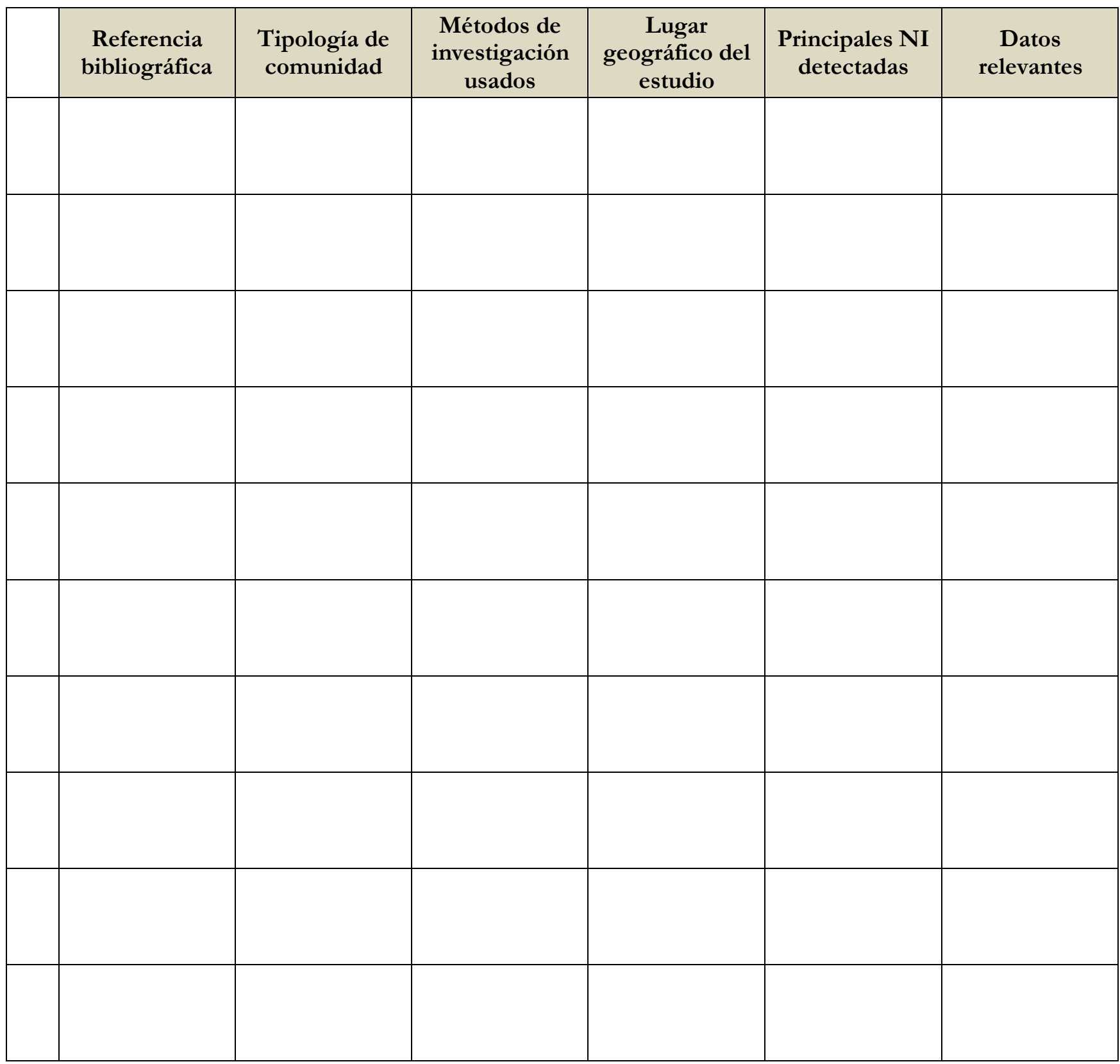




\section{Anexo C}

Estimación de NI en el curso "Recursos de información para la comunidad GLTTIBQ" (Universidad de Buenos Aires, Facultad de Filosofía y Letras, 28 de junio 2014)

Cuestionarios utilizados:

\section{USUARIOS}

1. A nivel personal ¿qué necesidades de información tiene?

2. ¿A dónde recurre para satisfacer esas necesidades?

3. ¿A recurrido a alguna biblioteca en Argentina para satisfacer esas necesidades?, en caso negativo explique el por que

4. ¿Cuáles son los temas o áreas de su interés?

\section{BIBLIOTECARIOS Y ESTUDIANTES DE BIBLIOTECOLOGÍA}

Tipo de biblioteca dónde se desempeña:

A. Su biblioteca ¿realiza estudios de usuarios en dónde se detallan las áreas de interés y temáticas de los mismos?

B. Dentro de su colección ¿posee material de interés para la comunidad GLTTIBQ?, en caso negativo explique el por que

C. Si es estudiante. En su proceso formativo ¿se le enseña Recursos Informativos para la comunidad GLTTIBQ?

D. ¿Cuáles son los temas o áreas de su interés? 


\section{INVESTIGADORES/DOCENTES}

1. Cuando debe abordar una investigación/proyecto/informe sobre la comunidad GLTTIBQ ¿cuáles son las fuentes que consulta que utiliza?

2. ¿Ha localizado los recursos informativos necesarios para sus investigaciones en alguna biblioteca Argentina?, en caso negativo, explique el por qué

3. ¿Cuáles son los temas o áreas de su interés personal?

\section{RESULTADOS}

Sobre 36 asistentes, se recibieron 29 resultados. Entre paréntesis, resultados numéricos:

La población que más estuvo representada en dicho curso, fueron los bibliotecarios (13) estudiantes de bibliotecología (10), investigadores/docentes (4) y usuarios (2)

- Los usuarios (2) poseen necesidades de información de nivel cultural, laboral, espiritual y de estudio. Recurren a Internet, libros de amigos y algunas bibliotecas. Sí, han recurrido a bibliotecas y las principales áreas de estudio son: cultura, arte, videoarte, estudios queer, cultura comunitaria, Bibliotecología, Biología y Teatro

Los investigadores (4) las fuentes que más consultan para los estudios de la comunidad GLTTIBQ, son: Internet (en primer lugar), recursos humanos, libros, blogs de docentes, páginas del GCBA, bibliotecas y buscadores académicos. No han localizado material en las bibliotecas por: no estar familiarizada con las búsquedas en biblioteca, no ha tenido que investigar, no hay bibliografía publicada en Argentina sobre temas específicos y por qué no localizan el material que necesitan.. Los temas de mayo interés son: familia, crianza, escuela, psicología, educación y género, teoría queer y género y libros de textos

- Los bibliotecarios (13). La mayoría NO realiza estudios de usuarios (11), en dos casos de bibliotecas públicas, sí lo realizan. La mayoría de las bibliotecas (8) no posee material de interés para la comunidad GLTTIBQ, acorde a lo que ellos detallaron:

\begin{tabular}{|l|l|l|}
\hline No & - & No recibimos material sobre el tema. La biblioteca es sobre patrimonio \\
& - & La selección del material la efectúa desde el departamento al que trabajo \\
& - & No, Nunca me han solicitado \\
& - & No, por la especialidad de la colección \\
& - & $\begin{array}{l}\text { El único tipo de material que se encuentra es en hemeroteca (sólo matrimonio } \\
\text { igualitario). Consulté con la directora de la institución y respondió que no }\end{array}$ \\
\hline
\end{tabular}




\begin{tabular}{|l|l|}
\hline hubo demandas, que en caso de haberla el material se compraría sin ningún \\
tipo de reparo. Como bibliotecaria, no tuve ningún tipo de solicitud ni \\
demanda al respecto. \\
En realidad, no sé cuál sería el material de interés para la comunidad \\
GLTTIBQ pero la respuesta anterior (contenidos curriculares) puede \\
extenderse a esta pregunta \\
- Considero que el material es de interés para aquel que lo quiera leer \\
(todo)(para todos) no tengo material específico sobre orientación sexual. \\
- \\
Dentro de la colección de la biblioteca no se posee material de interés \\
propiamente de la comunidad GLTTIBQ, como expliqué anteriormente, soy \\
relativamente nueva en el cargo, pero creo que no existe este tipo de material \\
por tratarse de una escuela religiosa. Sin embargo la razón por la que me \\
interesa el curso es por qué me gustaría saber dónde encontrar información de \\
interés para la comunidad GLTTIBQ, creo que es muy importante poder hacer \\
frente a las necesidades de información de los distintos tipos de usuarios. \\
\\
SI \\
-
\end{tabular}

Los estudiantes (10), no se les enseña 'Recursos de Información para la comunidad GLTTIBQ’ y los mayores temas de interés acorde a lo que describieron, son: "Historia, Autoayuda, Literatura infanto-juvenil, social (diversidad, inclusión), construcciones de género, estereotipos de géneros, identidad de género, profesiones, mercado laboral, Educación, Bibliotecología, Biología, Arte, Música, Turismo, Psicología, Bailes, Danzas españolas, Derechos de las personas y la diversidad sexual, Inclusión y acceso a la información, Protección de las trabajadoras sexuales, maltrato de género. Inserción a la comunidad de todas las personas, saber cómo satisfacer las demandas de información a la comunidad homosexual, Saber de términos de género que desconozco, Sociabilización, Comunicación, Integración de comunidades de todo tipo, Investigaciones sobre el tema, todo aquello que sirva para comunicarse y ayudar al entorno social en las bibliotecas, información relacionada con los niños, Historia de la homosexualidad, Sociología, Vinculación a la comunidad, Homosexualidad en adolescencia y pubertad, Discriminación en el ámbito laboral o de estudio, Maternidad-paternidad homosexual, Recursos en bases de datos académicas sobre Enfermedades de transmisión sexual en comunidades GLTTIBQ todo lo relacionado a la comunidad, Conservación preventiva, archivos históricos y archivo fotográfico, Recursos de información en diferentes áreas en relación con la comunidad." 


\section{BIBLIOGRAFÍA}

Dividida por áreas temáticas

\section{Metodología de la Investigación}

APA (American Phychological Association).(2010). Publication Manual of the American Phychological Association. (6 $6^{\text {th }}$ ed). Washington, DC: APA.

Barton, Alan H. y Lazarsfeld, Paul F. (1961). Some functions of qualitative analysis in social research. En Seymour M. Lipset y Neil. J. Smelser (Eds.) Sociology: The progress of a decade. Englewood Cliffs NJ: Prentice-Hall.

Beltrán, Oscar A. (2005). Revisiones sistemáticas de la literatura. Revista Colombiana de Gastroenterología, 20(1): 60-69. www.scielo.org.co/pdf/rcg/v20n1/v20n1a09.pdf [Consulta: febrero 2017]

González Teruel, A. y Barrios Cerrejón, M. (2012). Métodos y técnicas para la investigación del comportamiento informacional: fundamentos y nuevos desarrollos. Gijón: Trea.

Hernández Sampieri, R.; Fernández Collado, Carlos y Baptista Lucio, María del Pilar. (2010). Metodología de la Investigación. (5 ed.). México, DF: McGraw-Hill.

Sierra Bravo, R. (1988). Técnicas de Investigación Social: teoría y ejercicios. (5 $5^{\mathrm{a}}$ ed.) Madrid: Paraninfo.

Universidad de Buenos Aires. Facultad de Filosofía y Letras. (2014). Reglamento de Maestría. Resolución nº 562/14. UBA: FFyL.

Valles, Miguel S. (2007). Técnicas cualitativas de investigación social. Reflexión metodológica y práctica profesional. Madrid: Síntesis.

\section{Estudios Sexualidad y GLTTIBQ}

Bazán, Osvaldo. (2010). Historia de la homosexualidad en la Argentina: de la conquista de América al Siglo XXI. (ed. actualizada). Buenos Aires: Marea.

Bentham, Jeremy (2002). De los delitos contra uno mismo. Madrid: Biblioteca Nueva.

Berkins, Lohana y Josefina Fernández. (2005). La gesta del nombre propio: informe sobre la situación de la comunidad travesti en la Argentina. Buenos Aires: Madres de Plaza de Mayo.

Bogaert, A. F. (2004). Asexuality: prevalence and associated factors in a national probability sample. Journal of Sex Research, 41, 279-287. 
Boswell, John. (1980). Cristianismo, tolerancia y homosexualidad. Barcelona: Muchnik.

Butler, Judith (2001). El género en disputa. El feminismo y la subversión de la identidad. México: Paidós.

Butler, Judith (2002). Cuerpos que importan. Sobre los limites materiales y discursivos del sexo. Buenos Aires: Paidós.

Butler, Judith (2006). Deshacer el género. Barcelona: Paidós

CIDH (Comisión Interamericana de Derechos Humanos). (2015). Violencia contra Personas Lesbianas, Gays, Bisexuales, Trans e Intersex en América. Washington D.C., CIDH ww.oas.org/es/cidh/informes/pdfs/violenciaPersonaslgBti.pdf [Consulta: febrero 2017]

COGAM (Colectivo de lesbianas, gays, transexuales y bisexuales de Madrid). (20??). Glosario de conceptos sobre Diversidad Sexual: diversidad e inclusión. Madrid: COGAM www.cogam.es/.../glosario-de-conceptossobre-diversidad-afectivo-sexua [Consulta: febrero 2017]

Constitución de la Nación Argentina: publicación del Bicentenario. (2010). Buenos Aires: Corte Suprema de Justicia de la Nación / Biblioteca del Congreso de la Nación / Biblioteca Nacional. bibliotecadigital.csin.gov.ar/Constitucion-de-la-Nacion-Argentina-Publicacion-del-Bic[Consulta: febrero 2017]

Da Gris, Carlos A. (1965). El homosexual en la Argentina. Buenos Aires: Continental Service

De Beauvoir, Simone. (2012). El segundo sexo. Buenos Aires: Debolsillo.

Dover, Kenneth. J. (1980). Greek Homosexuality. Nueva York: Vintage Books.

Foucault, Michel. (1998). Historia de la sexualidad. La voluntad de saber. México, D. F.: Siglo XXI.

Fuskova, Ilse. (1994). Amor de mujeres: el lesbianismo en la Argentina hoy. Buenos Aires: Planeta.

Girard, Francoise. (2008). Negociando los derechos sexuales y la orientación sexual en la ONU. En Richard Parker, Rosalid Petchesky y Robert Sembrar (eds.). Politicas sobre sexualidad. Reportes desde las líneas del frente. (1 ${ }^{\mathrm{a}}$ ed.). México, D.F.: Sexuality Policy Watch, Fundación Arcoiris por el Respeto a la Diversidad Sexual y Grupo de Estudios sobre Sexualidad y Sociedad. (p. 347-398). www.sxpolitics.org/frontlines/espanol/book/pdf/sexpolitics.pdf [Consulta: febrero 2017]

Goldenweiser, Alexander. (1929). Sex and primitive society. En Sex in civilization. V. F. Calverton y S. D. Schmalhaunsen (Edit.) (p. 53-66).New York: Macaulay.

Guasch, Óscar. (1998). La sociedad rosa. Barcelona: Anagrama. 
Guasch, Óscar. (2000). La crisis de la heterosexualidad. Barcelona: Laertes.

Highleyman, Liz A. (2014). Brief history of the Bisexual Movement.[En línea]. Boston: Biresource. http://biresource.org/pamphlets/history.pdf [Consulta: febrero 2017].

Hobbes, Thomas. (2005). Leviatán, o de la materia, forma y poder de una república eclesiástica y civil. Buenos Aires: FCE.

Lamas, Marta. (2001). Ciudadanía y feminismo. México, DF: Instituto Federal Electoral.

Ley 25.673: Ley Nacional de Salud Sexual y Procreación Responsable (2002, 30 de octubre). Boletín Oficial de la República Argentina, Año CX, 30.032, noviembre 22, 2002. http://www.msal.gob.ar/saludsexual/lev.php [Consulta: febrero 2017].

Ley 26.061: Ley Nacional de Protección Integral de los Derechos de las Niñas, Niños y Adolescentes (2005, 28 de septiembre). Boletín Oficial de la República Argentina, Año CXIII, 30.767, octubre 26, 2005. http: $/ /$ www.senado.gov.ar $/$ web $/$ proyectos $/$ verExpe.php?origen $=C D \&$ tipo $=$ PL\&numexp $=65 / 04 \&$ enro comision $=\&$ tConsulta $=2$ [Consulta: febrero 2017].

Ley 26.150: Ley Nacional de Educación Sexual Integral (2006, 4 de octubre). Boletín Oficial de la República Argentina, Año CXIV, 30.017, octubre 26, 2006. www.me.gov.ar/me prog/esi/doc/lev26150.pdf [Consulta: febrero 2017].

Ley 26.485: Ley Nacional de Protección Integral a las Mujeres (2009, 11 de marzo). Boletín Oficial de la República Argentina, Año CXVII, 31.632, abril $1^{\circ}$, 2009. https://www.oas.org/dil/esp/Ley de Proteccion Integral de Muieres Argentina.pdf [Consulta: febrero 2017].

Ley 26.618: Ley de Matrimonio Igualitario. (2010, 15 de julio). Boletín Oficial de la República Argentina, Año CXII, 31.632, abril 14, 2009. www.saij.gob.ar/..ley...matrimonio...08.../123456789-0abc-defg160001fcanirtcod [Consulta: febrero 2017].

Ley 26.743: Identidad de Género (2012, 9 de mayo). Boletín Oficial de la República Argentina, Año CXX, 32.404, mayo, 24, 2012. www.tgeu.org/sites/default/files/ley 26743.pdf [Consulta: febrero 2017].

Lind, Amid y Sofia Argüello (2009). Ciudadanías y sexualidades en América Latina. Íconos: revista de Ciencias Sociales, 35: 13-18 http://revistas.flacsoandes.edu.ec/iconos/article/view/374/361 [Consulta: febrero 2017].

Llamas Muñoz, Ricardo. (1998). Teoría torcida. Prejuicios y discursos en torno a la "bomosexualidad". Madrid: Siglo XXI.

Martínez Estrada, Ezequiel. (1981). La cabeza de Goliat. Buenos Aires: CEAL. 
Martínez, Luciano. (2008). Transformaciones y renovación: los estudios lésbicos-gays y queer latinoamericanos. Revista Iberoamericana, 74(225): 861-876. $\quad$ htps://revistaiberoamericana.pitt.edu/ois/index.php/Iberoamericana/issue/view/194/showToc [Consulta: febrero 2017]

Meccia, Ernesto. (2003). Derechos molestos. Análisis de tres conjeturas sociológicas relativas a la incorporación de la problemática homosexual en la agenda política argentina. Revista Argentina de Sociología, 1(1): 59-76. http://www.redalyc.org/articulo.oa?id=26900105 [Consulta: febrero 2017]

Meccia, Ernesto. (2006). La cuestión gay. Un enfoque sociológico. Buenos Aires: Gran Aldea Editores.

Meccia, Ernesto. (2008). Siempre en agenda. La cuestión de los derechos sexuales en la programática del Estado argentino. Una perspectiva sociológica. Cuadernos de Estudios Latinomericanos, 6: 181-234. bdigital.ufp.pt/bitstream/10284/3025/3/181-234.pdf [Consulta: febrero 2017 ]

Meccia, Ernesto. (2008). La carrera moral de Tommy. Una historia de vida relativa a la transformación de la homosexualidad de colectividad a categoría social. En Pecheny, Mario (Comp.). Todo sexo es politico. Estudios sobre diversidad sexual en Argentina. Buenos Aires: Libros del Zorzal.

Meccia, Ernesto. (2010). Los peregrinos a la ley. Una tipología de discursos sobre expertos, jueces y legisladores en torno a las demandas LGTB y al matrimonio igualitario. En Clérico, Laura y Martín Aldao. Matrimonio igualitario. Perspectivas sociales, políticas y jurídicas. Buenos Aires: EUDEBA.

Meccia, Ernesto. (2013). Los últimos homosexuales. Sociología de la homosexualidady la gaycidad. Buenos Aires: Gran Aldea.

Mérida Jiménez, Rafael. (2002). Sexualidades transgresoras. Una antología de estudios queer. Barcelona: Icaria.

Miano Borruso, Marinella. (2003). Hombre, mijer y muxe en el Istmo de Tebuantepec. México, D.F.: Escuela Nacional de Antropología e Historia.

Phillips, Jason D. y Amanda N. Price. (2012). Selected List of GLBT Academic Publications. The Serials Librarian 63(1): 55-81.

Piotto, Alba. (2015, 8 de febrero). Argentina, la MecaTrans. Suplemento Clarin Viva, 34-37 http://www.clarin.com/viva/Revista Viva-trans-identidad de genero 0 1300070254.html[Consulta: febrero 2017] 
Principios de Yogyakarta sobre la aplicación de la legislación internacional de derechos humanos en relación con la orientación sexual y la identidad de género (2007). Yogyakarta. http://www.yogyakartaprinciples.org/principles sp.htm[Consulta: febrero 2017]

Rich, Adrienne. (1996). Heterosexualidad obligatoria y existencia lesbiana. DUODA: Revue $d^{\prime}$ Estudis Feministes, 10: 15-42. www.mpisano.cl/.../Heterosexualidad-obligatoria-y-existencia-lesbiana-Adrienne-Rich [Consulta: febrero 2017]

Rodríguez González, Félix. (2008). Diccionario gay - lésbico. Vocabulario general y argot de la homosexualidad. Madrid: Gredos.

Rousseau, Jean Jacques. (2004). El origen de la desigualdad entre los hombres. Madrid: Leviatán.

Sampedro, J.L. (2002). El mercado y la globalización. Barcelona: Ediciones Destino.

Weeks, Jeffrey. (1998). Sexualidad. México, D.F.: Paidós-Programa Universitario de Estudios de Género.

\section{Servicios de Información a la Comunidad y Diversidad Sexual}

Albright, Meagan. (2006). The public library's responsibilities to LGBT communities: recognizing, representing and serving. Public Libraries, 45(5): 52-56.

Berman, S. (1981).The Joy of Cataloging: Essays, Letters and Other Explosions. Oryx Press: Phoenix, AZ.

Betancour Betancour, Adriana. (1997). Biblioteca pública y democracia. Bogotá: Fundalectura.

Braquet, Donna y Bharat Mehra. (2007). Library and information science professionals as community action researchers in an academic setting: top ten directions to further institutional change for people of diverse sexual orientations and gender identities. Library Trends, 56(2): 542565.

Brett, Phil. (1992). Politics and public library provision for lesbians and gay men in London. International Journal of Information and Library Research, 4 (3), 195-211.

Bunch, Allan J (2001). Antecedentes históricos de los servicios de información a la comunidad. Revista Interamericana de Bibliotecología, 24(2): 25-44. http://aprendeenlinea.udea.edu.co/revistas/index.php/RIB/article/viewFile/3195/2962 [Consulta: febrero 2017]

Bunch, Allan J. (2001, septiembre). Servicio de información a la comunidad, Condado de Peterborough. Presentado en I Coloquio Latinoamericano y del Caribe de Servicios de Información a la 
Chu, Clara M. (2014). Investigación sobre necesidades y uso de la información en grupos multiculturales. En Tarango, Javier y otros (Editores). Educación y servicios bibliotecarios: conectando fronteras. Buenos Aires. Alfagrama.

CILIP (2004). Sexual orientation and libraries [En línea]. London: CILIp. http://www.cilip.org.uk/professionalguidance/equalopportunities/briefings/sexuality.htm[Consulta: febrero 2017]

Colomer Bartroli, Mercé. y M.E. Silleras. (1998, octubre). Tecnología y calidad al servicio del ciudadano: el Centro de Información Municipal. Presentado en FESABID 98, Valencia, España,http://www.ciepi.org/fesabid98/Comunicaciones/me silleras.htm[Consulta: febrero 2017]

Currant, S.E. (2002).In or Out? An examination of public library staff attitudes towards the provision and promotion of gay and lesbian materials in South Yorkshire (Tesis de Maestría).University of Sheffield, Reino Unido http://dagda.shef.ac.uk/dissertations/2001-02/Internal/Currant_Sarah_MScIM.pdf [Consulta: febrero 2017]

Díaz-Jatuf, Julio. (2012, octubre 3-5). Implementación del primer curso universitario sobre Bibliotecología Social en Argentina: promoviendo los recursos, concientizando los servicios. En IX Encuentro de Directores y VIII de Docentes de Escuelas de Bibliotecologia y Ciencia de la Información del MERCOSUR, Montevideo, Uruguay http://eprints.rclis.org/17796/ [Consulta: febrero 2017]

Díaz-Jatuf, Julio. (2014). LGBT Thought and Culture. De bibliotecas y bibliotecarios: Boletín electrónico ABGRA6(4). http://www.abgra.org.ar/newsletter/ABGRA-Boletin-2014 A6 N4 Jatuf.pdf [Consulta: febrero 2017]

Díaz-Jatuf, Julio. (2015). Crítica a la ceguera de las bibliotecas argentinas por la exclusión social de la comunidad GLTTIBQ (gay, lésbica, transexual, travesti, intersexual, bisexual, queer). Crítica Bibliotecológica: revista de las Ciencias de la Información Documental, 8(1): 65-71. https://sites.google.com/site/zapopanmuela/final librarianship critique journal vol 8 no 1 jan-jun 2015.pdf [Consulta: febrero 2017]

Díaz-Jatuf, Julio. (2015). Servicios de Información a la Comunidad (SIC) para la población GLTTIBQ (gay, lésbica, travesti, transexual, intersexual, bisexual, queer) en Argentina/Brasil: propuesta formativa en la Maestría en Bibliotecología y Ciencia de la Información en el marco MERCOSUR. De bibliotecas y bibliotecarios: Boletin electrónico ABGRA, 7(3). http://www.abgra.org.ar/newsletter/ABGRA-Boletin-2015-A7-N3-InfoComunitaria.pdf [Consulta: febrero 2017] 
Díaz-Jatuf, Julio. (2015, agosto). Videos musicales: Bibliotecología Social y comunidad GLTTIBQ (gay, lésbica, travesti, transexual, intersexual, bisexual, queer). En XI Jornadas de Material Didáctico y Experiencias Innovadoras en Educación Superior, Ciudad Autónoma de Buenos Aires, Argentina. http://eprints.rclis.org/25626/ [Consulta: febrero 2017]

Díaz-Jatuf, Julio Curso. (2016, agosto). Bibliotecología Social: de la teoría a la práctica: cinco años generando contenidos y prácticas en la enseñanza no convencional. En $12^{\mathrm{a}}$ Jornada de las Bibliotecas y Centros de Documentación de la Universidad de Buenos Aires, Ciudad Autónoma de Buenos Aires, Argentina http://eprints.rclis.org/29877/ [Consulta: febrero 2017]

Fairbrother, p. (1998). Information provision for gay user. Community Librarian, 20: 1-4.

Fikar, Charles R. y Latrina Keith. (2004). Information needs of gay, lesbian, bisexual, and transgendered health care professionals: results of an Internet survey. Journal of the Medical Library Association, 92(1): 56-65. http://www.ncbi.nlm.nih.gov/pmc/articles/PMC314103/ [Consulta: febrero 2017].

Fois, Silvia y Javier Gimeno Perelló, Javier. (2008, noviembre 5-7). Una aproximación a la Bibliotecología crítica, socio-política, progresista y alternativa. En IV Congreso Nacional de Bibliotecología, Documentación, Archivística y Museología, Potosí, Bolivia. https://googlegroups.com/group/biblioinfo-sociedad.../Ponencia.doc? [Consulta: febrero 2017]

GAY-LIBN: The Gay/Lesbian/Bisexual Librarians Network (11 Jan 2007). Re: introduction and request [En línea]. http://www-lib.usc.edu/ trimmer/gay-libn.html [Consulta: febrero 2017]

Glodoski, K. (1992) Controversy: "American Libraries" highlight GLBTF on cover of July/August issue http://libraryhistory.pbworks.com/w/page/16964638/Gav,\%20Lesbian,\%20Bisexual\%20Task\%20Force\%20(GLBTF) [Consulta: febrero 2017]

Goldthorp, J. (2006). The social inclusion of lesbians as borrowers from Scottish public libraries, explored through the visibility of lesbian fiction. (Tesis de Maestría). Robert Gordon University, Reino Unido.

Greenblatt, Ellen (2013). Serving LGBTIQ library and archives users: essays on outreach, service, collections and access. Jefferson, NC: McFarland.

Greenblatt, E.; Gough, C., (Eds.)(1990). Gay and Lesbian Library Service. McFarland \& Company, Inc.: Jefferson, NC.

Healy, E. (1998). Untitled letter. Community Librarian, 21: 16. 
Library Association.(1996).Sexual orientation and libraries.London: Library Association.

Martín Vega, Arturo. (1998, octubre). El servicio de referencia comunitaria. Presentado en FESABID 98, Valencia, España.

Mejía, M. (1991). Lineamientos sobre la biblioteca pública como centro de desarrollo cultural comunitario. Bogotá: CERLAC.

Melo, Adrián. (2013). Historia de la literatura gay en Argentina: representaciones sociales de la homosexualidad masculina en la ficción literaria. Buenos Aires: Lea.

Merlo Vega, J.A. y Merlo Vega, M.J. (1998, octubre).Servicios de información en línea para el desarrollo local. Presentado en FESABID 98, Valencia, Españahth://gredos.usal.es/jspuil bitstream/10366/18014/1/DBD Servs.\%20inf.\%20local.pdff [Consulta: febrero 2017].

Morales Campos, Estela. (2001, septiembre). Los servicios de información en las políticas públicas. Presentado en I Coloquio Latinoamericano y del Caribe de Servicios de Información a la Comunidad, Medellín, Colombia.

Naidoo, Jamie Campbell. (2012). Rainbow family collections: selecting and using children's books with lesbian, gay, bisexual, transgender, and queer content. Santa Barbara: Libraries Unlimited.

Reverz, B. (2001, septiembre). Políticas de información, bibliotecas públicas y desarrollo local y regional. Presentado en I Coloquio Latinoamericano y del Caribe de Servicios de Información a la Comunidad, Medellín, Colombia.

Sabelli, Martha. (2003). La enseñanza universitaria y su extensión en comunidades de frontera: un proyecto dirigido a promover políticas sociales para el ciudadano como usuario de la información y la lectura. Transinformação, 15(2):119-133. http://www.scielo.br/scielo.php?script=sci arttext\&pid=\$010337862003000200002 [Consulta: febrero 2017].

Sabelli, Martha. (2008). La información y el ciudadano en el entorno de la Sociedad de la Información: percepción de los actores politicos y sociales en el Uruguay. Montevideo: Ediciones de la Banda Oriental.

Sabelli, Martha. (2013). Los servicios de información para las comunidades locales en situación desfavorable: las políticas de información y el rol de los actores políticos y sociales(p. 90-114) [Libro electrónico]. En Castellón, Alina Cuadrado (coord.) Gestión de información y conocimiento: herramientas para el desarrollo local y comunitario. Cáceres: Fundación Ciencias de la Documentación. 
Saugy de Babini, Dominique. (1982). Política nacional de información. Buenos Aires (Tesis de Doctorado) Universidad de El Salvador, Buenos Aires, Argentina.

Seidel, H. (1998). The 'Invisibles': lesbian women as library users. Progressive Librarian, 14(spring). http://www.libr.org/PL/14 Seidel.html [Consulta: febrero 2017].

Shera, Jesse. (1990). Los fundamentos de la educación bibliotecológica. México: UNAM.CUIB.

Soto, Susana. (1992). Information in dentistry: patterns of communication and use. (Tesis de Doctorado) University of Sheffield, Reino Unido. http://etheses.whiterose.ac.uk/2955/1/DX184702.pdf [Consulta: febrero 2017].

Tarango, Javier y otros (Editores) (2014). Educación y servicios bibliotecarios: conectando fronteras. Buenos Aires. Alfagrama.

\section{Los Estudios de Usuarios y el Comportamiento Informativo: las Necesidades de Información}

Beiriger, Angie y Rose M. Jackson. (2007). An assessment of the information needs of transgender communities in Portland, Oregon. Public Library Quarterly, 26(1): 45-54.

Belkin, Nicholas J. (1978). Information concepts for information science.Journal of Documentation, 34(1): 55-85

Belkin, Nicholas J. (1980). Anomalous states of knowledge as a bases for information retrieval. Canadian Journal of Information Science. 5: 133-143.

Bettiol, Eugenia Maranhão. (1990). Necessidades de informação: uma revisão. Revista da Biblioteconomia da Brasilia, 18(1): 59-69. http://bogliolo.eci.ufmg.br/downloads/BETTIOL.pdf [Consulta: febrero 2017]

Calva González, Juan José. (2004). Las necesidades de información: fundamentos teóricos y métodos. México, DF: UNAM. CUIB. 132.248.242.6/ publica/ conmutarl.php?arch=1 $\mho i d x=162$ [Consulta: febrero 2017]

Cirigliano, Gustavo FJ. (1971). La conducta informativa en universitarios argentinos: investigación sobre la habilidad y capacidad de los jóvenes graduados universitarios para manejar y utilizar las fuentes de información bibliográficas. Buenos Aires: Centro de Investigaciones Bibliotecológicas, Facultad de Filosofía y Letras, Universidad de Buenos Aires. Como continuación da esta investigación se desarrolló otro 
proyecto: Investigación sobre la capacidad de los estudiantes avanzados de las universidades estatales argentinas para la investigación bibliográfica, cuyos datos y conclusiones permanecen inéditos y depositados en el Instituto de Investigaciones Bibliotecológicas (Facultad de Filosofía y Letras, UBA). (Romanos de Tiratel, 2000)

Creelman, J.A.E. y Harris, R.M. (1990). Coming out: the information needs of lesbians. Collection Building, 10(3/4): 37-41.

Dervin, Brenda y Michael Nilan. (1986). Information needs and uses. Annual Review of Information Science and Technology, 21: 3-33.

Díaz-Jatuf, Julio y Fernández, Ezequiel. (2012, agosto). Aproximación a las necesidades de información en estudiantes de la carrera de Asistentes Dentales de la Facultad de Odontología de la Universidad de Buenos Aires durante 2013. En $8^{a}$ JUBA: Jornadas de Bibliotecas y Centros de Documentación de la Universidad de Buenos Aires, Ciudad Autónoma de Buenos Aires, Argentina. http://eprints.rclis.org/17490/1/Eze.pdf [Consulta: febrero 2017]

Díaz-Jatuf, Julio y Fernández, Ezequiel. (2013, agosto). Necesidades de información en estudiantes del curso universitario de Asistentes Dentales de la Facultad de Odontología de la Universidad de Buenos Aires: abordaje comparativo 2013-2012. En 9a JUBA: Jornadas de Bibliotecas y Centros de Documentación de la Universidad de Buenos Aires, Ciudad Autónoma de Buenos Aires, Argentina. http://eprints.rclis.org/19938/1/AOO-I.pdf [Consulta: febrero 2017]

Díaz-Jatuf, Julio y Panzer, Samanta. (2014, agosto). Uso didáctico del cuestionario para detectar necesidades de información en alumnos/usuarios de pregrado de la Biblioteca "Prof. Dr. José Arce" de la Facultad de Odontología de la Universidad de Buenos Aires. En X Jornadas de Material Didáctico y Experiencias Innovadoras en Educación Superior, Ciudad Autónoma de Buenos Aires, Argentina. http://eprints.rclis.org/23596/1/Necesidades.pdf [Consulta: febrero 2017]

Díaz-Jatuf, Julio y Sergi, Andrea. (2014, septiembre). Seguimiento de las necesidades de información en estudiantes del curso universitario de Asistentes Dentales de la Facultad de Odontología de la Universidad de Buenos Aires durante el período 2013-2013. En $10^{a}$ JUBA: Jornadas de Bibliotecas y Centros de Documentación de la Universidad de Buenos Aires, Ciudad Autónoma de Buenos Aires, Argentina. http://eprints.rclis.org/23698/1/JUBAJDJ.pdf [Consulta: febrero 2017]

Díaz-Jatuf, Julio. (2015, noviembre). Aportes de la Cátedra Libre Bibliotecología Social sobre necesidades y servicios de información para la comunidad GLTTIBQ (gay, lésbico, travesti, 
transexual, intersexual, bisexual, queer). En VII Encuentro Ibérico EDICIC 2015, Madrid, España http://edicic2015.org.es/ucmdocs/actas/art/68-Diaz CaLiBiSo.pdf [Consulta: febrero 2017]

Díaz-Jatuf, Julio, Humana, Silvia y Araníbar, Blanca. (2016, abril). Necesidades de información en mujeres de Tilcara, Jujuy, Argentina: abordaje socio-demográfico. En $48^{\circ}$ Reunión Nacional de Bibliotecarios, Ciudad Autónoma de Buenos Aires, Argentina http://eprints.rclis.org/29209/[Consulta: febrero 2017]

Durrance, Joan C. (1984). Armed for action: library response to citizen information needs. Nueva York: Neal-Schuman.

Durrance, Joan C. (1989). Information needs: old song, new tune. School Library Media Quaterly, 17(3): 126-130.

Fernández, Ezequiel y Díaz-Jatuf, Julio. (2013, octubre). Proyecto de estudio de necesidades de información en la Hemeroteca de la Biblioteca "Prof. Dr. José Arce" de la Facultad de Odontología - Universidad de Buenos Aires. En $1^{a}$ Jornadas Virtuales Iberoamericanas de Ciencias de la Información y la Documentación, Ciudad Autónoma de Buenos Aires, Argentina. http://eprints.rclis.org/16243/1/2.pdf[Consulta: febrero 2017]

Figueiredo, Nice Menezes de. (1983). Aspectos especiais de estudos de usuários. Ciência da Informação, 72(2): 43-57. http://ridi.bict.br/bitstream/123456789/390/1/NICECI1983.pdf[CConsulta: febrero 2017]

Figuereido, Nice Menezes de. (1994). Estudos de uso e usuários da informação. Brasilia, DF: IBICT. Iivroaberto.ibict.br/.../Estudos\%20de\%20uso\%20e\% [Consulta: febrero 2017].

González Teruel, Aurora. (2005). Los estudios de necesidades y usos de la información: fundamentos y perspectivas actuales. Valencia: Universidad de Valencia

Hernández Salazar, Patricia (coord.) (1997). Seminario latinoamericano sobre formación de usuarios de la información $y$ los estudios de usuarios: memorias. México: UNAM

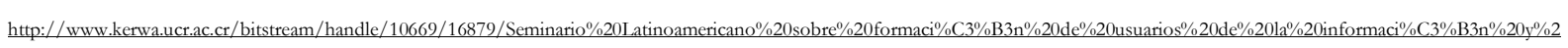

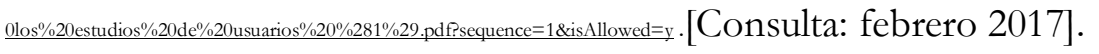

Hewins, Elizabeth T. (1990). Information needs and use studies. Annual Review of Information Science and Technology, 25: 145-172.

Keilty, Patrick. (2009). Lesbian, Gay, Bisexual and Transgender information needs. Encyclopedia of Library and Information Science (3rd ed.): 3275-3280. 
Kingston, M.J. (1998). The information needs of GLBT college students.(Tesis de Maestría). University of Indiana, Estados Unidos. http://matthewkingston.com/libraryscience/503-paper.htm[Consulta: febrero 2017].

Kogotkov, S.D. (1986). Formation of information needs. Naucho Tekhnicheskaya Informatsiya, 2(2): $38-47$.

Krikelas, James. (1983). Information seeking behavior: patterns and concepts. Drexel Library Quarterly. 19: 5-20.

Kuhlthau, Carol C. (1991) "Inside the search process: information seeking from the user's perspective". Journal of the American Society for Information Science, 42(5): 361-371. http://ptarpp2.uitm.edu.my/silibus/insidesearch2.pdf[Consulta: febrero 2017].

Kuhlthau, Carol C. (1993). Seeking meaning. New Jersey, Ablex.

Kuhlthau, Carol Collier. (1993). Seeking meaning: a process approach to library and information services. Norwood, NJ: Ablex.

Line, M.B (1974). Draft definitions: information needs, wants, demands and use. ASLIB Proceedings. 26(2): 87

Norman, M. (1999). OUT on loan: a survey of the use and information needs of users of the Lesbian, Gay and Bisexual Collection of Brighton and Hove Libraries. Journal of Librarianship and Information Science, $\quad 31 \quad$ (4), 188-196. http://www.swetswise.com/swetsfo/swproxy?url=http\%3A\%2F\%2Flis.sagepub.com\%2Fcgi $\% 2$ Freprint $\% 2 F 31 \% 2 F 4 \% 2 F 188$.pdf\&ts=11696530 59128\&cs=2258857453 [Consulta: febrero 2017]

Núñez Paula, I.A. (1991). Metodología para la introducción del enfoque sociopsicológico en las entidades de información. Ciencias de la información. 22(4): 1020.http://www.bvs.sld.cu/revistas/aci/vol5 3 97/aci06397.htm [Consulta: febrero 2017]

Núñez Paula, I.A. (1992). Guía metodológica para el estudio de las necesidades de formación y de información de los usuarios o lectores. Ciencias de la Información. 23(2): 119123.http://scielo.sld.cu/scielo.php?script=sci arttext\&pid=\$1024-94351997000300006 [Consulta: febrero 2017]

O'Leary, Meagan. (2005). Pink perceptions: The information needs of lesbian, gay, bisexual, and transgender library users as perceived by public librarians and by the LGBT communities within Sheffield, UK and Denver, CO. (Tesis). University of Sheffield, Reino Unido http://dagda.shef.ac.uk/dispub/dissertations/200405/External/Oleary Meagan MALib.pdf[Consulta: febrero 2017]. 
Paisley, William J. (1968). Information needs and uses. Annual Review of Information Science and Technology, 3: 1-30.

Pérez Giffoni, María Cristina y Martha Sabelli. (2010). Los estudios de usuarios de información: construcción de una línea de investigación y docencia en el Uruguay. Montevideo: EUBCA.

Romanos de Tiratel, Susana. (1997). Los estudios de usuarios y el desarrollo de la colección en las bibliotecas. Libraria 1(1), 12-21.

Romanos de Tiratel, Susana. (2000). Accessing information use by humanists and social scientists: a study at the Universidad de Buenos Aires, Argentina. Journal of Academic Librarianship, 26(5), 346-354. http://comminfo.rutgers.edu/ tefko/Courses/612/Articles/deTiratel.pdf[Consulta: febrero 2017].

Romanos de Tiratel, Susana. (2000). Conducta informativa de los investigadores argentinos en Humanidades y Ciencias Sociales. Revista Española de Documentación Cientifica, 3, 268-286. redc.revistas.csic.es/index.php/redc/article/download/324/495 [Consulta: febrero 2017].

Romanos de Tiratel, Susana. (2000). Necesidades, búsqueda y uso de la información: revisión de la teoría. Información, Cultura y Sociedad, 2, 9-44. http://eprints.rclis.org/16966/1/n02a02pdf.pdf[Consulta: febrero 2017].

Romanos de Tiratel, Susana. (2012). El legado bibliográfico-bibliotecológico de Josefa Emilia Sabor (1916-2012). Información, Cultura y Sociedad, 27: 11-33. http://revistascientificas.filo.uba.ar/index.php/ICS/article/view/681 [Consulta: febrero 2017].

Sabelli, Martha y Verónica Rodríguez Lopater (Comps.)(2012). La información y las jóvenes en contextos desfavorables: construyendo puentes para la inclusión social desde la investigación. Montevideo: Universidad de la República.

Sabelli, Martha.; Rodríguez Lopater, V.; Bercovich, I y Szafran Maiche, p. (2012). Las brechas informativas y digitales de las mujeres jóvenes y adolescentes en situación vulnerable. (p. 33-53). En Programa Integral Metropolitano. Montevideo: SCEAM.

Sanz Casados, Elías. (1994). Manual de estudios de usuarios. Madrid: Fundación Germán Sánchez Ruipérez.

Savolainen, Reijo. (1993). The sense-making theory: reviewing the interests of a user-centered approach to information seeking and use. Information Processing \& Management. 29(1): 13-28. 
Tamborenea, Blanca Raquel. (1999). Los estudiantes de teatro en el uso de servicios de información teatral. Revista Argentina de Bibliotecología, 2, 72-79. http://www.sai.com.ar/bibliotecologia/rab/pdfs/rab v2 19.pdf[Consulta: febrero 2017]

Tamborenea, Blanca Raquel. (2002). Comportamiento de los usuarios frente a la información en las escuelas de teatro. Palabra Clave, 75-88. http://sedici.unlp.edu.ar/handle/10915/14111[Consulta: febrero 2017]

Taylor, Robert S. (1968). Question-negotiation and information seeking in libraries. College \& Research Libraries. 29(3): 178-194. https://faculty.washington.edu/jwi/lis521/Taylor1968.pdf [Consulta: febrero 2017]

Villaseñor, Isabel. (2014). Los estudios de usuarios de información en España. Estado de la cuestión. En Fernandez Bajón, María Teresa y otros (Edit). Nuevos hábitos de consumo de información y lectura para la inclusión social. (p. 345-361). Madrid: Universidad Complutense de Madrid.

Wilson, Tom D. (1981). On user studies and information needs. Journal of Documentation. 37(1): 315. www.asiaa.sinica.edu.tw/ ccchiang/GILIS/LIS/p658-Wilson.pdf [Consulta: febrero 2017]

Wilson, Tom D. (1997). Information behavior: an interdisciplinary perspective. Information Processing \& Management, 33(4): 551-572.

Wilson, Tom D. (1999). Models in information behavior research. Journal of Documentation. 5(3): 249-270. http://informationr.net/tdw/publ/papers/1999]Doc.html[Consulta: febrero 2017]

Wilson, Tom D. (2000). Human information behavior. Information Science, 3(2): 49-55. http://inform.nu/Articles/Vol3/v3n2p49-56.pdf[Consulta: febrero 2017] 